\title{
EFSUMB Guidelines on Interventional Ultrasound (INVUS), Part IV EUS-guided Interventions: General aspects and EUS-guided sampling (Long Version)
}

\author{
EFSUMB Leitlinien interventioneller Ultraschall (INVUS), Teil IV \\ Endosonografisch gestützte Interventionen: allgemeine Aspekte und \\ endosonografisch gestützte Materialgewinnung (Langversion)
}

Authors

Affiliations
C. Jenssen ${ }^{1}$, M. Hocke ${ }^{2}$, P. Fusaroli ${ }^{3}$, O. H. Gilja ${ }^{4}$, E. Buscarini ${ }^{5}$, R. F. Havre ${ }^{6}$, A. Ignee $^{7}$, A. Saftoiu ${ }^{8}$, P. Vilmann ${ }^{9}$, E. Burmester ${ }^{10}$, C. P. Nolsøe ${ }^{11}$, D. Nürnberg ${ }^{12}$, M. D’Onofrio ${ }^{13}$, T. Lorentzen ${ }^{11}$, F. Piscaglia ${ }^{14}$, P. S. Sidhu ${ }^{15}$, C. F. Dietrich ${ }^{16,17}$

Affiliation addresses are listed at the end of the article.

\section{Key words}

- guideline

endoscopic ultrasound

EUS-guided sampling

- EUS-guided fine needle aspiration

- rapid onsite cytopathological evaluation

- cytopathological reporting

- quality indicators

adverse events
Bibliography

Dol http://dx.doi.org/

10.1055/s-0035-1553785

Published online: October 29,

2015

Ultraschall in Med 2016; 37:

E33-E76 @ Georg Thieme

Verlag KG Stuttgart · New York .

ISSN 0172-4614

\section{Correspondence}

Prof. Dr. med. Christoph F.

Dietrich

Med. Klinik 2,

Caritaskrankenhaus Bad

Mergentheim

Uhlandstr. 7

D-97980 Bad Mergentheim

Germany

Tel.: ++49/(0)7931/58-22 01/

2200

Fax: ++49/(0)7931/58-22 90

Christoph.dietrich@ckbm.de

\section{Abstract \\ $\nabla$}

The fourth part of the European Federation of Societies for Ultrasound in Medicine and Biology (EFSUMB) Guidelines on Interventional Ultrasound describes general aspects of endoscopic ultrasound-guided diagnostic and therapeutic interventions and assesses the evidence for endoscopic ultrasound-guided sampling. Endoscopic ultrasound combines the most advanced high-resolution ultrasound imaging of lesions within the wall and in the vicinity of the gastrointestinal tract and safe and effective fine needle based tissue acquisition from these lesions. The guideline addresses the indications, contraindications, techniques, adverse events, training and clinical impact of EUSguided sampling. Advantages and drawbacks are weighed in comparison with image-guided percutaneous biopsy. Based on the most current evidence, clinical practice recommendations are given for crucial preconditions and steps of EUS-guided sampling as well as for safe performance. Additionally, the guideline deals with the principles and reliability of cytopathological reporting in endoscopic ultrasound-guided sampling (long version).

\section{Introduction: Diagnostic and therapeutic EUS-guided interventions}

This is the first of two guidelines (part IV and V) within the framework of the European Federation of Societies for Ultrasound in Medicine and Biology (EFSUMB) Guidelines on Interventional Ultrasound describing endoscopic ultrasound (EUS)guided diagnostic and therapeutic interventions. Part IV deals with the indications and clinical im-

\section{Zusammenfassung \\ $\nabla$}

Der vierte Teil der Leitlinien der European Federation of Societies for Ultrasound in Medicine and Biology (EFSUMB) zur interventionellen Sonografie beschreibt allgemeine Aspekte endosonografisch gestützter diagnostischer und therapeutischer Interventionen und bewertet die Evidenz für die endosonografisch gestützte Materialgewinnung. Die Endosonografie vereint fortgeschrittene hochauflösende Ultraschallbildgebung von Läsionen in der Wand des Gastrointestinaltrakts und in dessen Umgebung mit der Möglichkeit, daraus mit Feinnadeltechniken effizient und risikoarm Material für die feingewebliche Diagnostik zu entnehmen. Die Leitlinie thematisiert Indikationen, Kontraindikationen, Techniken, unerwünschte Ereignisse, Training und klinischen Stellenwert der endosonografisch gestützten Materialgewinnung. Dabei werden Vorund Nachteile im Vergleich zur perkutanen bildgebend gestützten Biopsie abgewogen. Auf der Grundlage der aktuellen Evidenz werden für die klinische Praxis Empfehlungen zu den entscheidenden Voraussetzungen und Schritten sowie für eine sichere Durchführung der endosonografisch gestützten Materialgewinnung gegeben. Ergänzend adressiert die Leitlinie Prinzipien und Verlässlichkeit zytopathologischer Befundung von durch endosonografisch gestützte Biopsie gewonnenem Material (Langversion).

pact of EUS-guided sampling ${ }^{1}$ and gives evidencebased recommendations for the safe and efficient performance of this technique based on the available evidence at the time of manuscript preparation. It is complemented by a guideline on EUSguided therapeutic interventions (part V) [1]. Methods of guideline development are described

\footnotetext{
${ }^{1}$ Term is explained in the addendum on terminology.
} 
in the introduction to the EFSUMB Guidelines on Interventional Ultrasound (INVUS) [2]. Levels of Evidence (LoE) and Grades of Recommendations (GoR) have been assigned according to the Oxford Centre for Evidence-based Medicine criteria (March 2009 edition) [http://www.cebm.net/oxford-centre-evidence-basedmedicine-levels-evidence-march-2009].

\section{General considerations}

Endoscopic ultrasound (EUS; synonym: endosonography) ${ }^{2}$ represents an interdisciplinary high-performance imaging method which combines endoscopy and ultrasound by using special transducers mounted at the tip of the endoscope [3-9]. EUS facilitates the use of high-frequency scanning and advanced techniques like $3 \mathrm{D}$ reconstruction, color Doppler, contrast enhancement and real-time elastography in anatomical regions that are poorly accessible to transabdominal or transthoracic ultrasonography. Detailed examination of the pancreaticobiliary system and gastrointestinal (GI) tract as well as of adjacent structures (e.g. liver or mediastinum) is now feasible. Prior to 1992, EUS was solely an imaging technique, but with the introduction of EUS-guided fine-needle aspiration (EUS-FNA) ${ }^{3}$ [10], it became possible to obtain a definite cytopathological or histopathological diagnosis of mediastinal, abdominal, retroperitoneal and pelvic lesions, establishing EUS-FNA as a crucial procedure. Further advances in 1996, allowed EUS-guided celiac plexus neurolysis [11], EUS-guided drainage of GI tract-adjacent fluid collections and pancreatic pseudocysts [12]. Furthermore, EUS guidance or assistance plays a crucial role in other minimally invasive drainage procedures, e.g. in obstructed biliary and pancreatic ducts [7-9, 13-16]. A first experience with endobronchial ultrasound-guided transbronchial fine-needle aspiration (EBUSTBNA) ${ }^{4}$ was reported in 2003 [17].

\section{Equipment and setup}

EUS equipment comprises a flexible video echoendoscope with a radial or linear transducer design mounted at the tip of the endoscope. The flexible scopes are linked both with an endoscopic video processor and an ultrasound processor, allowing for simultaneous endoscopic and ultrasound imaging. Several echoendoscopes are available commercially [3-9, 18]. The endoscopic image allows for orientation and navigation in the GI tract or tracheobronchial tree to the target area, while the ultrasound image is acquired only following gas aspiration, for optimal coupling of the tissue-transducer interface. Tissue-transducer coupling may be further improved with instillation of water in the GI lumen or in the balloon surrounding the transducer to obtain better quality images $[7-9,19]$.

Radial and linear echoendoscopes have variable frequencies (5$12 \mathrm{MHz}$ ). The ultrasound examination field of radial echoendoscopes is perpendicular to the long axis of the endoscope, with obtained images often concordant with computed tomography (CT)/ magnetic resonance (MR) imaging, especially in the mediastinum and the rectum $[6,19]$. Initial studies mainly used radial echoendoscopes with a mechanical scanner, imaging for GI (mainly esophago-gastric and rectal) and pancreaticobiliary cancer staging $(75.6 \%$ of original EUS articles up to 2001) [20]. Comparative studies (including a single randomized controlled trial [RCT]), have shown

\footnotetext{
2 Term is explained in the addendum on terminology.

${ }^{3}$ Term is explained in the addendum on terminology.

${ }^{4}$ Term is explained in the addendum on terminology.
}

superiority of electronic vs. mechanical radial transducers with image quality [21 - 23]. Radial echoendoscopes cannot be used to guide diagnostic and therapeutic interventions. Linear echoendoscopes have an ultrasound examination field in the longitudinal axis of the echoendoscope, allowing performance of needle-based diagnostic and therapeutic interventions through real-time visualization [16]. A wide variety of accessory equipment for EUS-guided interventions is commercially available [24]. For endobronchial ultrasound (EBUS), specifically designed linear echoendoscopes based on flexible bronchoscopes are available [25]. Radial and linear echoendoscopes with electronic transducers incorporate functions for the examination of vascularity with color Doppler or tissue compressibility with strain elastography [7, 19, 26-29]. Several RCTs compared the diagnostic accuracy of both types of echoendoscopes, with no advantage of either radial or linear EUS for the staging of esophago-gastric cancer $[30,31]$ or for the detection and staging of pancreatic cancer reported [32,33]. A therapeutic echoendoscope with a forward-viewing 90-degree curved array at the front of the scope has a potential advantage of allowing interventions with an axial application of force during needle insertion and stenting, with comparable imaging quality and equal performance in EUS-guided drainage of pancreatic pseudocysts being reported [34-36].

EUS mini-probes, with a diameter between 2 and $3 \mathrm{~mm}$, are catheter-like and are passed through the biopsy channel of a conventional endoscope. Most are mechanical radial transducers, requiring a separate driving unit between the transducer and the ultrasound processor [7, 9]. Mini-probes have a high-frequency transducer $(>10 \mathrm{MHz})$. Due to their high resolution but limited penetration, these high-frequency mini-probes are used for the diagnosis and staging of small $(<2 \mathrm{~cm})$ esophago-gastric, colorectal and bronchial lesions (endoluminal), and in pancreaticobiliary diseases (intraductal ultrasound probes, IDUS) [37 - 51].

For rectal examinations, where traditionally rigid radial or linear transrectal probes are used, flexible radial and linear echoendoscopes can stage lower colorectal cancers and image inflammatory bowel disease and submucosal tumors [52 - 54]. A comparative study showed that the staging performance of a flexible radial echoendoscope and a rigid linear probe was equivalent [53]. Both rigid (linear and curved-array) ultrasound probes with a biopsy channel as well as flexible linear and forward-viewing echoendoscopes can be used for transrectal EUS-guided interventions [55 62].

\section{Recommendation 1}

Linear echoendoscopes are indispensable for EUS-guided sampling and injection treatments (LoE 5, GoR D). Strong consensus (100\%).

\section{Recommendation 2}

For one-step EUS-guided drainage procedures, a large-channel therapeutic linear echoendoscope is recommended (LoE 5, GoR D). Strong consensus (100\%).

\section{Patient preparation and monitoring}

Patient preparation is identical to flexible endoscopy, with fasting for 6 hours and clear fluids permitted until 2 hours prior. All preprocedural considerations of gastrointestinal endoscopy should be followed, including detailed informed consent, management of an- 
ticoagulation and antiplatelet therapy, indication for prophylactic antibiotics and need for sedation [63]. With EUS-guided transmural drainage procedures, carbon dioxide insufflation of the gastrointestinal lumen should be considered, in particular in the drainage of walled-off pancreatic necrosis; this minimizes the risk of gas embolism.

The American Society of Gastrointestinal Endoscopy (ASGE) has defined several evidence-based preprocedural quality indicators, including:

1. appropriate and well-documented indication,

2. obtaining and documenting of informed consent based on the discussion of specific risks associated with the particular EUS procedure,

3. performing of preprocedure history and directed physical examination,

4. assessing and documenting of the risk for adverse events,

5. administration of prophylactic antibiotics in the setting of EUS-guided sampling of pancreatic cystic lesions (PCL),

6. monitoring and documentation of sedation,

7. proper management and documentation of antithrombotic treatment,

8. preprocedural team time-out ${ }^{5}$, and

9. performing of EUS by a well-trained endosonographer [64].

EUS and EUS-guided interventions are complex and lengthy procedures, more than standard endoscopy, usually requiring more patient sedation $[65,66]$ but are often well tolerated, including in pediatric and elderly patients [67 - 70]. EUS (including EBUS) can be safely performed using conscious sedation (midazolam) perhaps combined with an opioid (fentanyl or pethidine) [71-73]. Alternatively, propofol sedation is a more efficient approach, with better patient and operator satisfaction and is increasingly used [72, 74-79]. Sedation practices vary between countries, but sedation during EUS procedures with electronic patient monitoring is standard practice. Propofol sedation has a good safety profile, especially for lengthy interventions like therapeutic EUS [72, $74-78,80-83]$, but controversies surrounding the personnel administrating propofol remain. These legal issues have to be resolved according to local conditions and national legislations. Endoscopist- and nurse-administered propofol sedation has been shown to be safe and effective in EUS and EUS-guided interventions (including EBUS-TBNA) in both average-risk and high-risk patients [79, 82-85]. National legal restrictions in many countries do not permit non-anesthesiologist administration of propofol. It has been established in only a few European countries, including Austria, Denmark, Germany, Greece, the Netherlands, Sweden, and Switzerland $[86,87]$.

\section{Recommendation 3}

Carefully monitored conscious or deep sedation should be routinely offered to all patients undergoing EUS-guided interventions (LoE 1b, GoR B). Strong consensus (100\%).

\section{Recommendation 4}

Controlled propofol sedation should be used with due consideration of national legal regulations, and the experience and training of the medical personnel (LoE 5, GoR D). Strong consensus (100\%).

\footnotetext{
${ }^{5}$ Term is explained in the addendum on terminology.
}

\section{Platforms for EUS-guided diagnostic and therapeutic} interventions

Needles for EUS-guided sampling are commercially available from several manufacturers. The fine needles, size range of 25 19 Gauge (G) [16, 24, 88 - 90], allow needle choice based on the target lesion location, the expected diagnosis, the necessity for further procedures and examiner experience in order to maximize yield and minimize complications and costs [90, 91]. "Histology needles" include: trucut needles, needles with side fenestration and reverse bevel technology [91 -98] and needles with a shark mouth-like needle tip geometry.

Therapeutic EUS-guided interventions commence with puncture of the targeted lesion for initial access, followed by therapeutic injection or a guidewire-assisted drainage procedure. A $22 \mathrm{G}$ needle allows only 0.018 inch guidewires. Therefore, $19 \mathrm{G}$ needles are normally used, allowing passage of stiffer 0.035 inch guidewires. Either conventional or special (smooth end to prevent guidewire shearing) access aspiration needles may be used for the initial access. Diathermic devices (needle knifes or cystotomes, 6-10 French) with a round cutting tip and a stabilizing sheath allowing passage of multiple guidewires are also reported. A variety of biliary dilatation balloons (up to $8 \mathrm{~mm}$ diameter) and biliary endoprotheses $(7,8.5$ or 10 French plastic) can be used for drainage, and covered self-expandable metallic stents have been used for pancreatic and biliary drainage [1, 13 - 16, 99 - 103].

\section{Indications and contraindications}

EUS has evolved as a diagnostic and therapeutic procedure with substantial clinical impact, altering management in a number of patients [3, 15, 20, 64, 91, 104-107]. Appropriate (evidencebased) indications are listed in 0 Table 1, [3, 7 - 9, 64, 91, 108 113].

Absolute contraindications of EUS are similar to those of conventional advanced endoscopy procedures. Specific contraindications of EUS-guided sampling and therapeutic interventions are related to unacceptable risks of bleeding, infection, and perforation ( Table 2; section 5) $[8,9,16,110,114,115]$, which should be assessed prior to the intervention on an individual basis weighing procedural risk vs. clinical impact.

\section{Recommendation 5}

As EUS is an advanced invasive procedure, it requires a proper indication, assessment of individual risks and contraindications, detailed informed consent, careful consideration of antithrombotic therapy and antibiotic prophylaxis, and a pre-interventional team time-out ${ }^{6}$ (LoE 5, GoR D). Strong consensus (100\%).

\section{Education and training in endoscopic ultrasound Preconditions for performing EUS}

EUS has evolved into an advanced endoscopic procedure requiring structured training as supported by the ASGE core curriculum for EUS [116]. Certain conditions need to be attained prior to commencing an EUS program; state-of-the-art EUS equipment and accessories should be in place, previous EUS experience and training ( $>12$ months) with proficiency in basic EUS should be available, the presence of a multidisciplinary team with expertise in gastro-

\footnotetext{
${ }^{6}$ Term is explained in the addendum on terminology.
} 
Table 1 Established indications of endoscopic ultrasound.

\begin{tabular}{|c|c|}
\hline \multicolumn{2}{|c|}{ diagnostic evaluation (including EUS-guided sampling) } \\
\hline \multirow[t]{5}{*}{$\begin{array}{l}\text { pancreatico-biliary } \\
\text { disorders }\end{array}$} & $\begin{array}{l}\text { obstructive jaundice/biliary stricture of } \\
\text { unknown etiology }\end{array}$ \\
\hline & suspected bile duct stones \\
\hline & biliary and idiopathic acute pancreatitis \\
\hline & (early) chronic pancreatitis \\
\hline & solid and cystic focal pancreatic lesions \\
\hline \multirow{2}{*}{$\begin{array}{l}\text { esophagogastroduo- } \\
\text { denal tumors }\end{array}$} & subepithelial tumors \\
\hline & enlarged gastric folds/wall thickening \\
\hline \multirow[t]{2}{*}{ mediastinal diseases } & primary central lung/mediastinal tumors \\
\hline & mediastinal lymphadenopathy \\
\hline rectal diseases & $\begin{array}{l}\text { fistulas, abscesses, extraluminal tumors, } \\
\text { subepithelial tumors }\end{array}$ \\
\hline \multicolumn{2}{|c|}{ staging of various cancers } \\
\hline $\begin{array}{l}\text { upper gastrointestinal } \\
\text { cancer }\end{array}$ & $\begin{array}{l}\mathrm{T} \text { (tumor) and } \mathrm{N} \text { (nodal) stage, } \mathrm{M} \text { (metastatic) } \\
\text { stage (celiac trunk lymph nodes, left adrenal, } \\
\text { left liver lobe, ascites, etc.) }\end{array}$ \\
\hline lung cancer & $\begin{array}{l}\text { T and N stage (EUS and EBUS), M stage } \\
\text { (abdominal lymph nodes, left adrenal, left } \\
\text { liver lobe) }\end{array}$ \\
\hline rectal cancer & $\mathrm{T}$ and $\mathrm{N}$ stage \\
\hline $\begin{array}{l}\text { pancreatico-biliary } \\
\text { cancers }\end{array}$ & $\begin{array}{l}\text { T and } \mathrm{N} \text { stage, } \mathrm{M} \text { stage (left liver lobe, ascites, } \\
\text { mediastinal lymph nodes, etc.); evaluation of } \\
\text { resectability and vascular invasion }\end{array}$ \\
\hline \multicolumn{2}{|c|}{ EUS-guided therapeutic interventions } \\
\hline \multirow[t]{3}{*}{ drainage procedures } & $\begin{array}{l}\text { transmural drainage of (per-)pancreatic and } \\
\text { peri-intestinal fluid collections (pseudocysts, } \\
\text { walled-off pancreatic necroses, abscesses, } \\
\text { postoperative fluid collections) }\end{array}$ \\
\hline & bile duct and gallbladder drainage \\
\hline & pancreatic duct drainage \\
\hline \multirow[t]{3}{*}{ injection treatment } & celiac plexus/ganglia neurolysis and block \\
\hline & $\begin{array}{l}\text { glue or coil embolization of bleeding varices, } \\
\text { visceral pseudoaneurysms, and other vascu- } \\
\text { lar lesions }\end{array}$ \\
\hline & $\begin{array}{l}\text { ethanol-ablation of small pancreatic } \\
\text { insulinomas }\end{array}$ \\
\hline other interventions & placement of fiducials \\
\hline
\end{tabular}

enterology, pulmonary medicine, oncology, surgery, imaging and pathology is desired.

\section{Methods and models for training}

Various approaches for structured training have been described. Support includes EUS textbooks and atlases, DVDs and online resources [7-9, 19, 117-122]. Computer-based simulators are a valuable option, improving trainee procedural skills before performing supervised clinical endosonographic procedures [117, 120, 123 -130]. EUS-guided sampling and therapeutic intervention training with animal models and supervised hands-on may facilitate more rapid learning for clinical application and may minimize false-negative sampling in patients [117, 123, 131]. The live pig is a good animal model for EUS and EUS-guided interventions, performed under general anesthesia, endotracheal intubation and mechanical ventilatory support [132]. Studies evaluating live animal model teaching of EUS, EUS-guided sampling and EUS-guided celiac plexus neurolysis showed that visualization of anatomical landmarks and performance significantly increased after several training sessions [133-135]. A study found EUSguided sampling performed by supervised fellows to be as safe and accurate as the results of the experienced attending operators [136]. Objective assessment tools with rating scales for various steps of EUS-guided sampling (in particular EBUS-TBNA) have
Table 2 Indications and contraindications of EUS-guided sampling.

\begin{tabular}{|c|c|c|}
\hline $\begin{array}{l}\text { frequent/ } \\
\text { established } \\
\text { indications }\end{array}$ & $\begin{array}{l}\text { less frequent/ } \\
\text { emerging indica- } \\
\text { tions }\end{array}$ & contraindications \\
\hline $\begin{array}{l}\text { pancreatic solid } \\
\text { lesions }\end{array}$ & $\begin{array}{l}\text { retroperitoneal } \\
\text { masses }\end{array}$ & absolute \\
\hline $\begin{array}{l}\text { pancreatic cystic } \\
\text { lesions }\end{array}$ & $\begin{array}{l}\text { mediastinal } \\
\text { masses }\end{array}$ & $\begin{array}{l}\text { no impact on patient } \\
\text { management }\end{array}$ \\
\hline lymph nodes & $\begin{array}{l}\text { perianastomotic } \\
\text { masses }\end{array}$ & lack of informed consent \\
\hline \multirow[t]{7}{*}{$\begin{array}{l}\text { subepithelial } \\
\text { tumors }\end{array}$} & $\begin{array}{l}\text { adrenal gland } \\
\text { masses }\end{array}$ & $\begin{array}{l}\text { mediastinal cysts (risk of } \\
\text { infection) }\end{array}$ \\
\hline & liver masses & relative \\
\hline & $\begin{array}{l}\text { ascites and perito- } \\
\text { neal nodules }\end{array}$ & severe coagulopathy \\
\hline & $\begin{array}{l}\text { gastrointestinal } \\
\text { wall thickening }\end{array}$ & $\begin{array}{l}\text { continued oral anticoa- } \\
\text { gulation }\end{array}$ \\
\hline & $\begin{array}{l}\text { bile duct stric- } \\
\text { tures/lesions }\end{array}$ & $\begin{array}{l}\text { continued treatment } \\
\text { with ADP antagonists } \\
\text { (clopidogrel, prasugrel, } \\
\text { ticagrelor) }\end{array}$ \\
\hline & kidney masses & $\begin{array}{l}\text { large vessels in the } \\
\text { expected needle track }\end{array}$ \\
\hline & $\begin{array}{l}\text { focal splenic } \\
\text { lesions }\end{array}$ & \\
\hline
\end{tabular}

been developed to measure competency for mediastinal staging of NSCLC, which can potentially be used in other diagnostic scenarios [125, 127, 130, $137-140]$.

\section{Learning curve and minimum number of supervised pro-} cedures

Few articles address the minimum number of EUS examinations required to attain competency [116]. The efficiency and success of EUS-guided sampling are dependent on the experience of the endosonographer and the cytopathologist. Reports on the skill acquisition of individuals for EUS [141, 142] and for EUS-FNA of solid pancreatic lesions $[143,144]$ challenge the ASGE recommendations that comprehensive competence in all aspects of EUS requires at least 150 supervised cases, including 50 EUSFNA [145]. A prospective evaluation of 12 months of EUS training for 12 trainees without prior experience found a large variation in skill acquisition, with nobody gaining acceptable performance in diagnostic EUS before having performed 225 examinations [141]. For EUS-FNA of solid pancreatic lesions, the sensitivity significantly and continuously increased for the first 30 cases [143]. Further observation of 3 separate periods of 100 pancreatic EUSFNA following basic skills acquisition demonstrated further improvement in terms of a decreasing number of diagnostic needle passes $^{7}$ and decreasing adverse events in period 3 compared to periods 1 and 2 [144]. A 7-year experience in pancreatic EUSFNA showed a significant correlation between years of operator experience and the mean of annual EUS examinations in the preceding 3 years with fewer needle passes $[146,147]$. A similar effect of cumulative EUS-FNA experience over a 13-year period on the diagnostic accuracy of pancreatic EUS-FNA was also reported, representing a joint learning curve of both endosonographers and cytopathologists [148]. A survey of participants of a European EUS workshop found a high annual hospital case load of EUS-

\footnotetext{
${ }^{7}$ Term is explained in the addendum on terminology.
} 
FNA but not the years of individual EUS experience to be a significant predictor of self-reported sensitivity of EUS-FNA [149]. In two gastroenterological centers, the rate of non-diagnostic specimens from EUS-FNA decreased significantly after a 1- or 2-month joint training period of cytopathologists and endosonographers $[150,151]$. In another EUS center, the rate of non-diagnostic or false findings ${ }^{8}$ of EUS-FNA reached an acceptable level $(<10 \%)$ at 121 and 97 examinations, respectively. This level of competency was achieved after performance of 48 EUS-FNA of mediastinal lymph nodes compared to 171 (non-diagnostic) or 186 (misdiagnosis) pancreatic EUS-FNA [152].

Similar experience has been reported in EUS-guided sampling for lung cancer staging. The performance of 4 pulmologists improved significantly during a supervised training course. However, only $2 /$ 4 achieved the mean score of experienced endosonographers after 17 and 23 procedures. 20 EUS-guided sampling sessions were insufficient to achieve a consistently high level of competency for trainees [140]. For EBUS-TBNA, in pulmonary medicine fellows, the majority achieved the first independent successful performance of EBUS-TBNA following a training protocol (that included theoretical education and simulation sessions) after an average of 13 procedures [153]. Studies show significant variation in learning curves for EBUS-TBNA [153 - 160] with an acceptable 90\% accuracy of EUS-TBNA achieved after performing 50-80 procedures $[154-156,160]$. In a study with 9 interventional pulmonology fellows, skill improvement was ongoing for lymph node identification by EBUS and EBUS-TBNA even after 200 cases [160].

Compared with the gaining of expertise in EUS and EUS-FNA for a gastroenterologist or EBUS and EBUS-TBNA for a pulmonologist, diagnostic handling of EUS-FNA samples is simpler for experienced cytopathologists. After performing a short intensive training session, experienced general pathologists who had little prior experience with EUS-FNA demonstrated marked improvement in the reproducibility of cytological diagnoses [161]. A continuous dialog and common training of endosonographers and cytopathologists is the cornerstone of diagnostic success in EUS-guided sampling [110].

\section{Recommendation 6}

Education and training for EUS procedures should be performed systematically in a standardized fashion. Various learning methods should be used, including textbooks, online resources, and EUS phantoms, before performing hands-on human cases (LoE 5, GoR D). Strong consensus (100\%).

\section{Recommendation 7}

Standardized criteria and assessment tools should be developed and applied for assessing the skills of individual trainees before credentialing competency (LoE 1b, GoR B). Strong consensus $(100 \%)$.

\section{Recommendation 8}

At least 50 EUS-guided sampling procedures are needed in order to attain basic competency in EUS-guided interventions (LoE 5, GoR D). Strong consensus (100\%).

\footnotetext{
${ }^{8}$ Term is explained in the addendum on terminology.
}

\section{Quality indicators and benchmarking}

The ideal benchmark for the performance of EUS-guided sampling would be the actual positive and negative predictive value of malignancy diagnosis, requiring data from surgical pathology or from long-term follow-up. Due to the increasing use of neoadjuvant treatments and practical constraints, this is not always available in clinical practice. Recent reviews and a position paper of the ASGE have proposed appropriate process and outcome measures for monitoring and benchmarking the performance of EUS procedures $[64,89,91,110]$. With particular emphasis on EUS-guided sampling, useful quality indicators may be:

a) percentage of appropriate indications for performing EUSguided sampling based on guidelines ( $\bullet$ Table 2) [64]

b) prospective documentation of adverse events after EUS-guided sampling (performance target: >98\%) [64]

c) incidence of adverse events after EUS-guided sampling (performance targets: acute pancreatitis $<2 \%$, clinically significant bleeding < $1 \%$ ) $[64,89,110]$

d) frequency of algorithmic EUS-guided sampling of both suspected metastatic disease (in particular lymph nodes, ascites, adrenal and liver metastases) and the primary tumor in cases, in which results of EUS staging would impact further clinical management (performance target: > 98\%) [64]

e) the yield of malignant diagnoses ${ }^{9}$ in EUS-guided sampling of solid pancreatic masses and the sensitivity for diagnosis of pancreatic cancer (performance targets: $\geq 70 \%$ and $85 \%$, respectively) [64, 89, 91, 110, 162]

f) the percentage of adequate samples ${ }^{10}$ (performance target: $\geq 85 \%)[64,89,110]$ and

g) the frequency of inconclusive cytopathological diagnoses ${ }^{11}$ (atypical, suspicious: $\leq 10 \%$ ) $[89,110,152]$.

Particular quality parameters for EUS-guided therapeutic interventions have not yet been established, but should be derived from those for EUS-guided sampling and advanced endoscopic and interventional procedures $[64,163]$.

\section{Recommendation 9}

Appropriate indicators should be implemented to monitor the quality of EUS-guided interventions (LoE 5, GoR D). Strong consensus (100\%).

\section{EUS-guided sampling: Indications and clinical impact}

General indications of EUS-guided sampling

EUS has high accuracy for the diagnosis and staging of benign and malignant conditions within and outside the gastrointestinal tract [106, 107]. EUS-guided sampling relies on its ability to obtain specimens with either fine-needle aspiration (FNA) or fineneedle biopsy $(\mathrm{FNB})^{12}[91,110]$.

First described in 1992 [10], EUS-guided sampling has become an indispensable adjunct to EUS, and has been shown to be feasible and safe in obtaining tissue diagnosis in the majority of lesions within EUS reach [164]. The practical clinical applications of EUS-

\footnotetext{
${ }^{9}$ Term is explained in the addendum on terminology.

10 Term is explained in the addendum on terminology

11 Term is explained in the addendum on terminology.

12 Term is explained in the addendum on terminology.
} 
guided sampling, validating its use in diagnostic and staging algorithms, showing it is cost-effective and showing its significant effect on patient outcome, have been dealt with in numerous articles $[91,96,104,110]$ ( $\odot$ Table 2 ).

Several prospective and retrospective studies and meta-analyses have substantiated the key importance of EUS-guided sampling, particularly in suspicious nodal disease for staging, guiding treatment, and predicting outcome in non-small cell lung cancer (NSCLC) [165-170], various extrathoracic malignancies [171, 172], upper gastrointestinal cancer [173, 174], rectal cancer [58], as well as for proving recurrence of malignancy [55, 175 178]. Specimens provided by EUS can be examined by immunohistochemical and biological marker analysis to identify specific tumor characteristics for personalized treatment [179-187]. The minimally invasive characteristics of EUS-guided sampling make this the most favorable option in terms of patient acceptance, safety profile, repeatability and cost-effectiveness.

There is limited data comparing EUS-guided sampling with percutaneous (CT- or US-guided) sampling of pancreatic lesions [188 - 191]. Typically, the diagnostic accuracy of EUS-guided sampling is similar to that of percutaneous techniques in comparative studies [188 - 191]. One retrospective analysis found EUS had superior accuracy when evaluating lesions $<3 \mathrm{~cm}(\mathrm{p}=0.015)$ [189]. The complication rate and patient preferences were favorable for EUS [190 - 192]. Importantly, one study in pancreatic cancer suggested that peritoneal seeding occurred more frequently in patients following percutaneous rather than with EUS-guided sampling [192]. One RCT did not meet enrollment targets as patients and referring physicians specifically requested EUS-guided sampling [190]. A cost-minimization analysis demonstrated that EUS-guided sampling was the better initial test and the preferred secondary test following failure of other techniques for the diagnosis of pancreatic cancer, when considering the total expected costs for a successful diagnosis [193]. Evidence from large tertiary referral centers shows that implementation of an EUS-FNA service in pancreatic cancer was accompanied by a marked cytological improvement of sample adequacy and accuracy, leading to widespread replacement of other techniques of tissue acquisition [194]. A 5-year retrospective claims analysis of Medicare patients undergoing sampling of pancreatic malignancies showed an ongoing trend towards EUS-guided sampling. However, in spite of higher costs, the application of percutaneous image-guided sampling remained prevalent in particular outside major academic and urban hospitals [195].

Recommendation 10

EUS-guided sampling should be considered for tissue diagnosis of lesions in or adjacent to the gastrointestinal tract when the result is likely to alter clinical management (LoE 2a, GoR B). Strong consensus (100\%).

\section{EUS-guided sampling for primary diagnosis}

Solid pancreatic lesions

Solid pancreatic lesions suspected as ductal pancreatic adenocarcinoma (PDAC) are typically targets for EUS-guided sampling. Metastases and/or primary lesion sampling is indicated when the lesion is non-resectable allowing appropriate radiotherapy/ chemotherapy. EUS-guided sampling of potentially resectable tumors will follow local protocols to obtain confirmation of malignancy prior to surgical intervention.
EUS has a high positive predictive value (PPV) and a fair negative predictive value (NPV) in diagnosing PDAC. Several studies report a sensitivity between $85-93 \%$ and a specificity between $96-$ $100 \%$ ( Table 3) [196 - 200].

With neuroendocrine tumors (second most common solid pancreatic lesion), studies report high sensitivity and diagnostic accuracy for EUS-guided sampling using immunocytochemical evaluation [201, 202]. Ki-67 grading of neuroendocrine pancreatic tumors is reliable using EUS fine-needle samples with adequate cellularity [203-205].

Other pancreatic lesions should also be considered in the differential diagnosis; solid pseudopapillary neoplasm, "mass-forming" pancreatitis, lymphoma and metastases (melanoma, kidney, breast, lung, ovarian) [206 - 220]. EUS-guided sampling is a reliable method to differentiate PDAC from neuroendocrine pancreatic tumors and other rare pancreatic neoplasms (non-PDAC), each with differing outcomes and alternative treatment strategies [146-148, 221].

\section{Recommendation 11}

In pancreatic masses, EUS-guided sampling should be preferred in potentially resectable lesions and in unresectable lesions in which percutaneous biopsy is not feasible (LoE $2 b$, GoR C). Strong consensus (100\%).

\section{Recommendation 12}

EUS-guided sampling should be preferred over percutaneous biopsy in pancreatic masses prior to neoadjuvant radiotherapy/chemotherapy (LoE 2b, GoR C). Strong consensus (100\%).

\section{Recommendation 13}

EUS-guided sampling is recommended in potentially resectable, pancreatic masses that are atypical for pancreatic ductal adenocarcinoma (LoE 3b, GoR C). Strong consensus (100\%).

\section{Pancreatic cystic lesions}

There is a wide differential diagnosis of pancreatic cystic lesions (PCL) including both benign and malignant. True pancreatic cysts should be differentiated from pseudocysts, which is not always possible based on morphological features. The most common benign true pancreatic cyst is the serous cystadenoma. Mucinous cystadenoma and branch-duct intraductal papillary mucinous neoplasm (BD-IPMN) are often thought of as being borderline for malignancy, whereas a main-duct intraductal papillary mucinous neoplasm (MD-IPMN) is at high risk for malignancy. Neuroendocrine cystic tumors and solid pseudopapillary tumors are rare [222-224].

EUS-guided sampling is performed when the other diagnostic modalities are inconclusive, if a PCL with "suspicious" features (other than an enhancing solid component) has been demonstrated, for risk-assessment of BD-IPMN, or in advanced malignant PCLs when chemotherapy is considered [225, 226]. It aims to differentiate mucinous from non-mucinous and malignant from benign lesions. For best diagnostic accuracy, EUS-FNA cytology and biochemical aspirate assays should be reviewed in combination with the EUS findings, clinical history and other imaging techniques $[225,227,228]$. A study (92 patients) of small pancreatic cysts con- 


\begin{tabular}{|c|c|c|c|c|}
\hline first author of meta-analysis & $\begin{array}{l}\text { included } \\
\text { studies }\end{array}$ & patients & $\begin{array}{l}\text { pooled } \\
\text { sensitivity }\end{array}$ & $\begin{array}{l}\text { pooled } \\
\text { specificity }\end{array}$ \\
\hline \multicolumn{5}{|c|}{ solid pancreatic lesions/pancreatic cancer } \\
\hline Hewitt M] et al. 2012 [196] & 33 & 4984 & $85 \%\left(91 \%{ }^{1}\right)$ & $98 \%(94 \% 1)$ \\
\hline Puli SR et al. 2013 [199] & 41 & 4766 & $86.8 \%$ & $95.8 \%$ \\
\hline Chen J et al. 2012 [198] & 15 & 1860 & $92 \%$ & $96 \%$ \\
\hline Chen G et al. 2013 [197] & 31 & 4840 & $89 \%\left(91 \%^{2}\right)$ & $96 \%\left(94 \%^{2}\right)$ \\
\hline Hébert-Magee S et al. 2013 [200] ${ }^{3}$ & 34 & $\begin{array}{l}3644(2285 \\
\text { pancreatic } \\
\text { cancer) }\end{array}$ & $88.6 \%$ & $99.3 \%$ \\
\hline \multicolumn{5}{|c|}{ cystic pancreatic lesions/mucinous neoplasms } \\
\hline Thornton GD et al. $2013[234]^{4}$ & 18 & 1438 & $54 \%$ & $93 \%$ \\
\hline Thosani N et al. $2010[239]^{4}$ & 11 & 376 & $63 \%$ & $88 \%$ \\
\hline Suzuki R et al. $2014[240]^{5}$ & 4 & 96 & $65 \%$ & $91 \%$ \\
\hline Wang QX et al. 2015 [241] & 16 & 1024 & $\begin{array}{l}51 \%^{6} \\
52 \%^{7}\end{array}$ & $\begin{array}{l}94 \%^{6} \\
97 \%^{7}\end{array}$ \\
\hline \multicolumn{5}{|c|}{ biliary strictures and gallbladder masses/cholangiocarcinoma } \\
\hline Navaneethan U et al. 2014 [273] & $\begin{array}{c}6 \\
\left(5^{8}\right)\end{array}$ & $\begin{array}{c}196 \\
\left(146^{8}\right)\end{array}$ & $\begin{array}{l}66 \% \\
\left(80 \%^{8}\right)\end{array}$ & $\begin{array}{l}\text { not included } \\
\text { in analysis }\end{array}$ \\
\hline Wu LM et al. 2011 [274] & 9 & 284 & $84 \%$ & $100 \%$ \\
\hline \multicolumn{5}{|c|}{ mediastinal lymph nodes/nodal lung cancer staging } \\
\hline Puli SR et al. $2008[319]^{9}$ & 76 & 9310 & $88 \%$ & $96.4 \%$ \\
\hline Chandra S et al. $2012[339]^{10}$ & 14 & 1658 & $92 \%$ & $100 \%$ \\
\hline Micames CG et al. $2007[165]^{11}$ & 18 & 1201 & $83 \%$ & $97 \%$ \\
\hline Silvestri GA et al. 2013 [389] ${ }^{11}$ & 26 & 2443 & $89 \%$ & $100 \%$ \\
\hline Adams K et al. $2009[166]^{12}$ & 14 & 1658 & $88 \%$ & $100 \%$ \\
\hline Gu P et al. $2009[167]^{12}$ & 11 & 1299 & $93 \%$ & $100 \%$ \\
\hline Dong $X$ et al. $2013[169]^{12}$ & 9 & 1066 & $90 \%$ & $99 \%$ \\
\hline Silvestri GA et al. 2013 [389] ${ }^{12}$ & 26 & 2756 & $89 \%$ & $100 \%$ \\
\hline Zhang R et al. $2013[168]^{13}$ & 8 & 822 & $86 \%$ & $100 \%$ \\
\hline Dhooria S et al. $2015[170]^{14}$ & 4 & 425 & $91 \%$ & $100 \%$ \\
\hline $\begin{array}{l}1 \text { atypical, suspicious, and malignant, dete } \\
2 \text { prospective studies only; } \\
3 \text { referring to pancreatic adenocarcinoma, } \\
4 \text { mucinous vs. non-mucinous PCL; } \\
5 \text { malignant vs. benign IPMNs; } \\
6 \text { benign vs. malignant PCL, malignant cytc } \\
7 \text { benign vs. malignant PCL, malignant cytc } \\
\text { malignancy; } \\
8 \text { studies with a visible mass in EUS; } \\
{ }^{9} \text { mediastinal lymph nodes, EUS-FNA; } \\
10 \text { mediastinal lymph nodes, EBUS-TBNA; } \\
11 \text { nodal staging of lung cancer, EUS-FNA; } \\
12 \text { nodal staging of lung cancer; EBUS-TBN } \\
13 \text { nodal staging of lung cancer, combined } \\
14 \text { nodal staging of lung cancer. combined }\end{array}$ & $\begin{array}{l}\text { ive for maligr } \\
\text { ive for maligr }\end{array}$ & $\begin{array}{l}\text { d high-grade dy } \\
\text { d high-grade dy }\end{array}$ & a; & gnancy, potential \\
\hline
\end{tabular}

Table 3 Meta-analyses on the diagnostic accuracy of EUS-guided sampling of solid and cystic pancreatic lesions, biliary cancer, lung cancer and mediastinal lymphadenopathy.

firmed that in the absence of worrisome imaging features or highrisk stigmata (according to the international consensus guideline [225]) and high-grade atypia or malignancy in cyst-fluid aspirates, there was a $99 \%$ predictive value for safe nonsurgical management [229]. A management strategy for asymptomatic PCLs based on risk stratification using EUS-guided sampling and cyst fluid analysis was cost-effective in comparison with a conservative follow-up or an aggressive surgical approach [230].

Levels of carcinoembryonic antigen (CEA) and amylase yield a suboptimal diagnostic accuracy of $60-86 \%$ for distinguishing between mucinous and non-mucinous PCLs. Levels of amylase $<250$ U/L virtually exclude pseudocysts, while high levels of CEA reliably indicate the mucinous nature of a PCL [231 - 234]. Differentiation of mucinous vs. non-mucinous pancreatic cystic lesions yield varying CEA cut-off values between $30 \mathrm{ng} / \mathrm{ml}$ and $>800 \mathrm{ng} /$ $\mathrm{ml}$ and varying diagnostic accuracies [231, 232, 235 - 238]. CEA levels are not predictive of malignancy [235]. A high CA 125-level in the cyst fluid may be helpful in differentiating mucinous cystadenoma from intraductal papillary mucinous neoplasm (IPMN)
[237]. EUS morphology, cytology and biochemical cyst-fluid analysis in 976 patients compared to 198 patients with histology or malignant cytology as the diagnostic standard demonstrated that in the prediction of a mucinous cyst, CEA was significantly more accurate (86\%) than EUS morphology (48\%) and cytology (58\%). Cytology was the most accurate test (75\%) for the diagnosis of a malignant cystic neoplasm [235]. However, the value of cytology is limited by the low cellularity of cyst fluid. The specificity of cytological diagnosis of malignant PCLs is adequate (88-97\%), but the sensitivity is low (51-65\%, ○ Table 3) [234, 239-241]. It is suggested that high-grade atypia be defined as "positive cytology" [242, 243], but there is considerable interobserver variability for the grading of cellular atypia in pancreatic cyst fluid [244, 245]. Newer techniques, e.g. cystic fluid molecular marker assays (DNA quantity and methylation, K-ras mutation, and others) [246 - 250] and intracystic probe-based confocal laser endomicroscopy, are being developed [251, 252]. The incremental diagnostic value of molecular analysis over biochemical analysis of cyst fluid is low. For most parameters the specificity is high, but 
the sensitivity is reported only between $20-50 \%$. However, the combination of molecular analysis and CEA or cytology has a better performance for the diagnosis of neoplastic mucinous PCLS than either of the individual tests [248, 253, 254].

\section{Recommendation 14}

Biochemical, cytological, and molecular analysis of EUS aspirates from pancreatic cystic lesions may facilitate differentiation between mucinous and non-mucinous cysts and evaluation of the malignancy risk ( LoE 2a, GoR B). Strong consensus $(100 \%)$

\section{Biliary cancer}

Several studies report successful EUS-guided sampling of gallbladder wall lesions [255 - 259], extrahepatic cholangiocarcinoma and indeterminate biliary strictures [255, 260 - 271], as well as tumors of the papilla of Vater [272], but with a wide variation in sensitivity (43-100\%). In the evaluation of indeterminate biliary strictures, the NPV (29-72\%) of EUS-guided sampling of biliary malignancy was poor. A meta-analysis reported a $66 \%$ sensitivity of EUS-guided sampling for the diagnosis of cholangiocarcinoma responsible for an indeterminate bile duct stricture ( $\bullet$ Table 3) [273]. A further meta-analysis of the accuracy of EUS-guided sampling of both bile duct strictures and gallbladder masses reported a sensitivity of $84 \%$ ( Table 3) [274]. One prospective study quoted a higher sensitivity for distal than for proximal cholangiocarcinoma [269]. EUS-guided sampling proved to be successful following failed or negative ERCP-guided brushing or biopsy [261, 263-267, 273]. Comparison of EUS-guided sampling with that of ERCP-guided techniques revealed a better outcome for EUS in gallbladder cancer, biliary strictures produced by pancreatic cancer rather than cholangiocarcinoma, and in EUS-visible masses, with a combined approached considered clinically appropriate [257, 259, 262, 271, 273]. EUS-guided sampling of hilar lymph nodes may be used to diagnose and stage suspected biliary cancer [257, 258, 260, 266, $270,275]$.

\section{Recommendation 15}

Complementary to ERCP-guided brushing and biopsy, EUSguided sampling may be used for diagnosis of indeterminate biliary strictures and gallbladder masses (LoE 2a, GoR B). Strong consensus (100\%).

\section{Subepithelial gastrointestinal tumors}

Differential diagnosis of gastrointestinal subepithelial tumors (SETs) includes leiomyoma, schwannoma, gastrointestinal stromal tumor (GIST), lipoma, ectopic pancreas, neuroendocrine tumor, cyst and others [276-278]. While a reliable differential diagnosis is possible on EUS features alone in some SETs, so, with the frequently occurring hypoechoic SET originating from the $4^{\text {th }}$ layer (muscularis propria), i.e. GIST, leiomyoma and schwannoma, diagnosis may be problematic. In the stomach, the majority of hypoechoic SETs are GISTs, with a variable malignant risk, dependent on the size and number of mitoses per high power microscopic field. Approximately $25 \%$ of incidentally detected hypoechoic gastric SETs are benign leiomyomas or schwannomas for which surgery is unnecessary [276-278]. EUS-guided sampling combines smear cytology (SC) with immunohistochemistry for maximal di- agnostic accuracy. The diagnostic yield remains suboptimal using standard EUS needles of various diameters, ranging from $20 \%$ [279] to $93 \%$ [280], as retrieved tissue is not always sufficient to allow immunohistochemical analysis [280 - 294]. The European Society of Gastrointestinal Endoscopy (ESGE) guideline on EUS-guided sampling in gastroenterology states that in hypoechoic SETs of the stomach $<20 \mathrm{~mm}$ the usefulness of EUS-guided sampling is limited due to the moderate diagnostic yield and lacking capability to determine the mitotic index [104].

"Histology" needles, e.g. trucut needles and aspiration needles with side holes and reverse bevel technology (ProCore), have been introduced in an attempt to overcome these limitations and to retrieve a core sample suitable for immunohistochemistry. While the results obtained with trucut needles are not superior to those of standard aspiration needles (diagnostic yield 35 $79 \%$ ) [279, 287, 288, 295], results of an RCT ( $n=28$ patients with SET) encourage further evaluation of the ProCore needle, with a diagnostic yield significantly higher compared with aspiration needles (75\% vs. $20 \%$ ) [294].

A comparison of the diagnostic yield, specimen size, and procedure time for EUS-guided sampling of upper GI SETs using a forward-viewing vs. a traditional oblique-viewing echoendoscope showed no significant differences between the echoendoscopes with regard to puncture success and diagnostic yield. Procedure time was shorter and specimens larger using the forward-viewing echoendoscope [296].

Immunohistochemical diagnosis is valuable in poor surgical candidates or with SETs located in challenging surgical positions, e.g. gastric cardia. EUS-guided sampling is beneficial in suspected non-resectable GISTs, when primary treatment with tyrosine kinase inhibitors is planned following confirmed diagnosis. Pretreatment genotyping, evaluation of biological aggressiveness using the Ki-67 index and mitotic count, and prediction of primary resistance against Imatinib is feasible using EUS-FNA specimens [187, 297, 298]. In esophageal SETs or SETs $<2 \mathrm{~cm}$, EUS-guided sampling is not necessary as it is unlikely to influence management; surgical resection is not usually indicated [278]. In resectable SETs, tissue diagnosis is not necessary before surgery [278].

\section{Recommendation 16}

EUS-guided sampling may be used for differential diagnosis of subepithelial gastrointestinal tumors $\geq 20 \mathrm{~mm}$ in cases with high surgical risk or suspected non-resectability (LoE 2b, GoR C). Strong consensus (100\%).

\section{Lung cancer}

In suspected lung cancer conventional techniques (bronchoscopic or percutaneous-transthoracic biopsy) fail to establish a histological diagnosis in up to $1 / 3$ of patients. EUS allows effective transesophageal or transbronchial guidance for sampling of centrally located lung masses or lymph nodes adjacent to the esophagus or the respiratory tract [299-306]. There is a high diagnostic yield (87.6\%) for EUS-guided sampling with suspected malignant central lung mass or in the presence of a peripheral lung nodule and PET-positive mediastinal lymph nodes following at least one unsuccessful attempt at diagnostic flexible bronchoscopy or CTguided transthoracic needle aspiration. The endosonographic approach had an accuracy of $90.1 \%$ for the diagnosis of lung cancer, thus avoiding invasive and expensive surgical procedures [304]. Subtyping of non-small cell lung cancer is the basis of persona- 
lized oncological treatment and is feasible using EUS-guided sampling (including EBUS-TBNA) in $77-90.6 \%$ of cases [307309]. The rate of non-small cell lung cancer not otherwise specified (NSCLC-NOS) was reduced by $50 \%$ in patients who underwent cell block $(C B)^{13}$ immunohistochemistry [307]. Furthermore, in cases with $\mathrm{CB}$, a significantly higher agreement of subtyping between EUS-/EBUS fine-needle aspirates and matched biopsies compared to cases without CB (96\% vs. $69 \%$ ) has been shown [310]. Genotyping (e.g. molecular analysis: EGFR, KRAS, EML4ALK rearrangement) was possible using EUS/EBUS fine-needle aspirates in 77 - 98.4\% [180, 307 - 309, 311 - 313]. With EBUS-TBNA a minimum of four needle passes provided an adequate material for subtyping and molecular profiling of NSCLC cases [309].

\section{Recommendation 17}

In suspected lung cancer EUS-guided sampling (EUS-FNA, EBUS-TBNA) of centrally located mass lesions or suspicious lymph nodes is recommended to establish a definite tissue diagnosis complementing other diagnostic techniques (LoE $2 \mathrm{~b}$, GoR B). Strong consensus (100\%).

\section{Mediastinal and abdominal lymphadenopathy of unknown origin}

Based on EUS morphology alone [314], confident classification as malignant or benign is achievable in $25 \%$ of lymph nodes [ 315 , 316]. EUS-FNA has a higher accuracy than EUS features alone $[317,318]$. A meta-analysis $(n=9310)$ showed significant improvement in evaluating mediastinal lymphadenopathy with EUS-guided sampling over EUS features of lymph nodes (sensitivity $88 \%$ vs. $84.7 \%$; specificity $96.4 \%$ vs. $84.6 \%$ ) ( Table 3) [319]. The probability of malignancy is low if no EUS malignant lymph node criteria are present. Therefore, in addition to patient history, endosonographic lymph node features may facilitate endosonographic lymph node-sampling [318, 320 - 327].

Several studies and meta-analyses have demonstrated a high diagnostic yield and accuracy of EUS-guided sampling (EUS-FNA and EBUS-TBNA) for the evaluation of indeterminate mediastinal and abdominal lymphadenopathy, with or without a malignant disease background [170, 172, 176, 319, 323, 328 - 348]. Experienced cytopathologists demonstrate excellent reproducibility of cytological diagnoses on mediastinal lymph node specimens, and short, comprehensive training further improved the interobserver agreement between the least and the most experienced [161]. The diagnostic yield of EUS-guided lymph node sampling may be significantly improved by ancillary tests (e.g. immunohistochemistry and molecular analysis) [331, 340, 342, 347, 349 - 358]. EUS-guided sampling (EUS-FNA, EBUS-TBNA) shows satisfactory yield for the diagnosis and subtyping of primary and recurrent malignant non-Hodgkin-lymphoma, particularly if flow cytometry, immunohistochemistry, and cytogenetic analysis are used in specimen processing. The reported diagnostic accuracies (44-96.7\%) and feasibility of the WHO subclassification system $(66.6-88.8 \%)$ was varied [329, 332, 340, 342, 344, 351, $354,359-365]$. Flow cytometry was a necessary complement of cytology [211, 329]. The diagnostic yield may be lower for primary diagnosis of malignant lymphoma compared with recurrent disease, and for correctly classifying Hodgkin's lymphoma

${ }^{13}$ Term is explained in the addendum on terminology. and low-grade non-Hodgkin's lymphoma compared with highgrade diffuse large B-cell lymphoma [362, 365].

EUS-guided sampling (EUS-FNA, EBUS-TBNA) of mediastinal and abdominal lymph nodes is a reliable technique for definite tissue diagnosis of stage I and II sarcoidosis, whereas bronchoscopy with mucosal and transbronchial biopsy and bronchoalveolar lavage fails in approximately $50 \%$ of cases [366-379]. CB technique as well as combining histopathological evaluation of EUS core biopsies with conventional SC both improve the diagnostic yield, reducing the false-negative rate of EUS- and EBUS-guided tissue sampling in sarcoidosis [350, 369, 372]. Stage I is more accurately diagnosed compared to stage II sarcoidosis [372, 375]. The sensitivity (54-93\%) and accuracy of EUS-FNA and EBUS-TBNA are superior in comparison to bronchoscopy-related biopsy techniques [371, $373,375,378]$. An international randomized clinical multicenter study recently compared endosonographic sampling techniques (EUS-FNA and EBUS-TBNA) of mediastinal lymph nodes with bronchoscopy using mucosal and transbronchial lung biopsy for the diagnosis of stage I/II sarcoidosis. The diagnostic yield of endosonographic sampling to detect non-caseating granuloma (80\%) was significantly higher compared with bronchoscopy (53\%) and bronchoalveolar lavage (54\%) [373]. A meta-analysis (2097 patients, prevalence of sarcoidosis $15 \%$ ) reported a diagnostic yield of $79 \%$, a sensitivity of $84 \%$, and a specificity of $100 \%$ for the diagnosis of sarcoidosis using EBUS-TBNA [379].

Besides sarcoidosis, granulomatous lymphadenopathy may arise from a paraneoplastic "sarcoid-like reaction", tuberculosis, atypical mycobacteriosis, and other granulomatous diseases. Reliable tuberculosis diagnosis and differentiation from sarcoidosis is possible using endosonographic sampling techniques. Special staining, microbiological culture, and PCR are useful adjuncts to conventional cytopathological evaluation (see section 4) [336, 349, 352, 355, 357, 367, 380 - 386].

An RCT compared transbronchial vs. transesophageal sampling, using an ultrasound bronchoscope, for the diagnosis of mediastinal lymph nodes and other accessible lesions. There was an equal diagnostic yield and patient tolerance, but fewer anesthetic and sedative requirements, a shorter procedure time, less frequent oxygen desaturation and higher operator satisfaction in favor of transesophageal endosonographic sampling [387]. Combined transbronchial and transesophageal sampling, using an ultrasound bronchoscope, is superior compared with EBUS-TBNA alone for the diagnosis of mediastinal lymphadenopathy. The additional diagnostic gain of transesophageal sampling was 7.6\% [170].

\section{Recommendation 18}

EUS-guided sampling (EUS-FNA, EBUS-TBNA) is recommended as the primary diagnostic technique for tissue diagnosis of mediastinal or abdominal lymphadenopathy of unknown etiology (LoE 3a, GoR B). Strong consensus (100\%).

\section{EUS-guided sampling for tumor staging} Algorithmic approach

For tumor staging an algorithmic approach of EUS-guided sampling following the TNM classification of the respective malignant tumor is sensible. Potential sites of metastases within reach of EUS-FNA should be examined and sampled first, followed by regional lymph node stations, in which demonstration of metastatic involvement would alter management (e.g. N3- and N2stations in NSCLC [120, 388 -390] or liver hilum lymph nodes in 
unresectable hilar cholangiocarcinoma prior to liver transplantation [275]). The suspected primary tumor should be sampled last if necessary $[110,114,391]$. This systematic approach in an inverse TNM order addresses concerns that needle contamination with tumor cells from the first sampling target, from the instrumental channel or from gastrointestinal fluid could contribute to false-positive results from the subsequent targeted lesions [392 395]. Malignant cells have been identified within gastrointestinal luminal fluid in $48 \%$ of luminal cancer, and in $10 \%$ of extraluminal cancer patients undergoing EUS-FNA [393].

\section{Mediastinal lymph nodes}

In the absence of distant metastases, mediastinal lymph node involvement is the most important factor affecting the management and outcome of patients with NSCLC [389]. Esophageal EUS has a high sensitivity and specificity for malignant lymph node infiltration when found in the posterior mediastinum, aortopulmonary, subcarinal, and periesophageal regions [112, 319, 389, 396 - 398]. Meta-analyses report a sensitivity and specificity of between 83 $89 \%$ and $96.4-100 \%$, respectively, for nodal staging of lung cancer by EUS-guided sampling (EUS-FNA, EBUS-TBNA) ( $\bullet$ Table 3) [166 $170,320,339,389]$. Staging of NSCLC is an established indication for EUS-guided sampling of mediastinal lymph nodes. EUS has been shown to be more accurate than $\mathrm{CT}$ in defining disease stage [398-400]. EUS-guided sampling also impacts treatment choice and survival in patients with NSCLC. Patients with positive nodes were significantly more likely to receive chemotherapy and/or radiation therapy and less likely to undergo surgery compared with patients with negative node sampling. Patients with N2 or N3 disease by EUS-FNA had a significantly shorter survival time than node-negative patients. After adjusting for age, race, and sex, EUSguided sampling was the most important predictor of survival [401]. When implementing EUS in the staging algorithm, a significant reduction (up to $70 \%$ ) in unnecessary surgical exploration has been demonstrated [400, 402 - 404]. Staging accuracy was significantly improved, when EUS-guided sampling was performed in addition to mediastinoscopy. With the capability of EUS to detect metastatic mediastinal lymph nodes and to assess mediastinal tumor invasion, up to $16 \%$ of thoracotomies could have been avoided in one study [405].

Esophageal EUS and EBUS in combination allow targeting of nearly all relevant mediastinal lymph node locations [406-409]. Several studies and meta-analyses have shown that this combined approach improves lymph node staging, compared with either technique used alone [168, 170, 389, 390, 404, $410-418]$. A $21 \%$ increase in sensitivity for mediastinal nodal staging in proven or suspected lung cancer is achieved by performing combined endobronchial and esophageal endosonography-guided sampling compared with the esophageal approach alone (pooled data from 7 studies), and a $13 \%$ increase compared with EBUS-TBNA alone (pooled data from 9 studies) [390]. The accuracy of a combined endosonographic approach was significantly higher than PET-CT alone (90.0\% vs. $73.6 \%$ ) [415]. A comparison of two different approaches to combined endosonographic mediastinal staging of potentially operable lung cancer (EBUS first vs. esophageal EUS first) found no differences in efficacy and patient satisfaction. However, EBUS-guided sampling was the more efficient primary procedure [416]. Guidelines produced co-operatively by the ESGE, the European Respiratory Society (ERS) and the European Society of Thoracic Surgeons (ESTS) recommend the combination of EBUSTBNA and transesophageal EUS-FNA (using either a gastrointestinal echoendoscope or alternatively an ultrasound bronchosco- pe $=$ EUS-B-FNA) for the staging of patients with suspected or proven NSCLC and offer differentiated evidence-based recommendations for the use of endosonography for the diagnosis and staging of NSCLC in various clinical situations [390, 419-421].

Both esophageal EUS and EBUS have also been successfully used for the assessment of tumor spread to mediastinal lymph nodes (M1 disease) in a variety of extra-thoracic malignant disease [171, 328, 335, 337, 422-426]. In particular, the usefulness of EUS-guided sampling has been reported in the staging of patients with gastric cancer, pancreatic cancer, breast cancer, head and neck cancer, colorectal cancer, and lymphoma [173, 174, 361, 427-431]. A meta-analysis ( $n=533$ patients) showed a sensitivity of $85 \%$ and a specificity of $99 \%$ of EBUS-TBNA for the diagnosis of mediastinal lymph node metastases of extra-thoracic malignancies [172].

Esophageal cancer staging requires the detection and differential diagnosis of thoracic as well as abdominal lymph nodes (see next paragraph for the latter). The clinical impact of EUS-guided sampling is profound. EUS-FNA of mediastinal lymph nodes for the $\mathrm{N}$ staging of esophageal cancer is more sensitive and accurate than EUS alone and significantly impacts therapeutic decisions (e.g. surgical strategy) [432 - 434]. In most cases EUS demonstrates a more advanced stage than $\mathrm{CT}$, resulting in greater non-surgical management then if the EUS stage had been identical or less advanced [435]. There are limitations to EUS-guided sampling; it is not always technically feasible (peritumoral lymph nodes, stenotic tumors), it may increase the complication rate, it increases procedure costs [436], and with cancer cell contamination of the gastrointestinal lumen and the working channel of the echoendoscope, there is a risk of false-positive cytopathological diagnosis (see section 5)[392 - 394].

EUS-FNA was demonstrated to be accurate and sensitive when restaging patients as NO after neoadjuvant chemo-radiotherapy, thus guiding critical treatment decisions [437]. However, the restaging accuracy of EUS-FNA (78\%) was found to be significantly inferior to that of PET/CT (93\%), which is also superior with respect to predicting complete pathologic response [438].

\section{Abdominal lymph nodes}

Previous studies have shown high accuracy and clinical impact of EUS-guided sampling of celiac lymph nodes in esophageal cancer staging [439-441]. According to the current TNM classification, malignant celiac lymph nodes are no longer assigned M1a classification, and together with cervical and mediastinal lymph node metastasis, are included in the N category [442], with EUS-guided sampling only being useful in selected cases.

In addition to EUS-guided sampling of mediastinal lymph nodes, sampling of abdominal lymph nodes in gastric cancer may alter staging classification. Malignant involvement of distant lymph nodes (e.g. retropancreatic, mesenteric, para-aortic, mediastinal) is indicative of metastatic disease and resigns the patient to palliative care $[173,174]$.

EUS-guided sampling is not recommended for the staging of rectal cancer; it does not alter management compared to standard EUS alone. Most perirectal lymph nodes are malignant and are not suitable to be sampled because of the risk of traversing the primary tumor $[443,444]$. In patients with previous surgery and suspicion of cancer recurrence, EUS-guided sampling is useful for detecting perirectal or perianastomotic malignancy with greater accuracy than imaging alone [55]. 


\section{Adrenal glands and liver masses}

EUS-guided sampling of adrenal masses can provide valuable information for the staging of lung cancer and other malignancies. Particularly in lung cancer, 30 - $80 \%$ of adrenal masses are adenomas [445]. Sampling from the left adrenal gland is viable and safe; sampling from the right adrenal gland has also been reported. The diagnostic yield of EUS-guided sampling ranges from $76-100 \%$. Further management is altered in approximately $50 \%$ of lung cancer patients [446-458].

EUS and EUS-guided sampling are superior to CT for detecting small liver metastases [459, 460], and a 7-point scoring system (PPV 88\%) may be used to target EUS-guided sampling of these liver lesions [460]. The diagnostic yield is reported between 80 $98 \%$ with a substantial effect on clinical management [461 - 467]. Liver metastases are meaningful targets of EUS-guided sampling when the primary malignancy cannot be sampled due to intervening structures or if not detectable. EUS examination of the liver is incomplete, is limited to the left lobe, the proximal part of the right lobe and the hilum and should be considered complementary but not as an alternative to the other imaging techniques.

\section{Other metastatic locations and diagnosis of recurrent malignant disease}

EUS and EUS-guided sampling may play a pivotal role in the detection and diagnosis of disease recurrence or late distant spread of gastrointestinal cancer [391]. A high accuracy with clinical impact of EUS-guided sampling has been shown in establishing recurrent malignancy following curative treatment [55, $175-178$, $215,359,365,427,468]$, and metastatic disease, in particular affecting the pancreas [147, 206, 212, 213, 215], spleen [469, 470], pelvis [59, 61, 471], and peritoneal space [466, 472 - 483].

\section{Recommendation 19}

Combined EUS-guided sampling (EBUS-TBNA and EUS-FNA) is recommended for complete nodal staging of non-small cell lung cancer (LoE 1a, GoR A). Strong consensus (100\%).

\section{Recommendation 20}

EUS-guided sampling (EBUS-TBNA, EUS-FNA) may be used in mediastinal nodal and metastatic staging of other malignancies (LoE 3a, GoR B). Strong consensus (100\%).

\section{Recommendation 21}

EUS-guided sampling may be used for the detection of recurrence of malignancies (LoE 3b, GoR C). Strong consensus (100\%).

\section{Recommendation 22}

When biopsy of suspected metastatic lesions for staging purposes is contemplated, penetration of the primary tumor should be avoided (LoE 5, GoR D). Strong consensus (100\%).

\section{Recommendation 23}

In cases with suspected distant and/or nodal metastases, algorithmic sampling should be performed beginning with the potentially most advanced metastatic site and following an inverse TNM order (LoE 5, GoR D). Strong consensus (100\%).
EUS-guided sampling: Needle choice, sampling techniques and other factors influencing diagnostic yield 7

\section{Choice of needle type and diameter}

There are four types of needles commercially available for EUSguided sampling: standard aspiration needles (19 G, 22 G, 25 G for EUS-FNA; $21 \mathrm{G}$ and $22 \mathrm{G}$ for EBUS-TBNA), aspiration needles with a core trap and reverse bevel technology (19 G, 20 G, 22 G, $25 \mathrm{G}$ ), aspiration needles with a shark mouth needle tip geometry (19 G, 22 G, 25 G), and trucut needles (19 G).

\section{EUS-guided fine-needle aspiration for cytopathological processing}

Standard aspiration needles were originally designed to obtain cellular material for cytopathological examinations [110, 484, 485]. The cytological yield and diagnostic accuracy, in studies using predominantly $22 \mathrm{G}$ aspiration needles, are reported to be high for solid pancreatic lesions and metastatic lymph nodes, satisfactory for biliary mass lesions, but only moderate for gastrointestinal SETs and PCLs ( $\odot$ Table 3 ) [104, 110, 486, 487]. Currently, the $22 \mathrm{G}$ aspiration needle is most widely used, with increased utilization of $25 \mathrm{G}$ aspiration needles particularly for sampling and cytopathological evaluation of pancreatic lesions and lymph nodes [149, 488, 489].

\section{G vs. 25 G aspiration needles}

Meta-analyses demonstrate slight superiority of the $25 \mathrm{G}$ over the $22 \mathrm{G}$ aspiration needle for EUS-FNA of solid pancreatic lesions [490, 491]. In one meta-analysis of EUS-FNA of pancreatic and various peri-pancreatic lesions ( 8 prospective, 3 non-randomized and 5 randomized studies), $25 \mathrm{G}$ needles performed marginally better (difference of $12 \%$ ) with regard to the number of adequate needle passes in comparison to $22 \mathrm{G}$ needles. There was no significant advantage with regard to sensitivity (25 G: $91 \%, 22$ G: $78 \%$ ), specificity (both needle types: $100 \%$ ), needle visibility, diagnostic yield, number of needle passes or complication rates between 22 $\mathrm{G}$ and $25 \mathrm{G}$ needles [490]. A further meta-analysis (5 prospective studies, 3 RCTs) reported a significantly higher sensitivity when using the $25 \mathrm{G}$ vs. the $22 \mathrm{G}$ needle for EUS-FNA of solid pancreatic lesions (25 G: 93 \% vs. 22 G: $85 \%$ ). No significant differences were observed between needle diameters with regard to specificity (25 G: $97 \%$ vs. 22 G: $100 \%$ ), accuracy (25 G: $98 \%$ vs. 22 G: $97 \%$ ), and needle malfunction ( $25 \mathrm{G}$ : $15.7 \%$ vs. $22 \mathrm{G}$ : $12.8 \%$ ) [491]. The most likely reason for the superiority of the $25 \mathrm{G}$ aspiration needle is that needle passage may be easier when in a position requiring tight angulation of the tip of the echoendoscope (e.g. transduodenal access to pancreatic head lesions) and in very firm lesions (pancreatic cancer) [492 - 495]. This superiority was most pronounced for lesions located in the uncinate process of the pancreatic head [493]. Cross-over from the $22 \mathrm{G}$ needle to the $25 \mathrm{G}$ needle was more often needed for lesions in the uncinate process than elsewhere in the pancreas [494]. The quality of cytological smears is superior and bloody contamination is less pronounced with $25 \mathrm{G}$ compared with $22 \mathrm{G}$ needles [493, 496]. Further comparison of $22 \mathrm{G}$ and $25 \mathrm{G}$ EUS-FNA needles in solid and cystic pancreatic masses [497] and in solid pancreatic and non-pancreatic masses [498] found no significant differences between needle diameters with diagnostic accuracy [497, 498]. However, in one study $25 \mathrm{G}$ needles were easier to manipulate with fewer procedure-related complications (3.2\% vs. $10.6 \%$ with the $22 \mathrm{G}$ needle) [497]. In contrast, the other multicenter study reported a significantly better performance of the $22 \mathrm{G}$ 
needle in terms of visibility of the needle tip and performance of the procedure [498]. A further study demonstrated equivalency of $25 \mathrm{G}$ needles and $22 \mathrm{G}$ needles in lymph node biopsies, a nonsignificant advantage of $25 \mathrm{G}$ needles in solid pancreatic lesions and a non-significant advantage of $22 \mathrm{G}$ needles in SETs [494]. This agrees with two studies showing similar diagnostic yields for $22 \mathrm{G}$ needles and $25 \mathrm{G}$ needles for EUS-FNA of various nonpancreatic lesions and lymph nodes, but a higher yield of the 25 $\mathrm{G}$ aspiration needle for pancreatic lesions [291, 499]. In conclusion, the advantage of the $25 \mathrm{G}$ needle appears to be limited to pancreatic lesions, in particular within the pancreatic head.

A new algorithmic approach for needle choice (EUS-FNA: 25 G transduodenally, $22 \mathrm{G}$ all other routes; EUS-guided treatment: flexible $19 \mathrm{G}$ transduodenally, all other routes standard $19 \mathrm{G}$ ) was tested prospectively. Compared with the prior protocol (EUS-FNA $22 \mathrm{G}$ or $25 \mathrm{G}$ at the preference of the examiner; all therapeutic interventions: standard $19 \mathrm{G}$ ), the new algorithmic approach significantly reduced the technical failure rate from $10.9 \%$ to $1.8 \%$ [495].

$19 \mathrm{G}$ vs. $22 \mathrm{G}$ and $25 \mathrm{G}$ aspiration needles

There is limited data comparing the performance of the $19 \mathrm{G}$ aspiration needle with aspiration needles of a smaller diameter. There was no difference in diagnostic accuracy by intention-totreat analysis between the $19 \mathrm{G}$ and the $22 \mathrm{G}$ aspiration needle, but the $19 \mathrm{G}$ was superior to the $22 \mathrm{G}$ needle in terms of the amount of cellular material and diagnostic accuracy by per-protocol analysis (following exclusion of 5 technical failures, all with pancreatic head lesions). Further analysis favored the $19 \mathrm{G}$ aspiration needle for sampling of lesions within the pancreatic body and tail [500]. In a large retrospective analysis from an experienced center $(n=548)$ of EUS-guided diagnostic and therapeutic interventions, significantly more technical failures were observed with 19 G vs. 22 G and 25 G needles (19.7\% vs. $8.8 \%$ ) and with transduodenal vs. other access routes ( $24.4 \%$ vs. $5.2 \%$ ) [495]. These findings are in agreement with two studies showing that EUS-FNA of lesions within the uncinate process may not be possible using the stiff $19 \mathrm{G}$ aspiration needles [501, 502]. A flexible $19 \mathrm{G}$ aspiration needle has been shown to be effective for procuring aspirates from pancreatic head lesions even by the transduodenal route $[495,503,504]$. Equipotency of the flexible $19 \mathrm{G}$ aspiration needle and the $25 \mathrm{G}$ aspiration needle in terms of on-site diagnosis, technical failure and adverse events has been demonstrated [504].

$21 \mathrm{G}$ vs. $22 \mathrm{G}$ aspiration needles for EBUS-TBNA

A meta-analysis of 5 studies ( $n=1720$ patients) did not reveal significant differences in the diagnostic yield, sample adequacy, or the mean number of needle passes between the $21 \mathrm{G}$ and $22 \mathrm{G}$ needles during EBUS-TBNA [505].

\section{EUS-guided tissue acquisition for histopathological processing}

With increasing requirements of histopathological, immunohistochemical and molecular biological diagnosis [506, 507], three types of "histology needles" have been developed to facilitate acquisition of core cylinders suitable for histopathological examination: trucut needles [92, 93, 508, 509], aspiration needles with a side fenestration (core trap) and reverse bevel technology $[95,97,510,511]$ and aspiration needles with a shark mouth design. Acquisition of tissue suitable for histopathological processing is also possible with standard aspiration needles, not just with "histology needles" [96, 104, 110, 484, 485, 512, 513]. The diagnostic yield for histological material is dependent on the needle diameter.

\section{G standard aspiration needle}

Only a limited number of reports describing the use of a $25 \mathrm{G}$ aspiration needle for obtaining samples suitable for histopathological processing are available. For solid pancreatic lesions, histological yields are reported at $44 \%$ ( 1 needle pass) [504], and $81 \%$ ( 2 or 4 needle passes) [514]. In a randomized cross-over trial, $72 \%$ (low negative suction pressure) and 90\% (high negative suction pressure) of specimens obtained with $25 \mathrm{G}$ aspiration needles from solid pancreatic lesions were adequate for histopathological processing. $25 \mathrm{G}$ aspiration with high suction pressure was significantly more likely to provide an accurate diagnosis [515].

\section{G standard aspiration needle}

Studies using standard $22 \mathrm{G}$ aspiration needles reported material suitable for histological diagnosis in 28\% [516], $68 \%$ [517], $73 \%$ [291], 79\% [493], 80\% [217], 81\% [518], 82\% [283, 519], 84\% [519, 520], 87\% [521], 89\% [522], 92\% [205], 96\% [523] to $98 \%$ [463] (for details, see $96,110,485,486]$ ). In a study of factors influencing the success of EUS-FNA, the chance of acquiring adequate material for histopathologic evaluation was significantly higher for $22 \mathrm{G}$ aspiration needles (73\%) than for $25 \mathrm{G}$ aspiration needles (61\%) [291]. Some authors advocate using a high negative suction pressure $(30 \mathrm{ml}$ to $50 \mathrm{ml}$ ) to facilitate procurement of histological material [516, 518, 523]. Histological and immunohistochemical diagnosis using the $22 \mathrm{G}$ aspiration needle is reported particularly for gastrointestinal SETs [281, 283, 293], neuroendocrine pancreatic and other rare pancreatic tumors [205, 340,521 ], liver tumors [463] and autoimmune pancreatitis [217].

\section{G standard aspiration needle}

In several studies using the standard $19 \mathrm{G}$ aspiration needle, an adequate histological sample was obtained in 79\% [524], 88\% [504], 89\% [361], 94.7\% [503] 97.5\% [525] to $100 \%$ [332, 369] (for details, see $[96,485])$. To overcome the technical limitations of transduodenal puncture, removing the stylet before insertion of the needle into the working channel of the echoendoscope [525] or using a flexible nitinol needle [503] was advocated. Compared with a $25 \mathrm{G}$ aspiration needle, histological core procurement was significantly better with a flexible $19 \mathrm{G}$ aspiration needle ( $88 \%$ vs. $44 \%$ ). However, specimens supplied by the $19 \mathrm{G}$ needle were more often significantly contaminated with blood (severe blood contamination, $36 \%$ vs. $4 \%$ ) [504]. Using 19 G aspiration needles, it is possible to achieve histological material appropriate to diagnose and subtype malignant lymphoma (immunohistochemistry, flow cytometry, cytogenetic assessments) [361], diagnose stage I sarcoidosis [369], autoimmune pancreatitis [216] and parenchymal liver disease [513, 526, 527], differentiate GISTs from other types of gastrointestinal SET [280, 290], and grade pancreatic neuroendocrine tumors (Ki-67) [204].

\section{G trucut needle}

A 19 G trucut needle with a $20 \mathrm{~mm}$ tissue tray and a spring-loaded mechanism for endosonographic applications was first reported in 2002 [92, 93]. Results comparing the yield of EUS-guided trucut biopsy to standard aspiration needles have been unfavorable. Several technical limitations (rigidity, mechanical friction of the spring-loaded firing mechanism, technically demanding use, no fanning in multiple trajectories through the le- 
sion possible, minimal diameter of the target lesions of approximately $20 \mathrm{~mm}$ ) cause the diagnostic yield and accuracy to vary with no obvious advantage over standard aspiration needles (for details, see [96, 110, 484, 485]). Due to these drawbacks and the high cost of the needle platform, EUS-guided trucut biopsy has not prevailed in clinical practice. The ability to obtain a specific diagnosis by immunohistochemistry is significantly higher with EUS-guided trucut biopsy compared with EUS-FNA [94].

ProCore needles

Promising results using a $19 \mathrm{G}$ aspiration needle with a lateral opening near the needle tip (core trap) and reverse bevel technology (ProCore) were reported for EUS-guided biopsy in various mass lesions and lymph nodes, with the sample quality being adequate for histological assessment in $89.5 \%$ of cases [95]. ProCore needles are available with diameters of 19 G, 20 G, 22 G and $25 \mathrm{G}$. A high single-pass rate of $88.5 \%$ adequate histological samples with the $22 \mathrm{G}$ ProCore needle from pancreatic masses (mainly transduodenal biopsy) has been demonstrated [97]. A further study using the $22 \mathrm{G}$ ProCore needle for EUS-guided biopsy of various pancreatic and non-pancreatic mass lesions reported a similar yield of $83 \%$ adequate histological core samples [528]. However, a tissue core with material sufficient for cytopathological assessment was obtained in only $53 \%$ of small solid pancreatic lesions ( $\leq 20 \mathrm{~mm}$ ) [529] and in $46 \%$ of PCLs [530]. A high singlepass diagnostic yield was reported for EUS-guided sampling of solid pancreatic lesions with the $25 \mathrm{G}$ ProCore needle but with histological core material provided in only $32 \%$ [511]. A further study using the $25 \mathrm{G}$ ProCore needle reported diagnostic specimens in only $60.4 \%$ of EUS-guided biopsies of solid masses, lymph nodes and thickened gastric wall, with histological specimens provided in only $40.5 \%$ [531].

Comparative data on the efficacy of "histology needles" is expanding. Comparing the $22 \mathrm{G}$ ProCore needle and a $22 \mathrm{G}$ aspiration needle in EUS-guided sampling of solid pancreatic mass lesions, the diagnostic yield or quality of the histologic core did not differ significantly [510]. Further RCTs comparing the performance of standard $22 \mathrm{G}$ aspiration needles and ProCore needles confirmed similar accuracy of both needles in the diagnosis of solid pancreatic masses [532-534], with a lower number of needle passes needed for a diagnostically adequate sample with a 22 G core needle biopsy [532, 533]. Conversely, one study reported a better histological sample for the standard aspiration needle [534]. A further prospective study found a significantly lower capacity for diagnosis and more technical difficulties and failures with the $22 \mathrm{G}$ ProCore needle [535]. A retrospective comparative study reported similar performance of both needle types with a non-significant trend to a higher per-pass adequacy for the ProCore needle [536]. Only one RCT, comparing the performance of the $22 \mathrm{G}$ standard aspiration needle with that of the $22 \mathrm{G}$ ProCore needle in SETs, found a significant advantage of the ProCore needle in terms of improved capacity to obtain histological core samples and a higher diagnostic sufficiency rate [294].

A meta-analysis ( $n=1617$; including 641 cases with pancreatic mass lesions) compared the performance of the ProCore and standard needles for EUS-guided sampling of pancreatic and other lesions and found no significant difference in diagnostic adequacy or accuracy, histological core tissue procurement or mean number of passes to diagnosis. There was no difference observed between the 19, 22 or $25 \mathrm{G}$ needles for any of the outcome parameters [537].
A retrospective study suggested superiority of $21 \mathrm{G}$ aspiration needles over $22 \mathrm{G}$ aspiration needles in characterizing benign mediastinal lesions and subtyping NSCLC when using histopathological assessment of EBUS-TBNA samples [538].

\section{Recommendation 24}

In a referral EUS center it is advisable to have needles of different size available, and the choice among different needles should be made considering the anatomical location and the type of the target lesion and the preferred mode of processing of the material (LoE 2b, GoR C). Strong consensus (100\%).

\section{Recommendation 25}

$22 \mathrm{G}$ aspiration needles have a high diagnostic yield, low risk of adverse events, and good technical performance, and therefore should be regarded as the current standard for EUS-guided sampling (LoE $2 \mathrm{a}$, GoR B). Strong consensus (100\%).

\section{Recommendation 26}

$25 \mathrm{G}$ aspiration needles are not inferior to $22 \mathrm{G}$ aspiration needles with respect to cytological yield (LoE $1 \mathrm{a}, \mathrm{GoR}$ A). The use of $25 \mathrm{G}$ needles should be considered in particular for EUSguided transduodenal sampling of pancreatic head lesions (LoE 2a, GoR C). Strong consensus (100\%).

\section{Recommendation 27}

Due to a high rate of technical failure, the use of nonflexible 19 $\mathrm{G}$ needles is not recommended for transduodenal sampling of pancreatic head masses (LoE 2b, GoR B). Strong consensus (100\%).

\section{Factors influencing the yield of EUS-guided sampling} Features of the target lesion

The hypocellular character of the PCL aspirate renders the diagnostic yield and accuracy of EUS-guided sampling of PCLs considerably lower than in the case of solid pancreatic lesions ( $\bullet$ Table 3 ).

For gastrointestinal SETs the diagnostic yield of EUS-guided sampling (specific diagnosis) is approximately 34\% [286] to $82 \%$ [283], with most studies reporting a yield of $52-63 \%$ [278]. The sensitivity of EUS-FNA is influenced by size $(>10 \mathrm{~cm})$, location (duodenal), shape (irregular), and unclear layer of origin; all significantly associated with inadequate tissue yield and with nondiagnostic cytology samples [284].

Data on the influence of the size and site of solid pancreatic lesions on EUS-FNA accuracy are conflicting. In five studies of patients with solid pancreatic tumors, the sensitivity and diagnostic accuracy of EUS-FNA were correlated with tumor size [148, 539 542]. In the two largest cohorts, sensitivity and accuracy were significantly lower for tumors $<10 \mathrm{~mm}[148,541]$, the cut-off values of the other three studies being $20 \mathrm{~mm}$ [539], $25 \mathrm{~mm}$ [542] and $30 \mathrm{~mm}$ [540], respectively. Other studies did not show any association between the diagnostic performance characteristics of EUS-guided sampling and the diameter of the target lesion [152, 189, 291, 543, 544]. One study found the false-negative rate and the number of passes required for diagnosis to be higher in pancreatic tumors $>30 \mathrm{~mm}$ compared with tumors $\leq 30 \mathrm{~mm}$ 
[545]. Two studies reported tumor location in the body or tail to be associated with greater EUS-FNA sensitivity [148, 542]. In other studies, the anatomical location of pancreatic tumors was not predictive for the diagnostic yield and accuracy of EUS-guided sampling [540, 541, 544].

The diagnostic accuracy of EUS-FNA for pancreatic cancer is considerably hampered in patients with chronic pancreatitis [546550].

There are inconsistent results in studies evaluating the influence of biliary stents on EUS-FNA performance characteristics. In two retrospective studies, EUS-FNA was found to be accurate and safe in the diagnosis of pancreatic cancer, independent of the presence of a plastic or self-expanding metallic biliary stent [545, 551]. In another study, there was no significant difference in the diagnostic yield of EUS-FNA between patients without biliary stents and those with stents placed $>1$ day prior to EUS-FNA. Patients with stents placed immediately before EUS-FNA were significantly more likely to have indeterminate cytopathological results [552]. A further report suggested a significantly lower accuracy of EUSFNA for pancreatic head malignancy in patients with prior biliary stenting [553].

\section{Sampling technique}

Fanning technique

Large malignant tumors, lymph node metastases and inflammatory lymph nodes may develop necrosis, in particular centrally. Malignant lymph node infiltration may be focal and commences in the peripheral cortical zone. This suggests that EUS-FNA of the periphery of the lesion increases the diagnostic yield, but this is not supported by a study where aspiration from the edge of the lymph node did not increase the likelihood of a correct diagnosis [554]. Sampling of all parts of solid lesions and lymph nodes ("fanning technique") is recommended by the ESGE guidelines on EUS-guided sampling in gastroenterology [96]. According to the results of an RCT, fanning with a needle through multiple areas of a solid pancreatic lesion is not more accurate than a traditional approach where only a single area is targeted. However, significantly fewer passes are required when using the fanning technique to establish a diagnosis [555].

\section{Recommendation 28}

The fanning technique should be applied in EUS-guided sampling to increase sample adequacy (LoE $2 b$, GoR C). Strong consensus (100\%).

\section{Suction}

Traditionally, negative suction pressure using a $5 \mathrm{ml}$ or $10 \mathrm{ml}$ syringe is used to facilitate EUS-guided tissue acquisition. Alternatively, the fine-needle capillary sampling technique [556] or slow removal of the stylet ("slow-pull technique") [528] may be used to draw cells up into the needle lumen. Applying suction to the needle may increase the cellular yield of the aspirate but, at the same time, potentially increases artifacts and contamination by blood. Applying high negative pressure suction has been suggested to facilitate procurement of core tissue in EUS-FNA and EBUS-TBNA [283, 516, 518, 523, 557, 558]. In the United States, routine use of suction was preferred by $85.5 \%$ of EUS-FNA practitioners for the sampling of solid lesions, and by $67 \%$ for the sampling of lymph nodes [489]. There is controversial data on the use of suction in non-pancreatic and pancreatic EUS-guided sam- pling. An experimental study revealed that continuous suction using a $10 \mathrm{ml}$ syringe rather than intermittent suction or suction using $20 \mathrm{ml}$ or $30 \mathrm{ml}$ syringes provided optimal cellularity in EUSFNA of a mediastinal lymph node [559]. A further experimental study evaluated suction forces of traditional and side-hole aspiration needles of all 3 available diameters using $50 \mathrm{ml}$ negative pressure, $20 \mathrm{ml}$ negative pressure and the slow-pull technique. Suction forces increased with a larger needle diameter as well as with larger aspiration volume. The slow-pull technique generated a weak negative suction pressure of $1.4-4.8 \%$ of that generated with a $20 \mathrm{ml}$ syringe (needle diameter dependent), with the time to reach the maximum negative pressure also being needle diameter-dependent (with a $20 \mathrm{ml}$ syringe: $19 \mathrm{G}: 4 \mathrm{~s}, 22 \mathrm{G}: 11 \mathrm{~s}$; $25 \mathrm{G}: 80 \mathrm{~s}$ ) [560].

An RCT demonstrated that EUS-guided lymph node sampling with suction compared with the fine-needle capillary technique did not improve the likelihood of correct diagnosis, but, due to excessive bloody contamination, provided smears of significantly poorer quality [554]. This contradicts a further RCT $(n=52)$ with solid lesions, $66 \%$ lymph nodes. EUS-FNA with suction provided a greater number of cytological slides and a higher sensitivity and NPV without increasing the blood contamination [561]. For EBUS-TBNA of mediastinal lymph nodes, no difference in adequacy, diagnosis, or quality between suction and no suction was demonstrated in an RCT [562]. With various pancreatic and nonpancreatic targets (49\% lymph nodes), no difference in suction versus capillary sampling in terms of quality and diagnostic accuracy was found [556].

For sampling of pancreatic masses using 22 and $25 \mathrm{G}$ aspiration needles, one RCT favored EUS-guided fine-needle sampling with $10 \mathrm{ml}$ suction. Cytological samples in the suction group were associated with a significantly higher cellularity, diagnostic yield, sensitivity, and accuracy compared with those in the non-suction group. However, blood contamination of slides was greater in the suction group [563]. In a multicenter study, no suction, $10 \mathrm{ml}$ suction, and $20 \mathrm{ml}$ suction were compared in EUS-guided sampling of solid pancreatic lesions using a $22 \mathrm{G}$ aspiration needle in a prospective randomized fashion. The sample adequacy and accuracy were significantly better with $20 \mathrm{ml}$ suction $(87.5 \%$ and $86.2 \%$, respectively) compared with $10 \mathrm{ml}$ suction $(76.1 \%$ and $69.0 \%$, respectively) and no suction (45.4\% and $49.4 \%$, respectively) [564]. A retrospective study compared the slow-pull technique with suction in the sampling of solid pancreatic lesions. The slow-pull technique resulted in significantly less contamination with blood and higher sensitivity for the diagnosis of malignant tumors only when a $25 \mathrm{G}$ aspiration needle was used. No significant differences between the two techniques were observed in this study when a $22 \mathrm{G}$ aspiration needle was used [542].

\section{Recommendation 29}

For aspiration of cysts and fluid collections, negative pressure suction is recommended (LOE 5, GoR D). Strong consensus (100\%).

\section{Recommendation 30}

For sampling of solid pancreatic lesions, negative pressure suction should be considered (LOE 1b, GoR A). Strong consensus $(100 \%)$. 


\section{Recommendation 31}

In lymph nodes and other highly vascularized solid lesions, sampling without applying suction should be considered (LoE 2b, GoR C). Strong consensus (100\%).

\section{Use of a stylet}

The use of a stylet is intended to prevent clogging of the needle lumen and contamination of the aspirate by blood and gastrointestinal wall tissue, to express the aspirated material from the needle and to stabilize the needle. A removable stylet is included in all commercially available aspiration needle platforms and is recommended for use by manufacturers. In the United States, this stylet is used by the majority of EUS-FNA practitioners [489].

No advantage of using a stylet in terms of specimen quality and diagnostic yield has been demonstrated [565-569]. An RCT suggested a lower proportion of adequate samples and a higher probability for blood contamination in needle passes using a stylet compared with needle passes performed without a stylet [565]. A multicenter RCT reported non-inferiority of performing 22 G EUSFNA of various solid lesions without a stylet compared with using a stylet with respect to the acquisition rate of histological specimens (55.5\% vs. 55.0\%) [570].

\section{Recommendation 32}

Aspiration needles may be used with or without a stylet with the same diagnostic yield (LoE 1b; GoR A). Strong consensus (100\%).

\section{Number of needle passes}

The number of passes is determined based on the results of on-site cytopathological evaluation, should this be available (ROSE) ${ }^{14}$ [96, 571,572 ]. As an alternative to ROSE-guided sampling, a high number $(\geq 7)$ of needle passes is thought to be a predictor of a high diagnostic sensitivity of EUS-FNA [149]. If ROSE is not available, $69 \%$ of endosonographers in the United States will perform 3 - 5 needle passes, and $29 \%$ will perform 6 or more needle passes [489]. In Europe, $58.6 \%$ of endosonographers perform $\leq 3$ needle passes for diagnosis of lymphadenopathy, and $44.6 \%(\geq 25 \mathrm{~mm})$ or $48.8 \%$ $(<25 \mathrm{~mm})$ for the diagnosis of pancreatic lesions [149]. In patients with pancreatic and non-pancreatic lesions, the diagnostic accuracy with $\geq 3$ needle passes was significantly higher than that with $\leq 3$ needle passes (90\% vs. $78 \%$ ) [291]. In Germany, $84 \%$ of endosonographers select the number of needle passes depending on visual assessment of aspirates [488].

\section{Pancreatic lesions}

ROSE study results indicate that the diagnosis of a solid pancreatic lesion using standard aspiration needles may require $5-7$ passes [573 - 575]. When using a $25 \mathrm{G}$ aspiration needle for sampling of a solid pancreatic lesion, 2 - 4 needle passes were adequate for good diagnostic accuracy [499, 514, 515, 576]. Using a standard 22 G aspiration needle, $1-2$ needle passes were sufficient to achieve a high diagnostic yield and accuracy in $92 \%$ of cases with solid pancreatic lesions [521].

\footnotetext{
${ }^{14}$ The terms "number of passes" and ROSE are explained in the addendum on terminology.
}

Negative predictive factors for the number of diagnostic EUS-FNA needle passes include the following: intratumoral anechoic foci, well-differentiated pancreatic cancer, neuroendocrine tumor, coexistence of chronic pancreatitis, benign final diagnosis, pancreatic head location, diameter of the lesion (conflicting data) and prior attempts for tissue diagnosis [144, 148, 547, 573, 577, 578].

In the case of PCLs with no solid component, a single pass and complete cyst fluid aspiration should be performed to prevent cyst infection [96]. In the case of PCLs with a solid component, the diagnostic yield is significantly higher for $\geq 2$ needle passes (78\%) compared to one needle pass (44\%) [579].

\section{Non-pancreatic lesions}

In the case of lymph nodes, liver metastases and adrenal lesions, a lesser number of needle passes is sufficient to provide a high diagnostic yield. Approximately 3 needle passes were sufficient for EUS-FNA and EBUS-TBNA of lymph nodes [499, 554, 573, 575, 580]. One study indicated that 5 needle passes is optimum for the cytopathological diagnosis of lymph nodes [574]. For liver lesions, $2-3$ needle passes are adequate $[461,463,573]$. There is no evidence-based data to suggest an optimal number of needle passes in gastrointestinal subepithelial, adrenal, or other lesions.

\section{Recommendation 33}

If ROSE is not available, the number of needle passes should be based on gross visual inspection of the obtained material and the type of target lesion (LoE 2b, GoR C). Strong consensus (100\%).

\section{Targeted sampling}

EFSUMB guidelines recommend the use of contrast-enhanced endoscopic ultrasound (CE-EUS) and of EUS-elastography to facilitate differential diagnosis of solid pancreatic lesions, PCLs and lymph nodes [581, 582]. CE-EUS and EUS-elastography are appropriate to demonstrate avascular and soft areas (necrosis) within solid tumors and lymph nodes. It is speculated that tumor necrosis reduces the diagnostic yield of EUS-guided sampling of large malignant tumors [555]. Furthermore, it has been shown for gastrointestinal SET and large lymph nodes that EUS-guided puncture of necrosis may promote infection [114].

\section{Lymph nodes}

A reliable classification of benign and malignant lymph nodes is an important prerequisite for the correct prognosis and treatment guidance of malignancy. B-mode and color Doppler criteria lack good sensitivity and specificity for lymph node characterization, importantly overlooking focal metastatic infiltrations of small lymph nodes [583, 584].

CE-EUS improved the specificity in diagnosing benign lymph nodes, compared to B-mode EUS, but did not improve the identification of malignant lymph nodes in the mediastinum and abdomen [585]. Evaluation of CE-EUS enhancement patterns demonstrated an improvement in sensitivity and specificity, compared with B-mode EUS [586].

EUS-elastography, currently strain elastography, has been shown to increase the discriminatory ability of normal EUS criteria, and to improve the specificity of lymph node staging in gastrointestinal malignancy $[29,582]$. A meta-analysis calculated a sensitivity of $88 \%$ and specificity of $85 \%$ with EUS-elastography for differentiating between benign and malignant lymph nodes [587]. EUS- 
elastography has the potential to further improve the accuracy of EUS-FNA in nodal staging $[29,582,588]$. EFSUMB guidelines suggest using EUS-elastography for identifying suspicious lymph nodes and/or harder lymph node regions as targets of EUS-guided sampling [582]. There are no prospective studies comparing B-mode-guided and elastography-guided EUS-FNA in the staging of malignant lymph nodes.

\section{Solid pancreatic lesions}

The NPV of EUS-FNA for the diagnosis of PDAC is relatively low, estimated at $72 \%$ [196] and $58.5 \%$ [589]). The percentage of the cytopathological diagnostic category "atypical" with a malignancy rate of $25-100 \%$ (mean $58 \%$ ) in follow-up amounts to $1-14 \%$ (mean $5.3 \%$ ) in pancreatic EUS-FNA [152, 590 -593]. Therefore, guidelines advise against preoperative sampling of potentially resectable solid pancreatic mass lesions in operable patients unless there is high suspicion of a diagnosis other than PDAC (non-PDAC), particularly autoimmune pancreatitis [104, 594, 595]. Even with detailed preoperative diagnostic evaluation, the incidence of benign disease following pancreatoduodenectomy for presumed PDAC is $5-13 \%$, with $30-43 \%$ being focal autoimmune pancreatitis [595]. In specialized tertiary referral centers for EUS-FNA, $13 \%$ [148] to $21 \%$ [194] of focal pancreatic lesions referred for cytopathological diagnosis turn out to be benign, often focal chronic and autoimmune pancreatitis. In the case of solid pancreatic neoplasms, $12 \%$ to $25 \%$ turn out to be non-PDAC (e.g. neuroendocrine tumors, pancreatic metastases, mesenchymal tumors, lymphoma, solid pseudopapillary neoplasia) [146, 148, 194, 596]. The ratio of non-PDAC to PDAC is inversely related to the diameter of the tumor. In EUSFNA of solid pancreatic lesions ( $\mathrm{n}=996), 77.5 \%, 41.3 \%$ and $19.2 \%$ of solid pancreatic lesions measuring $<10 \mathrm{~mm}, 10-20 \mathrm{~mm}$, and $>20 \mathrm{~mm}$, respectively, turned out to be non-PDAC or benign [148]. A diagnosis of focal pancreatitis or non-PDAC will significantly affect the management and outcome of the patient, allowing watchful waiting for low-risk cystic neoplasias and small G1 neuroendocrine tumors, non-surgical treatment for mass-forming autoimmune pancreatitis, lymphoma and some metastases, and organ-preserving surgery for small neuroendocrine tumors. The selection of patients for EUS-guided sampling with a high suspicion of a diagnosis other than PDAC is of pivotal importance to avoid unnecessary pancreatic head resection with inherent morbidity and mortality [512].

Contrast-enhanced ultrasound (CEUS) and CE-EUS are able to discriminate hypovascular PDAC from other iso- and hypervascular solid pancreatic lesions (non-PDAC) with an accuracy $>85 \%$ $[581,597]$. Interobserver agreement has been shown to be moderate to excellent for CE-EUS in characterizing solid pancreatic lesions [598 -600]. A meta-analysis reported sensitivity and specificity of CE-EUS to diagnose PDAC at $94 \%$ and $89 \%$, respectively [601]. When there is a high suspicion of non-PDAC, patients with solid pancreatic mass lesions which are hypervascular or isovascular in comparison with the surrounding pancreatic parenchyma should be referred to pretherapeutic EUS-guided sampling. In iso- or hypervascular pancreatic masses with a negative sampling result, PDAC is unlikely. Conversely, negative results of EUS-guided sampling of solid pancreatic lesions which are hypovascular on CE-EUS should be considered false-negative, thus requiring repeat sampling or proceeding directly to surgery [600, 602]. An RCT demonstrated that CE-EUS-guided FNA of solid pancreatic lesions is more efficient than conventional EUS-FNA with fewer needle passes required to obtain a diagnostic sample [603].
EUS-elastography has a high sensitivity, but only a moderate specificity for differentiating malignant from benign solid pancreatic lesions [29]. Meta-analyses report a sensitivity of 95 - $97 \%$ (qualitative elastography: 98 -99\%; quantitative elastography using the hue histogram: $85-96 \%$ ) and a specificity of $67-76 \%$ (qualitative elastography: 69-74\%; quantitative elastography: 64$76 \%$ ) [604-608]. Chronic pseudotumor pancreatitis can be differentiated from PDAC by a difference in elastography appearance. Malignancy can be excluded with an NPV of $>90 \%$, if the lesion has soft elastographic features [29]. One study evaluating the performance of EUS-elastography for differentiating between PDAC and inflammatory masses found high sensitivity (for qualitative and quantitative elastography: $99 \%$ and $92 \%$, respectively), high diagnostic odds ratios (130 and 24.7, respectively) and moderate specificity (for qualitative and quantitative elastography: $76 \%$ and $68 \%$, respectively) [609]. EUS-elastography excludes rather than confirms a malignant pancreatic mass, and will not replace EUS-guided sampling. Used as a complementary technique to EUS, CE-EUS and EUS-FNA, it potentially may increase the yield of EUS-FNA and reduce unnecessary sampling [29, 604-607].

Combined CE-EUS and EUS-elastography had a high PPV of $96.2 \%$ and an NPV of $71.4 \%$ in the differentiation of hypovascular and hard pancreatic masses suggestive of PDAC [610]. EFSUMB guidelines recommend that in the case of persisting strong clinical suspicion of pancreatic cancer with inconclusive or negative EUSguided sampling, a hard focal lesion on elastography and/or a hypovascular lesion on CEUS and or CE-EUS indicates the need for repeat EUS-FNA or referral to surgery [582]. Repeat EUS-guided sampling in inconclusive cases, where pancreatic cancer remains likely, is able to establish a diagnosis in the majority of patients $(82-84 \%)[611,612]$.

Cystic pancreatic lesions

The presence of epithelial mural nodules, thick walls, and septa has been shown to be highly predictive for malignancy in BDIPMN $[613,614]$. International and European guidelines recommend surgical treatment of BD-IPMN in particular if enhancing nodules or "positive cytology" has been verified [225, 227]. Targeted biopsy of the cyst wall and solid components has a significant incremental diagnostic value over cyst-fluid aspiration alone for the diagnosis of mucinous and malignant cystic neoplasms $[579,615,616]$ and is recommended by the ESGE guideline on EUS-guided sampling in gastroenterology [96].

EUS and CE-EUS significantly improve the discrimination and characterization of mural nodules in IPMN in comparison with B-mode EUS and CT [617 - 620], suggesting that CE-EUS may facilitate EUS-guided sampling of solid components in PCLs.

\section{Subepithelial gastrointestinal tumors}

Differential diagnosis of hypoechoic gastric SETs by EUS and other imaging techniques is difficult [110, 277, 278, 290, 621]. Preliminary findings suggest that CE-EUS can discriminate GISTs (hypervascular) from benign lesions (leiomyoma, lipoma: hypovascular) [622]. GISTs with an intermediate and high risk of malignancy present with highly irregular vascular patterns and avascular necrotic areas [621, 623, 624]. The selection of hypovascular hypoechoic SETs, presumed not to be GISTs, for EUS-guided tissue acquisition with immunohistochemical phenotyping would help to prevent unnecessary surgery in $20 \%$ of asymptomatic patients with hypoechoic SETs of the stomach [277, 278, 621]. 


\section{Recommendation 34}

Contrast-enhanced EUS and/or EUS-elastography may be used to guide and target EUS-guided sampling of lymph nodes (LoE 2a), solid pancreatic masses (LoE 2a), pancreatic cystic lesions (LoE 2b) and gastrointestinal subepithelial tumors (LoE 3b) (GoR C). Strong consensus (100\%).

\section{Recommendation 35}

In addition to the aspiration of cyst fluid, the cyst wall and solid components, if present, should be sampled in pancreatic cystic lesions (LoE 2b, GoR B). Strong consensus (100\%).

\section{EUS-guided sampling: Processing and evaluation of specimens \\ $\nabla$}

Techniques for expelling a specimen from the needle

Techniques for expelling specimens are related to the needle system used. Most commercially available aspiration needles are based on the original Vilmann-Hancke system, consisting of a steel needle with a stylet, a metal spiral sheath, and a biopsy handle [625]. There are three different techniques for expelling a specimen: 1. Air flushing: the needle is flushed with an empty $5 \mathrm{ml}$ syringe, and the specimen is collected in a saline-filled Petri dish or a saline- or formalin-filled vial. 2. Saline flushing: the needle is flushed with a saline-filled $5 \mathrm{ml}$ syringe. 3 . Extrusion with the stylet: the stylet is reinserted slowly into the needle, and the specimen is expelled gently droplet by droplet onto glass slides, into a vial or Petri dish containing saline, a preservation-solution or a fixative. There is minimal evidence with regard to the method which is more effective. No differences between air flushing and stylet reinsertion with regard to the number of diagnostic specimens, overall accuracy and specimen quality were found in an RCT, but smears were bloodier following stylet use for expelling of the sample [563]. A combination of both approaches is possible [626]; use of the stylet method first followed by the air or saline flushing method is associated with a high diagnostic yield [627]. Practical aspects have to be taken into account. Gentle expelling of material from the needle using a stylet prevents splattering of the aspirated material. Controlled release of precise quantities of material onto slides is possible, and high-quality smears with minimal thick layer, air-drying or clotting artefacts may be prepared. It is better to forcefully expel some material from the needle by flushing. If the CB technique, standard histopathological processing, or thin-layer preparations are intended, flushing the needle content with air directly into the preservation or fixation fluid is most effective $[628,629]$.

Trucut needles have a $20 \mathrm{~mm}$ tissue tray [93]. The tissue core may be separated from the tray using a scalpel, a needle, or by washing out in formalin solution.

\section{Recommendation 36}

Material can be expelled from EUS aspiration needles using the stylet, by spraying with air on slides, or by flushing the needle with saline (LoE 2b, GoR B). Strong consensus (100\%).

\section{Recommendation 37}

Controlled release of the material onto slides using the stylet is the preferred method despite more blood contamination (LoE 5, GoR D). Strong consensus (100\%).

\section{Methods for specimen preparation and processing}

Optimizing specimen handling and processing may reduce nondiagnostic EUS-guided sampling $[517,630]$. The handling of specimens depends on the diagnostic methods used and the final cytopathological evaluation.

\section{Cytopathology: conventional smears and liquid-based preparations}

For cytological analysis specimens should be smeared onto slides (smear cytology, SC) or incorporated into special preservation solutions (liquid-based cytology, LBC) for further handling. Smearing techniques are described elsewhere [628, 629]. A smear may be wet-fixed or air-dried. The decision on the fixation technique determines the subsequently used staining methods. For Papanicolaou staining, wet fixation with $95 \%$ alcohol (spray fixation, immersion) is preferred. Air-dried specimens are suitable for nearly all methods particularly Romanowsky stains (e.g. MayGruenwald-Giemsa, Diff Quick, or Hemacolor). Air-dried specimens but not wet-fixed specimens are suitable for further immunocytological staining $[628,629,631]$.

The direct smearing technique requires controlled release of the specimen from the needle. Particularly with wet fixation immediate smearing is important to avoid drying artifacts of the specimen $[628,632]$.

LBC is based on ultracentrifugation and monolayer preparation using partially automated systems (e.g. ThinPrep, SurePath). Major advantages are independence from individual smearing techniques, purification and concentration of cellular material, and ability to perform ancillary testing. Disadvantages are filtering-induced cell loss, removal of potentially diagnostic relevant extracellular background, disintegration of cellular clusters and increased cost. Prospective comparative trials demonstrate that LBC (e.g. ThinPrep) was less sensitive with material obtained by EUS-/ EBUS-guided sampling from lymph nodes and pancreatic lesions compared with traditional SC [350, 633, 634]. A further RCT suggested that LBC may serve as a complementary preparation technique if blood contamination of smears is abundant [634].

\section{Histopathology: cell block and core tissue preparation} In general, histopathological processing including paraffin-embedding, microtome-sectioning, and staining is possible with small coherent tissue cores embedded in a formalin fixative or with $\mathrm{CB}$. A wide variety of ancillary diagnostic techniques (immunohistochemistry, molecular analysis) may be performed on histopathologically processed material $[110,285,517,521,628,629$, 631, 632, 635 - 637].

$\mathrm{CB}$ is increasingly used. After preparation, the specimen is processed using standard histopathological methods. CB may be prepared from any cell suspension (e. g. liquid aspirates, needle rinses, or specimen in preservative solutions for LB). Pellets of artificially aggregated cells are obtained by using repeated centrifugation and/ or special cell capturing gels [629-631,638].

Small core particles obtained with aspiration needles or "histology needles" can be directly delivered into formalin solution for fixation followed by standard histopathological processing $[95,332$, 
517, 630, 639, 640]. Alternatively, core particles may be isolated from samples expressed on glass slides or preservation solutions by the stylet method before further cytopathological processing ("split-up" method). For isolation sharp instruments like needle tips or scalpels can be used. If the needle load is split for cytopathological and histopathological examination, gross visual examination is reasonably accurate [285, 521, 641]. Tissue fragments appear white or discolored within the red cylinder of coagulated blood [332]. The gross visual assessment of histological material from solid pancreatic lesions using a $22 \mathrm{G}$ aspiration needle by the EUS examiner was unsuccessful in only $13.5 \%$ of cases [521]. The split method for cytopathological and histopathological evaluation does not interfere with the cytology result [642].

\section{Cytopathological evaluation of specimens}

\section{Cytopathological vs. histopathological evaluation}

In most cases of PDAC and lymph node metastases, cytopathological evaluation alone is adequate to establish a diagnosis of malignancy. The diagnostic accuracy of cytology obtained by EUSFNA for pancreatic cancer, biliary cancer, and malignant mediastinal lymphadenopathy is at least reasonable ( $\bullet$ Table 3 ). The diagnostic sensitivity of EUS-FNA cytology is highly dependent on the proficiency and experience of the cytopathologist evaluating the specimen $[152,161]$ and to a lesser extent on the availability of ROSE (see sub-section below).

In a number of clinical settings and target lesions, it is tissue architecture, immunohistochemistry and molecular analysis rather than cellular features that are essential for accurate pathological assessment $[636,637]$. For benign diseases, e. g. autoimmune pancreatitis [209, 216], differential diagnosis of SET (GIST vs. leiomyoma or schwannoma) [94, 280, 288, 290, 295, 298], subtyping of NSCLC and malignant lymphoma [310, 332, 361, 424, 538], diagnosis of rare tumors $[221,340,521]$, grading of neuroendocrine tumors [203-205], molecular profiling of solid tumors [180-184, 186, 307 - 309, 311 - 313, 517, 643, 644] and differential diagnosis of mediastinal lymph node metastases [94, 340, 356], a core sample is preferred to a cytological aspirate [110]. Immunohistochemistry and molecular analysis will become increasingly important to allow personalized oncological treatment [180-184, 186, 307 309, $311-313,517,643$ ]. Direct histopathological processing of material obtained with $22 \mathrm{G}$ EUS-FNA has been shown to preserve the tumor tissue architecture in $68 \%$ of diagnostic cases compared to $28 \%$ with the standard cytopathological approach including the $\mathrm{CB}$ technique. In this retrospective comparative study, the histological core tissue was more suitable for immunohistochemical and molecular studies [517].

A complementary approach: combining cytopathological and histopathological assessment

There are two reasonable strategies to achieve high diagnostic accuracy in EUS-guided sampling, without the attendance of a cytopathologist: combining cytopathological and histopathological evaluation [94, 148, 291, 345, 350, 521, 641, 645, 646], or relying on core tissue or $\mathrm{CB}$ material for histopathological assessment [95, 97, 216, 332, 361, 369, 503, 517, 524, 639, 640, 647, 648]. $55.8 \%$ of the participants of a European EUS workshop described routine collection of material for histopathological analysis. Routine isolation of small tissue cores for histopathological preparation is independently associated with the self-reported sensitivity of EUS-FNA [149]. Several studies have shown an incremental yield of combining SC with the CB technique or histological core assessment in terms of diagnostic yield and accuracy [148, 291,
$345,350,520,521,645,646,649]$. A multicenter study using a $22 \mathrm{G}$ aspiration needle demonstrated significantly better accuracy (87.5\%) and sensitivity (82.9\%) for combined histopathological and cytopathological analysis in pancreatic tumors than the accuracy and sensitivity of cytology $(77.6 \%$ and $68.1 \%$, respectively) or histology (71.4\% and $60 \%$, respectively) alone [521]. Studies combining cytological assessment of samples obtained with EUS-FNA and core tissue obtained with EUS-TCB from the same lesion also showed a slightly improved outcome (see [96, $110,486])$. For most indications, cytopathological and histopathological assessment should be used in a complementary manner rather than exclusively. Cytopathological methods perform better for the evaluation of nuclear and cellular characteristics, while histopathological assessment of $\mathrm{CB}$ and core samples are advantageous over cytopathological assessment in cases in which immunohistochemistry is able to establish a diagnosis, e.g. in non-PDAC, gastrointestinal SETs, rare benign diseases, and lymphadenopathy $[94,148,216,221,281,283,290,310,332,340$, $354,356,361,369,372,650]$.

\section{Specimen handling for diagnosis of infectious diseases}

Suspected infectious disease (e.g. abscesses, tuberculosis or atypical mycobacteriosis) requires specific handling of the aspirate. Diagnosis of lymph node tuberculosis and differentiation from other granulomatous and mycobacterial disease is a challenge; transesophageal EUS and EBUS may demonstrate tuberculous etiology of mediastinal lymphadenopathy with features such as hyperechoic foci, heterogeneous appearance or patchy anechoic and hypoechoic areas [324, 326]. Microbiological cultures are possible if samples are placed in saline, whereas a polymerase chain reaction (PCR) amplifying mycobacterial DNA requires the specimen to be placed in formalin [349, 352]. A moderate to high accuracy of SC including the Ziehl-Neelsen stain for acid-fast bacteria alone for the diagnosis of tuberculosis, and its differentiation from sarcoidosis or histoplasmosis has been shown [349, $367,380,382,385,386,651]$. Some limitations of cytopathological diagnosis have been reported; in a study of EUS-guided sampling of mediastinal lymphadenopathy, where granulomatous disease was prevalent in 206/281 patients, diagnosis was possible in 76 tuberculosis and 7 sarcoidosis patients only. The etiology was uncertain in the remainder of patients (59.7\%) [652]. Further studies showed significantly higher sensitivity of PCR vs. microbiological culture and/or SC, and of microbiological culture vs. SC [352, 355, 357, 653]. In a meta-analysis of 7 prospective and 7 retrospective studies, the overall diagnostic yield of EBUSTBNA for the diagnosis of mediastinal tuberculous lymphadenitis was $80 \%$ with the culture positive rate (54\%) being significantly higher than the SC positive rate (33\%) [654].

\section{Recommendation 38}

The processing of specimens obtained by EUS-guided sampling varies according to the cytopathological or histopathological methods used for diagnosis (LoE 2b, GoR C). Strong consensus (100\%).

\section{Recommendation 39}

Tissue fragments can be effectively isolated from the whole sample after gross visual examination without impairing the cytopathological result (LoE 2b, GoR B). Strong consensus (100\%). 


\section{Recommendation 40}

Without rapid on-site cytopathological evaluation, the combination of cytopathological and histopathological processing seems to provide the most reliable results ( $\mathrm{LoE} 2 \mathrm{~b}, \mathrm{GoR} B$ ). Strong consensus (100\%).

\section{Recommendation 41}

Specimens obtained with EUS-guided sampling can be used for special ancillary studies including microbiological culture, biochemical analysis, immunocytochemistry, immunohistochemistry, and molecular analysis (LoE 2b, GoR B). Strong consensus (100\%).

\section{Recommendation 42}

Liquid-based techniques may be used complementary to traditional smearing for cytopathological evaluation of specimens (LoE 2b, GoR C). Broad agreement (90\%).

\section{Recommendation 43}

For the diagnosis of tuberculosis, smear cytology including Ziehl-Neelsen stains should be combined with the microbiological culture of specimens transferred into sterile saline, and PCR amplification of mycobacterial DNA using formalinfixed specimens (LoE 2b, GoR B). Strong consensus (100\%).

\section{On-site assessment of the adequacy of specimens}

\section{Rapid on-site cytopathological evaluation}

ROSE is reported to be used in the majority of centers in the United States [162, 489], but on-site cytopathological service is not routinely available in Europe [149, 488]. The availability of onsite cytopathological evaluation was considered by the participants of an international EUS workshop to be a significant predictor of EUS-FNA yield and accuracy [149]. Positive assessments of the role of ROSE for EUS-FNA of solid pancreatic lesions and for EUS-FNA and EBUS-TBNA of lymph nodes have been documented $[148,379,553,573,612,633,655-664]$. A study reported that the introduction of ROSE decreased the need of repeat EUS-FNA of pancreatic lesions by $50 \%$ (5.8\% to $2.9 \%$ ) [665]. Mathematical models predict that any sampling policy using ROSE would achieve high adequacy rates with fewer needle passes than sampling policies using a fixed number of needle passes, in particular when the per-pass adequacy rate is low [571, 572]. An RCT showed that ROSE during EBUS-TBNA significantly decreased the number of needle passes and was associated with a significantly lower need for (EBUS-guided) TBNA of further target lesions ( $11 \%$ vs. $57 \%$ ). However, the sensitivity and accuracy of lung cancer diagnosis did not differ between the ROSE group and the non-ROSE group [663]. Similar results were reported from a multicenter RCT comparing EUS-FNA of solid pancreatic lesions with and without ROSE. ROSE-assisted EUS-FNA required fewer needle passes ( 4 vs. 7 ). However, there was no difference observed between the two groups with regard to yiekd of malignancy, adequacy, accuracy, sample quality, adverse events, procedure time, need for repeat procedures and costs [663a]. A high concordance of preliminary on-site interpretation and final cytopathological diagnoses has been shown [656, 662, 666, 667]. A significantly higher degree of concordance between on-site and final cytopathological diagnosis is reported for unequivocal diagnosis of malignancy (98.9\%) vs. non-malignancy (67.2\%) [656]. Other studies have suggested that ROSE is not essential for high diagnostic yield and accuracy of EUS-FNA [96, 110, 668-670]. With EUS-FNA performed in a study where 554 lesions were assessed, 2 centers used immediate on-site cytopathology and 2 did not. The results did not differ with or without ROSE [164]. In a study of 381 consecutive cases of pancreatic EUS-FNA, ROSE offered no benefit in reducing the non-diagnostic rate [671]. EUSFNA with ROSE vs. EUS-FNA without ROSE has not been compared in a prospective randomized study. Most EUS-FNA studies include only a single cohort. Only five studies with EUS-FNA of pancreatic lesions used a 2-cohort design with head-to-head comparison of adequacy and accuracy of ROSE vs. non-ROSE [672]. These studies have been included in a meta-analysis, showing that ROSE was associated with a significant $10 \%$ improvement of the per-case adequacy rate only in studies with a low adequacy rate $(<90 \%)$. No significant impact of ROSE on diagnostic yield, accuracy or number of needle passes was observed [672]. A second meta-analysis including 68 single-cohort and 2 two-cohort studies (ROSE vs. non-ROSE, > 10 cases) reported adequacy of EUS-FNA of solid pancreatic masses; ROSE was associated with a low, statistically significant advantage of adequacy rates (2.3\%). This was independent of whether ROSE was performed by a cytopathologist, a cytology technician, or a gastroenterologist. Studies without ROSE used an average of 0.6 fewer needle passes per case (2.6 vs. 3.2). In non-ROSE studies the adequacy rate decreased with increasing needle passes, but for ROSE studies, the per-case adequacy was not correlated with the number of needle passes [673]. A further meta-analysis included 34 studies (3644 patients, 2285 PDAC) evaluating EUS-FNA for PDAC. Per-case adequacy was non-significantly higher in ROSE studies than in studies without ROSE. In a multivariate analysis ROSE was the only significant determinant of EUS-FNA accuracy [200]. The largest meta-analysis assessing the diagnostic performance of EUS-FNA of solid pancreatic lesions (33 studies with 4984 patients) demonstrated significantly lower heterogeneity among studies with a cytopathologist present on-site, but advantages over studies without ROSE in terms of sensitivity ( $88 \%$ vs. $80 \%$ ) and the diagnostic odds ratio (relative DOR for no on-site cytopathologist, 0.36) did not reach statistical significance [196].

Conflicting results from two trials regarding the role of ROSE for the prediction of sample adequacy and accuracy in EUS-FNB using the ProCore needle have been documented. The prospective study compared a histological yield of 2 vs. 4 passes with a $25 \mathrm{G}$ ProCore needle. Irrespective of the number of needle passes performed, the diagnostic adequacy of $\mathrm{CB}$ was lower compared with ROSE of material obtained with the first ProCore needle pass ( $81 \%$ vs. $100 \%$ ) [514]. The retrospective study used a $22 \mathrm{G}$ ProCore needle to sample various gastrointestinal lesions with satisfactory accuracy ( $83 \%)$. ROSE of the core specimen had an excellent specificity and PPV (100\%). However due to insufficient cytopathological samples, the sensitivity (65\%) and NPV (39\%) were low [674]. Combining EUS-FNA (for ROSE) with EUS-guided ProCore biopsy (for histology) for non-pancreatic EUS-guided sampling increased procedure time (and costs) but not diagnostic accuracy [675]. ROSE has no value for the prediction of the diagnostic adequacy of EUS-guided core biopsy (EUS-FNB). Gross visual assessment of the core particles is more meaningful (see subsection on gross visual inspection below) [524]. 
In summary, ROSE has the potential to optimize the trade-off between needle passes and per-case adequacy for EUS-FNA of solid pancreatic lesions. However, the benefit of ROSE is relatively small and has to be balanced against the cost and time expenditure of a permanent on-site cytopathology service [575, 676678]. The ESGE guideline on learning, techniques, and complications of EUS-guided sampling in gastroenterology recommends implementation of ROSE preferentially during the learning phase of EUS-FNA and at centers with an adequacy rate of EUS-guided sampling below 90\% [96]. Telecytopathological rapid assessment of EUS-FNA/EBUS-TBNA samples could be a suitable time-effective alternative to maintaining an on-site cytopathological service in the endoscopy suite [679-684].

Gross visual inspection and ROSE performed by the endosonographer

In the absence of ROSE, gross visual assessment of a sample to assess the adequacy of EUS-guided sampling is possible [685]. Studies show conflicting levels of ability of endosonographers and trained EUS and cytology assistants to assess slide adequacy and to differentiate malignant and benign specimens. With SC, one study suggested that visual adequacy assessment of smears from EUS-FNA of solid pancreatic lesions by cytology technicians or trained EUS technicians is unreliable, and the agreement with final cytopathologic adequacy assessment is only fair (kappa 0.20 and 0.19 , respectively). There was a tendency to overestimate the amount of cytopathological material, but it should be noted that no formal staff training was given [686]. The ability of trained endosonographers to assess slide adequacy compared with a cytotechnologist was evaluated. In the determination of adequacy, differentiation of suspicious and malignant vs. benign specimens, no endosonographer was equivalent to the cytotechnologist [687]. Two studies compared performance parameters of EUSFNA over two consecutive periods with conflicting results. In the first period, ROSE was performed by trained endosonographers, in the second period by a cytopathologist. One study showed comparable performance in both periods [688], while the other study showed significant improvement by cytopathologist-performed ROSE in terms of inconclusive, inadequate samples and diagnostic accuracy [689]. However, in a multicenter study the assessment by the EUS examiner of adequacy of the macroscopic specimen was unsuccessful only in $7 \%$ (cytology) and $13.5 \%$ (histology), resulting in a high diagnostic yield of EUS-guided sampling of solid pancreatic lesions with only 1.88 passes using a $22 \mathrm{G}$ needle [521]. In a prospective evaluation of the visual assessment of core particles obtained with a 19 G ProCore needle, a core length of $\geq 4 \mathrm{~mm}$ is an indicator for an adequate histological sample and for a high overall, histological and cytological diagnostic yield [524].

All these studies lack information on the type and intensity of formal cytopathological training. Further studies have demonstrated the improved ability of endosonographers, following completion of structured training, to smear and stain slides, to operate a microscope [690], to judge the adequacy of a cytological specimen confidently [691], and to differentiate benign and malignant smears with an accuracy of $89 \%$ [692]. ROSE performed by an experienced endosonographer may be reliable, but requires completion of an intensive structured training program. Formal cytopathological training should be incorporated in EUS training programs.

\section{Recommendation 44}

Rapid on-site cytopathological assessment does not substantially improve the diagnostic yield of malignancy or generally reduce the number of needle passes. In centers with an adequacy rate $<90 \%$, ROSE may improve the adequacy of EUSguided sampling (LoE 2a, GoR C). Strong consensus (100\%).

\section{Recommendation 45}

Rapid on-site cytopathological assessment may be used to guide the number of needle passes, provide a reliable immediate diagnosis of malignancy, and assess the need for ancillary studies (LoE 2b, GoR C). Strong consensus (100\%).

\section{Reporting and reliability of cytopathology in EUS-guided} sampling

\section{Cytopathological reporting}

Several different classification systems are used as a basis for cytopathology reporting in EUS-guided sampling. In most cytopathological laboratories, the diagnostic categories for EUS cytology follow a Bethesda-like system (introduced originally for reporting gynecological, thyroid, and breast cytology): unsatisfactory, benign, atypical, suspicious, and positive for malignancy ${ }^{15}[590,693]$. Based on a standard nomenclature for FNA [694], the Papanicolaou Society of Cytopathology has developed guidelines on standardized terminology and nomenclature for pancreatobiliary cytopathology, recommending a six-tiered system of diagnostic categories: non-diagnostic, negative, atypical, neoplastic, suspicious, and positive ${ }^{16}$. The category "neoplastic" is unique for pancreatic cytopathology, including benign neoplasms (serous cystadenoma) as well as premalignant mucinous cysts, neuroendocrine tumors and solid-pseudopapillary neoplasias [695].

The inconclusive and ill-defined diagnostic categories "atypical" and "suspicious for malignancy"17 are inconsistently conveyed. In the USA, the usage and relative distribution of atypical and suspicious categories in EUS-FNA samples varied widely [591]. Several studies categorize suspicious or atypical findings as a malignant diagnosis ("positive"). Others interpret either category or atypical findings as representing a negative or inadequate sample. As a consequence, different combinations of diagnostic categories to define a malignant result lead to variable receiver-operator curves [589, $591,592]$. Therefore, comparison of study results of diagnostic performance parameters should be made with caution, particularly as the definition of the quality of specimens (i.e. adequacy, contamination, bloodiness) varies between cytopathologists (see the metaanalysis of EUS-FNA of solid pancreatic lesions [196], Table 3). Insufficient adherence to standardized nomenclature in cytopathological reporting hampers individual patient management and is a substantial obstacle for the comparison of results between centers and studies [629,695].

\section{Reliability of negative ("benign") results and findings} positive for malignancy/ neoplasia

A few studies have analyzed the reproducibility of cytopathological diagnoses of specimens obtained by EUS-guided sampling. A good-to-excellent diagnostic agreement between experienced

\footnotetext{
15 Terms are explained in the addendum on terminology

16 Terms are explained in the addendum on terminology

17 Terms are explained in the addendum on terminology
} 
cytopathologists was documented for the assessment of aspirations from mediastinal lymph nodes and masses [161, 405, 696], in the Ki-67 labelling index for grading of neuroendocrine pancreatic tumors [697], and in the assessment of core samples obtained with a ProCore needle [97, 531]. Fair to moderate interobserver agreement was described for the grading of pancreatic cancer [698], grading of atypia in PCLs [243 - 245], and classification of the subtype in NSCLC [699].

For clinical decision-making it is important to understand that there is still a significant risk of malignancy with negative findings in EUS-guided sampling, which is considerably high for PCLs, solid pancreatic lesions in patients with underlying chronic pancreatitis, indeterminate biliary strictures, and gastrointestinal SETs. The major cause for false-negative diagnoses of EUSguided sampling is sampling error, whereas interpretative error is rare $[110,263,486,546,547,589,591,700-705]$.

The specificity and PPV of cancer diagnosis by EUS-FNA have been estimated at $100 \%$. However, the gold standard was not surgical histology. In studies with good reference standards and long follow-up, false-positive findings have been reported for EUS-guided sampling in $1.1-5.3 \%$ when only cases with a positive cytopathological result were considered, and in $7.8 \%$ if suspicious cytopathology results were included. False-positive rates seem to be higher in luminal compared with extra-luminal (e.g. pancreatic) primary cancer [392, 706, 707]. False-positive findings may result from procedure-related factors, e.g. traversal of a neoplastic area, needle contamination with tumor cells [394, 395], or inadvertent aspiration of cancer cell-contaminated luminal fluid. Tumor cells within gastrointestinal luminal fluid are present in $48 \%$ of luminal cancers, and in $10 \%$ of extraluminal (pancreatic) cancers undergoing EUS-guided sampling [393]. A further source of a false-positive result is cytopathological misinterpretation, often occurring when the differential diagnosis includes entities with similar cytological morphologies (cellular mimicry), when reactive inflammatory epithelial alterations are misinterpreted as neoplastic, and/or when a distinct diagnosis is not expected e.g. in rare neoplasms $[110,486$, 589, $700-702,705,706,708,709]$.

\section{Malignancy risk associated with inconclusive findings}

Studies have evaluated the malignancy risk associated with inconclusive diagnostic cytopathological categories for EUS-guided sampling of pancreatic lesions. The suspicious category is associated with an $80-96 \%$ risk of neoplastic or malignant final diagnosis, whereas the atypical category carries a markedly variable and significantly lower malignancy risk [591, 592, 710]. A metaanalysis of the occurrence and outcome of the atypical category in EUS-guided sampling of solid pancreatic lesions included a total of 23 studies, of which 12 had complete outcome data [590]. The atypical category was reported between $1-14 \%$ (mean, $5.3 \%$ ), with the risk of malignancy associated with the atypical category ranging between $25-100 \%$ (mean 58\%). Significant heterogeneity was observed, with acknowledgement for a need of standardization of reporting and management of atypical categories in pancreatic EUS-FNA [590]. Heterogeneity can be partially explained by variability of the experience and disposition of the cytopathologist to commit to a malignant diagnosis [152, $590,710]$. Performing ancillary studies decreases an inconclusive diagnosis by $>50 \%$, demonstrated by a meta-analysis for K-ras gene mutation analysis in specimens obtained by EUS-guided sampling of solid pancreatic masses [711]. Several studies have evaluated clinical predictors associated with a high likelihood of a neoplastic diagnosis following an atypical cytopathological di- agnosis in pancreatic EUS-FNA. These predictors (e.g. presence of a mass, weight loss, obstructive jaundice, CA 19-9) can be used to adapt management of patients with inconclusive cytopathological diagnoses: ancillary testing, watchful waiting, repeat EUS-guided sampling, alternative diagnostic techniques, or initiation of a specific treatment [593, 705, 712-714]. Repeat EUS-guided sampling in patients with high clinical suspicion of malignancy has been shown to yield a conclusive and correct diagnosis in $73-84 \%$ of cases with primarily inconclusive cytopathological diagnosis of first EUS-guided sampling [593, 611, 612, $714,715]$.

\section{Recommendation 46}

A standardized and validated classification system should be used for cytopathology reporting in EUS-guided sampling (LoE 5, GoR D). Strong consensus (100\%).

\section{Recommendation 47}

After inconclusive cytopathological results, the use of ancillary studies and/or repeat EUS-guided sampling should be weighed against the clinical background of patient history, clinical and laboratory data, EUS morphology, results of other imaging tests and follow-up (LoE 2b, GoR B). Strong consensus (100\%).

\section{Adverse events of EUS-guided interventions and their prevention \\ $\nabla$}

\section{General considerations}

EUS-guided sampling (including EBUS-TBNA) is a safe diagnostic technique. Severe adverse events are rare. There is no evidence that needle size or needle type affects morbidity of EUS-guided sampling [96, 114, 490, 716]. A systematic review of complications of 51 EUS-FNA studies including 10941 patients describes an overall complication rate of $0.98 \%$ [717]. The complication rate was significantly higher in 31 prospective studies $(1.72 \%)$ than in 20 retrospective studies ( $0.64 \%)$, indicating an underestimation in retrospective studies. Complications include post-procedural pain (34\%), acute pancreatitis (34\%), fever and infectious complications (16\%), bleeding (13\%), bowel perforation ( $2 \%$ ) and bile leaks (1\%). The procedure-related mortality was estimated at $0.02 \%$ [717]. A pooled adverse events rate of $0.36 \%$ (serious adverse events in $0.14 \%$; no fatalities) was shown in a systematic review of 190 studies for intrathoracic endosonographic sampling ( $n=16181$; EUS-FNA and EBUS-TBNA) [718]. A nationwide survey in the Netherlands reported a $0.15 \%$ serious adverse events rate (mortality $0.04 \%$ ) of endosonographic sampling for pulmonary indications (14075 EUS-FNA and 2675 EBUS procedures). Poor performance status was the most important risk factor for fatal outcomes [719]. A nationwide survey of the Japan Society for Respiratory Endoscopy ( $\mathrm{n}=7345$ cases) showed a $1.23 \%$ overall complication rate and a $0.01 \%$ mortality rate of EBUSTBNA [720]. The frequency of complications reported for EBUSTBNA from the American College of Chest Physicians Quality Improvement Registry, Evaluation, and Education (AQuIRE) prospective database $(n=1317)$ was $1.44 \%$ [661].

The morbidity of EUS-guided therapeutic interventions is considerably higher than EUS-guided sampling, with the risk and type 
of complications depending on the type of procedure [115, 721, 722] (see part $V$ of INVUS guidelines [1]).

\section{Adverse events}

\section{Perforation}

The majority of perforations associated with EUS-guided sampling are caused by the gastrointestinal passage of the echoendoscope and not the sampling procedure. The large diameter and longer rigid tip of the gastrointestinal echoendoscope increases the risk of perforation of the upper gastrointestinal tract in comparison with conventional video gastroscopes. Multicenter surveys and studies report perforation rates of $0.03-0.15 \%$ [722 726]. The risk of duodenal perforation is higher than esophageal perforation [114, 722]. A specific risk factor for esophageal perforation is esophageal cancer with luminal narrowing $[722,725]$.

\section{Acute pancreatitis}

The frequency of acute pancreatitis following EUS-FNA of pancreatic lesions is between $0.19-2.35 \%$ [114]. A systematic review reported acute pancreatitis (mild in $75 \%$ ) occurring in $0.44 \%$ of patients following EUS-FNA of solid or cystic focal pancreatic lesions [717]. Pancreatitis risk is higher in patients with PCLs than in patients with solid pancreatic lesions [114, 717].

Intra- and extraluminal hemorrhage

Severe bleeding following EUS-FNA is a rare event occurring in $14 / 10941$ patients $(0.13 \%)$ included in a review of 51 EUS-FNA trials [717]. One study reported clinically asymptomatic extraluminal bleeding in 3/227 patients with normal clotting parameters $(1.3 \%)$ [727]. If extramural and intramural bleeding occurs following EUS-FNA, this is mild in most cases. A Japanese registry study reported an incidence of severe bleeding requiring endoscopic treatment or transfusion following EUS-FNA of pancreatic lesions of $0.23 \%$ [728]. There are three reports in the literature of fatal bleeding following pancreatic EUS-FNA [114]. There is indirect evidence that EUS-FNA of PCLs may cause a higher risk of bleeding compared with EUS-FNA of solid pancreatic lesions [717, 721, 729-731]. There is limited information on the effect of acetyl salicylic acid (ASA), other inhibitors of platelet aggregation, non-steroidal anti-inflammatory drugs (NSAIDs), oral anticoagulants and low molecular weight heparin (LWMH) on the bleeding risk of EUS-FNA. Results of one study suggest that there is no increased bleeding risk during EUS-FNA for patients taking ASA or NSAIDs, but a possible risk for patients receiving prophylactic LMWH [732]. One study of patients undergoing transbronchial lung biopsy showed that clopidogrel, especially when combined with ASA, greatly increased bleeding risk [733]. However, in 12 patients taking clopidogrel (in 8 patients combined with ASA), EBUS-TBNA proved to be safe without any serious bleeding events [734]. Guidelines suggest discontinuing oral anticoagulants, heparin and LMWHs in therapeutic dosages as well as ADP-antagonists before EUS-guided sampling, whereas withdrawal of ASA is recommended only before EUS-FNA of PCLs [96, 716, 735-737]. Most centers check platelet count and global coagulation parameters before performing EUS-FNA. Despite limited evidence for distinct cut-off values, a platelet count $<50000$ / $\mathrm{ml}$ and an international normalized ratio (INR) $>1.5$ are regarded as contraindications to EUS-guided sampling. There is no data regarding needle size, needle type, number of needle passes or other technical factors related to bleeding risk following EUSguided sampling.

\section{Recommendation 48}

In patients on antiplatelets and/or anticoagulants, a risk assessment balancing thromboembolic events versus bleeding should be performed prior to EUS-/EBUS-guided diagnostic and therapeutic interventions (LoE 5, GoR D). Strong consensus $(100 \%)$.

\section{Recommendation 49}

Decision on suspension of antiplatelet drugs and/or anticoagulants or delay of the procedure should be made based on an individual risk assessment (LoE 5, GoR D). Strong consensus $(100 \%)$.

\section{Fever and infection}

Bacteremia following upper as well as lower gastrointestinal tract EUS-FNA is a rare event [738 - 741]. In large series $0.4-1.0 \%$ of patients experienced febrile episodes following EUS-FNA for solid pancreatic masses [518, 742, 743]. For endosonographic sampling of mediastinal lesions, studies report an overall frequency of major infectious complications in $0.07 \%$ of patients [718]. Serious infectious complications have been reported following EUS-FNA of mediastinal cysts [114, 718], ascites [474], perirectal cysts [61], as well as of PCLs and (peri-) pancreatic fluid collections [164]. An invitro study confirms that EUS-FNA of sterile cystic lesions always causes transmucosal microbial contamination [744]. Of 909 patients who underwent EUS-FNA of PCLs, the overwhelming majority of patients received peri-interventional antibiotics (93.7\%), and the overall rate of cyst infection was estimated at $0.55 \%$ [717]. The incidence of infectious complications in studies that used antibiotic prophylaxis was low $(0-1.4 \%)$, suggesting a protective effect $[530,579,725,731,745-748]$. However, a retrospective comparative study showed no protective effect of peri-interventional antibiotic treatment [749], and there is a lack of prospective comparative studies. Despite the lack of convincing evidence, several guidelines recommend peri-interventional antibiotic treatment for EUS-FNA of PCLs [96, 716, 735]. Due to potentially catastrophic consequences of mediastinal infection, guidelines and reviews regard EUS-FNA of mediastinal cysts to be contraindicated [96, 114, $716,718,735]$. By contrast, EBUS-TBNA of mediastinal cysts seems to carry an acceptable risk [750]. A few reports on infectious complications following EUS-FNA of mediastinal lymph nodes (sarcoidosis and tuberculosis) $[718,719,751-753]$ and of SETs $[114,290$, 295] do not support performing peri-interventional antibiotics on a regular basis. Infectious complications after EUS-FNA of (peri-) rectal lesions are rare $[58,62,741,754,755]$, not justifying peri-interventional antibiotics.

\section{Recommendation 50}

Transesophageal EUS-guided sampling of cystic mediastinal lesions should be avoided due to the high risk of infection (LoE 4, GoR C). Strong consensus (100\%).

\section{Recommendation 51}

Peri-interventional antibiotic treatment is recommended for EUS-guided sampling of cystic lesions and fluid collections as well as in EUS-guided drainage procedures (LOE 5, GOR D). Strong consensus (100\%). 
Table 411 cases of needle track seeding or peritoneal dissemination following EUS-FNA [763 - 773].

\begin{tabular}{|c|c|c|c|c|}
\hline Reference & Target & EUS-FNA details & Complication & Outcome \\
\hline $\begin{array}{l}\text { Hirooka Yet al. } 2003 \\
\text { [763] }\end{array}$ & $\begin{array}{l}\text { malignant pancreatic IPMN } \\
\text { PT1pN0cM0 }\end{array}$ & $\begin{array}{l}\text { transgastric, } \\
22 \text { G needle, } \\
\text { number of needle passes: } \\
\text { not reported }\end{array}$ & $\begin{array}{l}\text { peritoneal carcinomatosis } \\
20 \text { months following EUS-FNA }\end{array}$ & $\begin{array}{l}\text { death } 25 \text { months following } \\
\text { EUS-FNA }\end{array}$ \\
\hline Shah JN 2004 [771] & $\begin{array}{l}\text { perigastric lymph node } \\
\text { metastasis (malignant } \\
\text { melanoma) }\end{array}$ & $\begin{array}{l}\text { transgastric, } \\
22 \text { G needle }\end{array}$ & $\begin{array}{l}\text { gastric wall metastasis } 6 \text { months } \\
\text { following EUS-FNA }\end{array}$ & $\begin{array}{l}\text { surgery, further follow-up } \\
\text { not reported }\end{array}$ \\
\hline $\begin{array}{l}\text { Paquin SC et al. } 2005 \\
\text { [764] }\end{array}$ & $\begin{array}{l}\text { pancreatic tail cancer } \\
\text { PT1pN0cM0 }\end{array}$ & $\begin{array}{l}\text { transgastric, } \\
22 \text { G needle, } \\
5 \text { needle passes }\end{array}$ & $\begin{array}{l}\text { gastric wall metastasis } 21 \text { months } \\
\text { following EUS-FNA }\end{array}$ & $\begin{array}{l}\text { palliative chemotherapy, } \\
\text { death } 12 \text { month after di- } \\
\text { agnosis }\end{array}$ \\
\hline Doi S et al. 2008 [772] & $\begin{array}{l}\text { mediastinal lymph node } \\
\text { metastasis (gastric cancer) }\end{array}$ & $\begin{array}{l}\text { transesophageal, } \\
19 \text { G needle, } \\
1 \text { needle pass }\end{array}$ & $\begin{array}{l}\text { esophageal wall metastasis } \\
21 \text { months following EUS-FNA }\end{array}$ & $\begin{array}{l}\text { successful radiation } \\
\text { treatment }\end{array}$ \\
\hline $\begin{array}{l}\text { Ahmed Ket al. } 2011 \\
\text { [766] }\end{array}$ & $\begin{array}{l}\text { cystic pancreatic body cancer } \\
\text { pT2pNOcM0 }\end{array}$ & $\begin{array}{l}\text { transgastric, } \\
\text { needle diameter not reported, } \\
\text { "multiple" needle passes }\end{array}$ & $\begin{array}{l}\text { gastric wall metastasis nearly } \\
4 \text { years following EUS-FNA }\end{array}$ & $\begin{array}{l}\text { death due to another } \\
\text { malignant disease }\end{array}$ \\
\hline $\begin{array}{l}\text { Chong A et al. } 2011 \\
\text { [765] }\end{array}$ & $\begin{array}{l}\text { cystic pancreatic tail cancer } \\
\text { PT2pNOcM0 }\end{array}$ & $\begin{array}{l}\text { transgastric, } \\
22 \text { G needle, } \\
2 \text { needle passes }\end{array}$ & $\begin{array}{l}\text { gastric wall metastasis } 26 \text { months } \\
\text { following EUS-FNA }\end{array}$ & $\begin{array}{l}\text { non-resectable, further } \\
\text { follow-up not reported }\end{array}$ \\
\hline $\begin{array}{l}\text { Katanuma A et al. } 2012 \\
\text { [767] }\end{array}$ & $\begin{array}{l}\text { solid pancreatic cancer } \\
\text { PT2pNOcM0 }\end{array}$ & $\begin{array}{l}\text { transgastric, } \\
22 \text { G needle, } \\
4 \text { needle passes }\end{array}$ & $\begin{array}{l}\text { gastric wall metastasis } 22 \text { months } \\
\text { following EUS-FNA }\end{array}$ & $\begin{array}{l}\text { surgery, further follow-up } \\
\text { not reported }\end{array}$ \\
\hline $\begin{array}{l}\text { Anderson B et al. } 2013 \\
\text { [773] }\end{array}$ & $\begin{array}{l}\text { celiac lymph node metastasis } \\
\text { of pancreatic head cancer }\end{array}$ & not reported & $\begin{array}{l}\text { transmural metastasis of the } \\
\text { gastroesophageal junction }\end{array}$ & not reported \\
\hline $\begin{array}{l}\text { Virgilio E et al. } 2014 \\
\text { [768] }\end{array}$ & $\begin{array}{l}\text { solid pseudopapillary } \\
\text { neoplasia of the pancreas }\end{array}$ & not reported & $\begin{array}{l}\text { delayed rupture of the solid pseudo- } \\
\text { papillary neoplasia into peritoneal } \\
\text { cavity ( } 20 \text { days following EUS-FNA, } \\
\text { probably due to infection) }\end{array}$ & not reported \\
\hline $\begin{array}{l}\text { Minaga K et al. } 2015 \\
\text { [769] }\end{array}$ & $\begin{array}{l}\text { solid pancreatic cancer } \\
\text { PT3pNOpMO R0 }\end{array}$ & $\begin{array}{l}\text { transgastric, } \\
22 \text { G needle, } \\
3 \text { needle passes }\end{array}$ & $\begin{array}{l}12 \mathrm{~mm} \text { subepithelial gastric wall } \\
\text { metastasis } 8 \text { months following } \\
\text { EUS-FNA }\end{array}$ & $\begin{array}{l}\text { surgery, further follow-up } \\
\text { not reported }\end{array}$ \\
\hline $\begin{array}{l}\text { Tomonari A et al. } 2015 \\
\text { [770] }\end{array}$ & $\begin{array}{l}\text { solid pancreatic cancer } \\
\text { PT3pNOpMO R0 }\end{array}$ & $\begin{array}{l}\text { transgastric, } \\
22 \text { G needle, } \\
2 \text { needle passes }\end{array}$ & $\begin{array}{l}32 \mathrm{~mm} \text { subepithelial gastric wall } \\
\text { metastasis } 28 \text { months following } \\
\text { EUS-FNA }\end{array}$ & $\begin{array}{l}\text { surgery, further follow-up } \\
\text { not reported }\end{array}$ \\
\hline
\end{tabular}

Tumor cell seeding and needle track metastasis

Several studies agree that EUS-guided sampling for malignant solid and cystic pancreatic tumors and for cholangiocarcinoma is not a risk factor for the development of peritoneal seeding, tumor recurrence, or decreased survival [756-762]. The risk of peritoneal seeding following biopsy of pancreatic cancer appears to be significantly lower with EUS-FNA compared to percutaneous FNA [191, 192]. However, 11 individual cases of tumor cell seeding caused by EUS-guided sampling of malignant pancreatic neoplasia ( $\mathrm{n}=8$, in 4 cases cystic tumors) [763-770] and of lymph node metastases $(n=3)$ [771 - 773] suggest cautious use of EUS-guided sampling (๑ Table 4).

\section{Recommendation 52}

Tumor cell dissemination along the needle track following EUS-guided sampling is an exceptionally rare event. Preoperative EUS-guided sampling of pancreatobiliary malignancies is not associated with increased risk of postoperative recurrence, decreased overall survival or decreased cancer-specific survival (LoE 2c, GoR B). Strong consensus (100\%).

\section{Miscellaneous complications}

There are reports of bile peritonitis following EUS-FNA of the gallbladder or of the liver in patients with biliary obstruction
[462, 774, 775], of pneumothorax following transesophageal EUS-FNA of mediastinal lymph nodes [305], pneumoperitoneum following EUS-FNA of a pancreatic tumor [776], and of pancreatic duct leak caused by EUS-FNA of pancreatic mass lesions [777, 778]. One case of phlegmonous gastritis following EUS-FNA has been reported [779]. Two cases of a hypertensive crisis induced by EUS-FNA of retroperitoneal paraganglioma or adrenal pheochromocytoma have been documented [780, 781].

\section{Risk factors for complications}

There is limited data linking complication rates of EUS-FNA with specific target lesions. Data from a systematic review confirmed that EUS-FNA is exceptionally safe for mediastinal lesions $(\mathrm{n}=1310$; complication rate: $0.38 \%)$, abdominal masses $(\mathrm{n}=381$; $0.26 \%)$ and adrenal glands $(n=81 ; 0 \%)$. Procedure-related morbidity seems to be higher for pancreatic lesions $(n=8246$ : $1.03 \%)$, liver lesions $(\mathrm{n}=344 ; 2.33 \%)$ and perirectal lesions $(\mathrm{n}=193: 2.07 \%)$ [717]. For sampling of mediastinal lymph nodes, in a systematic review of 190 studies including 16181 patients, a higher frequency of adverse events (predominantly infectious complications) was reported in patients investigated with EUSFNA $(0.30 \%)$ than in those where EBUS-TBNA was performed $(0.05 \%)$. Complications predominantly occurred in patients with cystic mediastinal lesions and sarcoidosis but were rare in lung cancer patients [718]. Several studies of the risk of EUS-FNA (particularly bleeding, infection, acute pancreatitis, and postopera- 
tive complications) demonstrated that this was higher in PCLs than in solid pancreatic lesions $[96,717,731,756]$. The incidence of adverse events after EUS-FNA of solid pancreatic lesions was significantly increased in small tumors $(\leq 20 \mathrm{~mm})$ and in neuroendocrine pancreatic tumors [782].

Several studies have shown that performing EUS with or without EUS-guided sampling and ERCP in a single session is safe [783790]. Prior biliary stenting has no influence on the risk of adverse events of EUS-guided sampling of suspected pancreatic cancer [552]. One study reported adverse events of EUS-guided sampling in patients with obstructive jaundice drained with plastic stents vs. self-expandable metal stents (SEMS) occurring more often in patients with plastic stents [791].

Observations from high-volume centers suggest that complications are more frequent in the learning phase of examiners [144, $164,639]$. Japanese centers reported that the rate of severe bleeding in low-volume hospitals was significantly higher than that in medium and high-volume hospitals ( $0.48 \%$ vs. $0.10 \%)$ [728].

\section{Recommendation 53}

EUS-guided sampling of solid lesions is a low-risk procedure. EUS-guided sampling of pancreatic cystic lesions has a higher frequency of adverse events compared to solid pancreatic lesions (LoE 2a, GoR B). Strong consensus (100\%).

\section{Recommendation 54}

EUS-guided sampling and ERCP may be safely performed in a single session (LoE 2b, GoR B). Strong consensus (100\%).

\section{Recommendation 55}

Any complications of EUS-guided sampling and therapeutic interventions should be documented in a standardized format in every center. The incidence of adverse events should be monitored and used as a quality indicator (LoE 5, GoR D). Strong consensus (100\%). 


\section{Addendum: Important terms used in this guidelines on EUS-guided sampling are defined and explained in - Table 5}

\section{$\nabla$}

Table 5 EUS-guided interventions: definitions of important terms

\section{Technical terms} Cell block (CB)

Endoscopic ultrasound (EUS) sampling

\begin{tabular}{|c|c|}
\hline Fine-needle & $\begin{array}{l}\text { Needles with an outer diameter of up to } 1.0 \mathrm{~mm} \\
\text { (18 Gauge) }\end{array}$ \\
\hline Needle pass & $\begin{array}{l}\text { One complete process of (EUS-guided) needle } \\
\text { sampling from insertion of the needle into the } \\
\text { target lesion to its withdrawal including several } \\
\text { to-and-fro movements within the lesion. Usually } \\
\text { several needle passes are performed in order to } \\
\text { get sufficient material from one lesion. }\end{array}$ \\
\hline $\begin{array}{l}\text { Rapid on-site } \\
\text { evaluation (ROSE) }\end{array}$ & $\begin{array}{l}\text { Immediate cytopathological evaluation of speci- } \\
\text { mens during the procedure at the site of EUS- } \\
\text { guided sampling aiming at improvement of the } \\
\text { diagnostic yield, optimization of the number of } \\
\text { needle passes required for diagnosis, and provid- } \\
\text { ing a preliminary diagnosis. }\end{array}$ \\
\hline Team time-out & $\begin{array}{l}\text { Time-out of the entire endoscopy team just prior } \\
\text { to the start of an advanced endoscopic procedure } \\
\text { (e. g. EUS-guided interventions), including verifi- } \\
\text { cation of patient identity, procedure to be per- } \\
\text { formed, informed consent, pre-interventional } \\
\text { imaging, necessary equipment, implants, indi- } \\
\text { vidual risk assessment, and special requirements } \\
\text { (e. g., preprocedure antibiotic administration). } \\
\text { a checklist may be used for verification. }\end{array}$ \\
\hline
\end{tabular}

\section{Outcome definitions in EUS-guided sampling}

Specimen adequacy
Preparation of small artificial tissue fragments, clots, or cell pellets from cellular material obtained by (EUS-/EBUS-guided) fine-needle aspiration for histopathological processing (usually formalinfixation, paraffin embedding, sectioning and staining) and evaluation. Various techniques are used for CB preparation.

For the purpose of this guideline, the term endodures using flexible and rigid endoluminal ultrasound probes within the upper and lower gastrointestinal tract and the tracheobronchial tree. The term endosonography is used synonymously.

All EUS-guided procedures aiming at retrieval of tissue or fluids for cytopathological, histopathological, biochemical, microbiological, and molecular evaluation. The term embraces transintestinal EUS-guided fine-needle aspiration (EUS-FNA) and endobronchial ultrasound-guided transbronchial needle aspiration (EBUS-TBNA) techniques using standard aspiration needles as well as transintestinal EUS-guided fine-needle biopsy (EUS-FNB) techniques using special needles designed for the procurement of tissue cores. The terms endosonographic sampling and EUS-guided tissue acquisition are used synonymously. Needles with an outer diameter of up to $1.0 \mathrm{~mm}$ One complete process of (EUS-guided) needle 列 to-and-fro movements within the lesion. Usually Percentage of specimens in which the material is representative for the target lesion and sufficient for cytopathological or histopathological preparation; the term may be used on a per-pass basis and a per-case basis. The terms "satisfactory" and "adequate" sometimes are used synonymously to describe representative and diagnostically sufficient samples. scopic ultrasound is used to describe all proce-

Table 5 (Continuation)

$\begin{array}{ll}\text { Diagnostic yield } & \begin{array}{l}\text { Percentage of samples for which tissue diagnosis } \\ \text { is possible; the term is usually defined on a per- } \\ \text { case basis. }\end{array} \\ \begin{array}{l}\text { Diagnostic } \\ \text { accuracy }\end{array} & \begin{array}{l}\text { Percentage of sampled cases with a tissue diag- } \\ \text { nosis that corresponds to the final diagnosis } \\ \text { (diagnostic gold standard varying between stud- } \\ \text { ies); usually, non-diagnostic (inadequate and in- } \\ \text { conclusive) cases are excluded from analysis. }\end{array} \\ \begin{array}{l}\text { Rate of inconclu- } \\ \text { sive (indetermi- }\end{array} & \begin{array}{l}\text { Percentage of sampled cases with the diagnostic } \\ \text { categories "atypical" or "suspicious". }\end{array}\end{array}$

nate) specimens

Diagnostic categories in cytopathology (based on the nomenclature and terminology of the Papanicolaou Society of Cytopathology [694, $695]$ and the Bethesda system for reporting in non-gynecologic cytopathology [693]) $)^{18}$

Non-diagnostic Specimen providing no diagnostically useful information about the sampled lesion (e. g. cellular material not representative of the target, scant cellularity or acellularity, aspirate containing only contaminants from the needle track, aspirate containing only necrotic material, severe contamination (e. g. blood), poor cellular preservation or inadequate preparation precluding cyto-/ histopathological evaluation).

The term "unsatisfactory" is used synonymously.

\section{Negative}

(for malignancy)

Benign

Atypical

icious

(for malignancy)

Positive

(for malignancy), malignant Specimen containing adequate cellular material with respect to the sampled lesion without any criteria of malignancy.

The Bethesda classification uses the category "benign" instead of "negative", if there are sufficient criteria to establish a specific benign diagnosis (including benign neoplasms) [693].

Specimen containing adequate cellular material with respect to the sampled lesion with features not consistent with normal or reactive cellular changes, but insufficient to classify them as neoplastic or malignant.

Neoplastic Specimen containing adequate cellular material with respect to the sampled lesion with features diagnostic of a distinct benign or premalignant/ low-grade malignant neoplasm. This term is unique for the six-tiered terminology of the guidelines of the Papanicolaou Society of Cytopathology for pancreatobiliary cytology $[694,695]$.

Specimen containing adequate cellular material with respect to the sampled lesion with features raising a strong suspicion for malignancy, but being qualitatively or quantitatively insufficient for a conclusive diagnosis of a (specific) malignant neoplasm.

Specimen containing adequate cellular material with respect to the sampled lesion displaying unequivocal features of a (specific) malignant neoplasm.

${ }^{18}$ For detailed definitions, explanations and examples see the guidelines of the Papanicolaou Society of Cytopathology $[694,695]$ and the guidelines of the College of American Pathologists [693]. In clinical practice, these terms are not consistently used. 


\section{Affiliations}

1 Department of Internal Medicine, Krankenhaus Märkisch Oderland Strausberg/Wriezen, Germany

2 Department of Internal Medicine 2, Helios Hospital Meiningen GmbH, Meiningen, Germany

3 Gastroenterology Unit, Department of Medical and Surgical Sciences University of Bologna/Hospital of Imola, Italy

4 National Centre for Ultrasound in Gastroenterology, Haukeland University Hospital, Bergen and Department of Clinical Medicine, University of Bergen, Bergen, Norway

${ }^{5}$ Department of Gastroenterology and Endoscopy, Ospedale Maggiore Crema, Italy

${ }^{6}$ Department of Medicine and National Centre for Ultrasound in Gastroenterology, Haukeland University Hospital, Bergen, Norway

7 Department of Internal Medicine 2, Caritas Krankenhaus, Bad Mergentheim, Germany

8 Department of Gastroenterology, Research Center of Gastroenterology and Hepatology, University of Medicine and Pharmacy, Craiova, Romania and Department of Endoscopy, Gastrointestinal Unit, Copenhagen University Hospital Herlev, Denmark

${ }^{9}$ GastroUnit, Department of Surgery, University Hospital Herlev, Copenhagen, Denmark

10 Department of Internal Medicine I, Sana Kliniken, Luebeck, Germany

11 Department of Gastric Surgery, Ultrasound Section, Herlev Hospital, University of Copenhagen, Denmark

12 Department of Gastroenterology, Brandenburg University of Medicine Theodor Fontane, Neuruppin, Germany

13 Department of Radiology, GB Rossi University Hospital, University of Verona, Italy

14 Unit of Internal Medicine, Department of Medical and Surgical Sciences, University of Bologna, Italy

15 Department of Radiology, King's College Hospital, London, UK

16 Department of Internal Medicine 2, Caritas Krankenhaus, Bad Mergentheim, Germany

17 Sino-German Research Center of Ultrasound in Medicine, The First Affiliated Hospital of Zhengzhou University, Zhengzhou, China

\section{Acknowledgement}

$\nabla$

We would like to acknowledge the advice from Lynne Rudd, EFSUMB general secretary, and the support of the EFSUMB INVUS committee.

\section{References}

1 Fusaroli $P$, Jenssen $C$, Hocke $M$ et al. EFSUMB guidelines on interventional ultrasound, part V. EUS-guided therapeutic interventions. Ultraschall in Med 2015, Epub ahead of print

2 Dietrich CF, Lorentzen T, Sidhu PS et al. An introduction into the EFSUMB guidelines on interventional ultrasound. Ultraschall in Med 2015, Epub ahead of print

3 Gan SI, Rajan E, Adler DG. ASGE Standards of Practice Committee. et al. Role of EUS. Gastrointest Endosc 2007; 66: 425 - 434

4 Yusuf TE, Tsutaki S, Wagh MS et al. The EUS hardware store: state of the art technical review of instruments and equipment (with videos). Gastrointest Endosc 2007; 66: 131 - 143

5 Tierney WM, Adler DG, Chand B. ASGE Technology Committee. et al. Echoendoscopes. Gastrointest Endosc 2007; 66: 435-442

6 Van Dam J, Sivak M. eds Gastrointestinal Endosonography. Philadelphia. London. Toronto. Montreal, Sydney, Tokyo: W.B. Saunders; 1999

7 Dietrich CF. ed. Endoscopic Ultrasound. An Introductory Manual and Atlas. Stuttgart, New York: Thieme; 2011

8 Jenssen C, Gottschalk U, Schachschal G et al. eds. Kursbuch Endosonografie. Stuttgart, New York: Thieme; 2014

9 Hawes RH, Fockens P, Varadarajulu S. eds. Endosonography. Philadelphia: Elsevier - Saunders; 2015

10 Vilmann P, Jacobsen GK, Henriksen FW et al. Endoscopic ultrasonography with guided fine needle aspiration biopsy in pancreatic disease. Gastrointest Endosc 1992; 38: 172 - 173

11 Wiersema MJ, Wiersema LM. Endosonography-guided celiac plexus neurolysis. Gastrointest Endosc 1996; 44: 656-662

12 Wiersema MJ. Endosonography-guided cystoduodenostomy with a therapeutic ultrasound endoscope. Gastrointest Endosc 1996; 44: $614-617$
13 Kaul V, Adler DG, Conway JD. ASGE Technology Committee. et al. Interventional EUS. Gastrointest Endosc 2010; 72: 1 -4

14 Dietrich $C F$, Hocke $M$, Jenssen $C$. Interventional endosonography. Ultraschall in Med 2011; 32: 8-22, quiz 23-25

15 Fabbri $C$, Luigiano $C$, Lisotti $A$ et al. Endoscopic ultrasound-guided treatments: are we getting evidence based-a systematic review. World J Gastroenterol 2014; 20: 8424-8448

16 Dietrich CF, Hocke $M$, Jenssen C. Interventional endosonography. In: Dietrich CF, Nuernberg D eds. Interventional Ultrasound. A Practical Guide and Atlas. Stuttgart, New York, Delhi, Rio: Thieme; 2015: 224 253

17 Krasnik M, Vilmann P, Larsen SS et al. Preliminary experience with a new method of endoscopic transbronchial real time ultrasound guided biopsy for diagnosis of mediastinal and hilar lesions. Thorax 2003; 58 : $1083-1086$

18 Varadarajulu S, Banerjee S, Barth BA. ASGE Technology Committee. et al. GI endoscopes. Gastrointest Endosc 2011; 74: 1 - 6 e6

19 Bhutani MS, Deutsch JC. eds. EUS Pathology with Digital Anatomy Correlation. Textbook and Atlas. Shelton: People's Medical Publishing House; 2010

20 Fusaroli $P$, Vallar R, Togliani T et al. Scientific publications in endoscopic ultrasonography: a 20-year global survey of the literature. Endoscopy 2002; 34: 451 - 456

21 Anderson MA, Scheiman JM. Initial experience with an electronic radial array echoendoscope: randomized comparison with a mechanical sector scanning echoendoscope in humans. Gastrointest Endosc 2002; 56 : $573-577$

22 Niwa K, Hirooka Y, Niwa Y et al. Comparison of image quality between electronic and mechanical radial scanning echoendoscopes in pancreatic diseases. J Gastroenterol Hepatol 2004; 19: 454-459

23 Papanikolaou IS, Delicha EM, Adler A et al. Prospective, randomized comparison of mechanical and electronic radial endoscopic ultrasound systems: assessment of performance parameters and image quality. Scand J Gastroenterol 2009; 44: 93 -99

24 Adler DG, Conway JD, Coffie JM et al. EUS accessories. Gastrointest Endosc 2007; 66: 1076-1081

25 Rintoul RC, Ahmed R, Dougherty B et al. Linear endobronchial ultrasonography: a novelty turned necessity for mediastinal nodal assessment. Thorax 2015; 70: 175-180

26 Fusaroli P, Saftoiu A, Mancino MG et al. Techniques of image enhancement in EUS (with videos). Gastrointest Endosc 2011; 74: 645 - 655

27 Pedrosa MC, Barth BA, Desilets DJ et al. Enhanced ultrasound imaging. Gastrointest Endosc 2011; 73: 857-860

28 Dietrich CF, Sharma M, Hocke M. Contrast-Enhanced Endoscopic Ultrasound. Endoscopic Ultrasound 2012; 1: 130-136

29 Dietrich CF, Saftoiu A, Jenssen C. Real time elastography endoscopic ultrasound (RTE-EUS), a comprehensive review. Eur J Radiol 2014; 83: $405-414$

30 Siemsen $M$, Svendsen $L B$, Knigge $U$ et al. A prospective randomized comparison of curved array and radial echoendoscopy in patients with esophageal cancer. Gastrointest Endosc 2003; 58: 671 - 676

31 Matthes $K$, Bounds BC, Collier K et al. EUS staging of upper GI malignancies: results of a prospective randomized trial. Gastrointest Endosc 2006; 64: 496 - 502

32 Gress F, Savides T, Cummings 0 et al. Radial scanning and linear array endosonography for staging pancreatic cancer: a prospective randomized comparison. Gastrointest Endosc 1997; 45: 138-142

33 Kanazawa K, Imazu $\mathrm{H}$, Mori $\mathrm{N}$ et al. A comparison of electronic radial and curvilinear endoscopic ultrasonography in the detection of pancreatic malignant tumour. Scand J Gastroenterol 2012; 47: 1313 1320

34 Voermans RP, Ponchon T, Schumacher B et al. Forward-viewing versus oblique-viewing echoendoscopes in transluminal drainage of pancreatic fluid collections: a multicenter, randomized, controlled trial. Gastrointest Endosc 2011; 74 : 1285 - 1293

35 Iwashita T, Nakai Y, Lee JG et al. Newly-developed, forward-viewing echoendoscope: a comparative pilot study to the standard echoendoscope in the imaging of abdominal organs and feasibility of endoscopic ultrasound-guided interventions. J Gastroenterol Hepatol 2012; 27: $362-367$

36 Fusaroli P, Ceroni L, Caletti G. Forward-view Endoscopic Ultrasound: A Systematic Review of Diagnostic and Therapeutic Applications. Endosc Ultrasound 2013; 2: $64-70$ 
37 Hunerbein M, Ghadimi BM, Haensch W et al. Transendoscopic ultrasound of esophageal and gastric cancer using miniaturized ultrasound catheter probes. Gastrointest Endosc 1998; 48: 371 - 375

38 Menzel J, Domschke W. Intraductal ultrasonography (IDUS) of the pancreato-biliary duct system. Personal experience and review of literature. Eur J Ultrasound 1999; 10: 105 - 115

39 Menzel J, Hoepffner N, Sulkowski U et al. Polypoid tumours of the major duodenal papilla: preoperative staging with intraductal US, EUS, and CT-a prospective, histopathologically controlled study. Gastrointest Endosc 1999; 49: 349-357

40 Menzel J, Poremba C, Dietl KH et al. Preoperative diagnosis of bile duct strictures-comparison of intraductal ultrasonography with conventional endosonography. Scand J Gastroenterol 2000; 35: 77-82

41 Harada $N$, Hamada S, Kubo $\mathrm{H}$ et al. Preoperative evaluation of submucosal invasive colorectal cancer using a $15-\mathrm{MHz}$ ultrasound miniprobe. Endoscopy 2001; 33: 237-240

42 Lugering N, Menzel J, Kucharzik T et al. Impact of miniprobes compared to conventional endosonography in the staging of low-grade gastric malt lymphoma. Endoscopy 2001; 33: $832-837$

43 Tseng LJ, Jao YT, Mo LR. Preoperative staging of colorectal cancer with a balloon-sheathed miniprobe. Endoscopy 2002; 34: 564-568

44 Stergiou N, Haji-Kermani N, Schneider C et al. Staging of colonic neoplasms by colonoscopic miniprobe ultrasonography. Int J Colorectal Dis 2003; 18: $445-449$

45 May A, Gunter E, Roth F et al. Accuracy of staging in early oesophageal cancer using high resolution endoscopy and high resolution endosonography: a comparative, prospective, and blinded trial. Gut 2004; 53: $634-640$

46 Chemaly M, Scalone O, Durivage $G$ et al. Miniprobe EUS in the pretherapeutic assessment of early esophageal neoplasia. Endoscopy 2008; 40: $2-6$

47 Mennigen R, Tuebergen D, Koehler $G$ et al. Endoscopic ultrasound with conventional probe and miniprobe in preoperative staging of esophageal cancer. J Gastrointest Surg 2008; 12: 256-262

48 Wehrmann T, Martchenko K, Riphaus A. Catheter probe extraductal ultrasonography vs. conventional endoscopic ultrasonography for detection of bile duct stones. Endoscopy 2009; 41: 133-137

49 Meister T, Heinzow HS, Osterkamp R et al. Miniprobe endoscopic ultrasound accurately stages esophageal cancer and guides therapeutic decisions in the era of neoadjuvant therapy: results of a multicenter cohort analysis. Surg Endosc 2013; 27: 2813-2819

50 Meister T, Heinzow HS, Woestmeyer C et al. Intraductal ultrasound substantiates diagnostics of bile duct strictures of uncertain etiology. World J Gastroenterol 2013; 19: 874-881

51 Gall TM, Markar SR, Jackson D et al. Mini-probe ultrasonography for the staging of colon cancer: a systematic review and meta-analysis. Colorectal Dis 2014; 16: $01-08$

52 Bhutani MS, Nadella P. Utility of an upper echoendoscope for endoscopic ultrasonography of malignant and benign conditions of the sigmoid/left colon and the rectum. Am J Gastroenterol 2001; 96: 33183322

53 Colaiacovo R, Assef MS, Ganc RL et al. Rectal cancer staging: Correlation between the evaluation with radial echoendoscope and rigid linear probe. Endosc Ultrasound 2014; 3: 161-166

54 Ellrichmann M, Wietzke-Braun P, Dhar S et al. Endoscopic ultrasound of the colon for the differentiation of Crohn's disease and ulcerative colitis in comparison with healthy controls. Aliment Pharmacol Ther 2014: 39: $823-833$

55 Hunerbein $M$, Totkas $S$, Moesta KT et al. The role of transrectal ultrasound-guided biopsy in the postoperative follow-up of patients with rectal cancer. Surgery 2001; 129: 164-169

56 Varadarajulu S, Drelichman ER. Effectiveness of EUS in drainage of pelvic abscesses in 25 consecutive patients (with video). Gastrointest Endosc 2009; 70: 1121 - 1127

57 Uchida N, Galasso D, Seerden TC et al. EUS-FNA of extracolonic lesions by using the forward-viewing linear echoendoscope. Gastrointest Endosc 2010; 72: $1321-1323$

58 Gleeson FC, Clain JE, Rajan E et al. EUS-FNA assessment of extramesenteric lymph node status in primary rectal cancer. Gastrointest Endosc 2011; 74: 897-905

59 Gleeson FC, Clain JE, Karnes RJ et al. Endoscopic-ultrasound-guided tissue sampling facilitates the detection of local recurrence and extra pelvic metastasis in pelvic urologic malignancy. Diagn Ther Endosc 2012; 2012: 21952
60 Gleeson FC, Larson DW, Dozois EJ et al. Local recurrence detection following transanal excision facilitated by EUS-FNA. Hepatogastroenterology 2012; 59: 1102 - 1107

61 Mohamadnejad M, Al-Haddad MA, Sherman S et al. Utility of EUS-guided biopsy of extramural pelvic masses. Gastrointest Endosc 2012; 75: $146-151$

62 Levy MJ, Abu Dayyeh BK, Fujii LL et al. Prospective evaluation of adverse events following lower gastrointestinal tract EUS FNA. Am J Gastroenterol 2014; 109: 676-685

63 Gorospe EC, Oxentenko AS. Preprocedural considerations in gastrointestinal endoscopy. Mayo Clin Proc 2013; 88: 1010-1016

64 Wani S, Wallace MB, Cohen J et al. Quality indicators for EUS. Gastrointest Endosc 2015; 81: 67 - 80

65 Parusel M, Krakamp B, Janssen J et al. Endoscopic ultrasonography (EUS) of the upper gastrointestinal tract - prospective multicenter study to evaluate time and staff requirements. Z Gastroenterol 2003; 41: $907-912$

66 Cheriyan DG, Byrne MF. Propofol use in endoscopic retrograde cholangiopancreatography and endoscopic ultrasound. World J Gastroenterol 2014; 20: $5171-5176$

67 Cohen S, Kalinin M, Yaron A et al. Endoscopic ultrasonography in pediatric patients with gastrointestinal disorders. J Pediatr Gastroenterol Nutr 2008; 46: $551-554$

68 Attila T, Adler DG, Hilden K et al. EUS in pediatric patients. Gastrointest Endosc 2009; 70: 892 - 898

69 Benson ME, Byrne S, Brust DJ et al. EUS and ERCP complication rates are not increased in elderly patients. Dig Dis Sci 2010; 55: 3278 - 3283

70 Attila T, Faigel DO. Endoscopic ultrasound in patients over 80 years old. Dig Dis Sci 2011; 56: 3065 - 3071

71 Bonta PI, Kok MF, Bergman JJ et al. Conscious sedation for EUS of the esophagus and stomach: a double-blind, randomized, controlled trial comparing midazolam with placebo. Gastrointest Endosc 2003; 57: $842-847$

72 Yarmus LB, Akulian JA, Gilbert C et al. Comparison of moderate versus deep sedation for endobronchial ultrasound transbronchial needle aspiration. Ann Am Thorac Soc 2013; 10: 121 - 126

73 Jeyabalan A, Medford AR. Endobronchial ultrasound-guided transbronchial needle aspiration: patient satisfaction under light conscious sedation. Respiration 2014; 88: $244-250$

74 Fanti L, Agostoni M, Arcidiacono PG et al. Target-controlled infusion during monitored anesthesia care in patients undergoing EUS: propofol alone versus midazolam plus propofol. A prospective double-blind randomised controlled trial. Dig Liver Dis 2007; 39: 81 - 86

75 Trummel JM, Surgenor SD, Cravero JP et al. Comparison of differing sedation practice for upper endoscopic ultrasound using expert observational analysis of the procedural sedation. J Patient Saf 2009; 5: 153 159

76 Nayar DS, Guthrie WG, Goodman A et al. Comparison of propofol deep sedation versus moderate sedation during endosonography. Dig Dis Sci 2010; 55: 2537-2544

77 Amornyotin S, Leelakusolvong S, Chalayonnawin W et al. Age-dependent safety analysis of propofol-based deep sedation for ERCP and EUS procedures at an endoscopy training center in a developing country. Clin Exp Gastroenterol 2012; 5: 123-128

78 Triantafillidis JK, Merikas E, Nikolakis D et al. Sedation in gastrointestinal endoscopy: current issues. World J Gastroenterol 2013; 19: 463-481

79 Chrissian AA, Bedi H. Bronchoscopist-directed Continuous Propofol Infusion for Targeting Moderate Sedation During Endobronchial Ultrasound Bronchoscopy: A Practical and Effective Protocol. J Bronchology Interv Pulmonol 2015; 22: 226-236

80 Yusoff IF, Raymond G, Sahai AV. Endoscopist administered propofol for upper-GI EUS is safe and effective: a prospective study in 500 patients. Gastrointest Endosc 2004; 60: 356-360

81 Agostoni M, Fanti L, Arcidiacono PG et al. Midazolam and pethidine versus propofol and fentanyl patient controlled sedation/analgesia for upper gastrointestinal tract ultrasound endoscopy: a prospective randomized controlled trial. Dig Liver Dis 2007; 39: 1024-1029

82 Dewitt J, McGreevy K, Sherman S et al. Nurse-administered propofol sedation compared with midazolam and meperidine for EUS: a prospective, randomized trial. Gastrointest Endosc 2008; 68: 499-509

83 Fatima H, DeWitt J, LeBlanc J et al. Nurse-administered propofol sedation for upper endoscopic ultrasonography. Am J Gastroenterol 2008; 103: $1649-1656$ 
84 Pagano N, Arosio M, Romeo F et al. Balanced Propofol Sedation in Patients Undergoing EUS-FNA: A Pilot Study to Assess Feasibility and Safety. Diagn Ther Endosc 2011; 2011: 542159

85 Redondo-Cerezo E, Sanchez-Robaina A, Martinez Cara JG et al. Gastroenterologist-guided sedation with propofol for endoscopic ultrasonography in average-risk and high-risk patients: a prospective series. Eur J Gastroenterol Hepatol 2012; 24: 506-512

86 Dumonceau JM, Riphaus A, Aparicio JR et al. European Society of Gastrointestinal Endoscopy, European Society of Gastroenterology and Endoscopy Nurses and Associates, and the European Society of Anaesthesiology Guideline: Non-anesthesiologist administration of propofol for GI endoscopy. Endoscopy 2010; 42: 960 - 974

87 Dumonceau JM, Riphaus A, Beilenhoff $U$ et al. European curriculum for sedation training in gastrointestinal endoscopy: position statement of the European Society of Gastrointestinal Endoscopy (ESGE) and European Society of Gastroenterology and Endoscopy Nurses and Associates (ESGENA). Endoscopy 2013; 45: 496 - 504

88 Vilmann P, Saftoiu A. Endoscopic ultrasound-guided fine needle aspiration biopsy: equipment and technique. J Gastroenterol Hepatol 2006; 21: $1646-1655$

89 Jenssen C. Diagnostische Endosonografie - State of the Art 2009. Endoskopie heute 2009; 22: 89-104

90 Vilmann P, Seicean A, Saftoiu A. Tips to overcome technical challenges in EUS-guided tissue acquisition. Gastrointest Endosc Clin N Am 2014; 24: $109-124$

91 Wani S, Muthusamy VR, Komanduri S. EUS-guided tissue acquisition: an evidence-based approach (with videos). Gastrointest Endosc 2014; 80: 939 - 959 e937

92 Wiersema MJ, Levy MJ, Harewood GC et al. Initial experience with EUSguided trucut needle biopsies of perigastric organs. Gastrointest Endosc 2002; 56: 275-278

93 Levy MJ, Jondal ML, Clain J et al. Preliminary experience with an EUSguided trucut biopsy needle compared with EUS-guided FNA. Gastrointest Endosc 2003; 57: 101-106

94 Saftoiu A, Vilmann P, Guldhammer Skov B et al. Endoscopic ultrasound (EUS)-guided Trucut biopsy adds significant information to EUS-guided fine-needle aspiration in selected patients: a prospective study. Scand J Gastroenterol 2007; 42: 117-125

95 Iglesias-Garcia J, Poley JW, Larghi A et al. Feasibility and yield of a new EUS histology needle: results from a multicenter, pooled, cohort study. Gastrointest Endosc 2011; 73: 1189-1196

96 Polkowski M, Larghi A, Weynand B et al. Learning, techniques, and complications of endoscopic ultrasound (EUS)-guided sampling in gastroenterology: European Society of Gastrointestinal Endoscopy (ESGE) Technical Guideline. Endoscopy 2012; 44: 190-206

97 Larghi A, Iglesias-Garcia J, Poley JW et al. Feasibility and yield of a novel 22-gauge histology EUS needle in patients with pancreatic masses: a multicenter prospective cohort study. Surg Endosc 2013; 27: 3733 3738

98 Lachter J. Basic technique in endoscopic ultrasound-guided fine needle aspiration for solid lesions: What needle is the best? Endosc Ultrasound $2014: 3: 46-53$

99 Artifon EL, Ferreira FC, Otoch JP et al. EUS-guided biliary drainage: a review article. JOP 2012; 13: 7-17

100 Giovannini M, Bories E, Téllez-Ávila FI. Endoscopic Ultrasound-guided Bilio-pancreatic Drainage. Endoscopic Ultrasound 2012; 1: 119-129

101 Giovannini M, Bories E. EUS-Guided Biliary Drainage. Gastroenterol Res Pract 2012; 2012: 348719

102 Kawakami H, Itoi T, Sakamoto N. Endoscopic ultrasound-guided transluminal drainage for peripancreatic fluid collections: where are we now? Gut Liver 2014; 8: 341 - 355

103 Widmer JL, Michel K. Endoscopic Ultrasound-Guided Treatment beyond Drainage: Hemostasis, Anastomosis, and Others. Clin Endosc 2014; 47: $432-439$

104 Dumonceau JM, Polkowski M, Larghi A et al. Indications, results, and clinical impact of endoscopic ultrasound (EUS)-guided sampling in gastroenterology: European Society of Gastrointestinal Endoscopy (ESGE) Clinical Guideline. Endoscopy 2011; 43: 897-912

105 Fusaroli P, Kypreos D, Alma Petrini CA et al. Scientific publications in endoscopic ultrasonography: changing trends in the third millennium. J Clin Gastroenterol 2011; 45: 400-404

106 Fusaroli P, Kypraios D, Eloubeidi MA et al. Levels of evidence in endoscopic ultrasonography: a systematic review. Dig Dis Sci 2012; 57 : $602-609$
107 Fusaroli P, Kypraios D, Caletti G et al. Pancreatico-biliary endoscopic ultrasound: a systematic review of the levels of evidence, performance and outcomes. World J Gastroenterol 2012; 18: 4243 - 4256

108 Yamao K, Sawaki A, Mizuno $N$ et al. Endoscopic ultrasound-guided fine-needle aspiration biopsy (EUS-FNAB): past, present, and future. J Gastroenterol 2005; 40: 1013-1023

109 Prasad P, Wittmann J, Pereira SP. Endoscopic ultrasound of the upper gastrointestinal tract and mediastinum: diagnosis and therapy. Cardiovasc Intervent Radiol 2006; 29: 947 - 957

110 Jenssen C, Dietrich CF. Endoscopic ultrasound-guided fine-needle aspiration biopsy and trucut biopsy in gastroenterology - An overview. Best Pract Res Clin Gastroenterol 2009; 23: 743 - 759

111 Godfrey EM, Rushbrook SM, Carroll NR. Endoscopic ultrasound: a review of current diagnostic and therapeutic applications. Postgrad Med J 2010; 86: 346-353

112 Jue TL, Sharaf RN, Appalaneni V. ASGE Standards of Practice Committee. et al. Role of EUS for the evaluation of mediastinal adenopathy. Gastrointest Endosc 2011; 74: 239-245

113 Khashab MA, Varadarajulu S. Endoscopic ultrasonography as a therapeutic modality. Curr Opin Gastroenterol 2012; 28: 467-476

114 Jenssen C, Alvarez-Sanchez MV, Napoleon B et al. Diagnostic endoscopic ultrasonography: assessment of safety and prevention of complications. World J Gastroenterol 2012; 18: 4659-4676

115 Alvarez-Sanchez MV, Jenssen C, Faiss S et al. Interventional endoscopic ultrasonography: an overview of safety and complications. Surg Endosc 2014; 28: $712-734$

116 DiMaio CJ, Mishra G, McHenry L. ASGE Training Committee. et al. EUS core curriculum. Gastrointest Endosc 2012; 76: 476-481

117 Burmester E, Leineweber T, Hacker $S$ et al. EUS Meets Voxel-Man three-dimensional anatomic animation of linear-array endoscopic ultrasound images. Endoscopy 2004; 36: 726-730

118 Baron TH. Endoscopic ultrasound training in mid-to-late career: Falling prey to the dark side or the bright side? Endosc Ultrasound 2014; 3: $200-201$

119 Săftoiu A, Popescu CF, Cazacu SM. Linear Endoscopic Ultrasound Atlas. In: www.EUSAtlas.ro

120 Konge L, Colella S, Vilmann P et al. How to learn and to perform endoscopic ultrasound and endobronchial ultrasound for lung cancer staging: A structured guide and review. Endosc Ultrasound 2015; 4: 4-9

$121 \mathrm{Kim}$ GH, Bang SJ, Hwang JH. Learning models for endoscopic ultrasonography in gastrointestinal endoscopy. World J Gastroenterol 2015; 21: $5176-5182$

122 Wang MH, Dy F, Vu VK et al. Structured endoscopic ultrasonography (EUS) training program improved knowledge and skills of trainees: Results from the Asian EUS Group. Dig Endosc 2015; 27: 687-691

123 Kefalides PT, Gress F. Simulator training for endoscopic ultrasound. Gastrointest Endosc Clin N Am 2006; 16: 543 - 552, viii

124 Stather DR, Lamb CR, Tremblay A. Simulation in flexible bronchoscopy and endobronchial ultrasound: a review. J Bronchology Interv Pulmonol 2011; 18: 247-256

125 Stather DR, Maceachern P, Rimmer K et al. Validation of an endobronchial ultrasound simulator: differentiating operator skill level. Respiration 2011; 81: $325-332$

126 Stather DR, MacEachern P, Chee A et al. Wet laboratory versus computer simulation for learning endobronchial ultrasound: a randomized trial. Can Respir J 2012; 19: 325 - 330

127 Stather DR, MacEachern P, Chee A et al. Evaluation of clinical endobronchial ultrasound skills following clinical versus simulation training. Respirology 2012; 17: 291 - 299

128 Stather DR, Chee A, Maceachern P et al. Evaluation of a novel method of teaching endobronchial ultrasound: physician- versus respiratory therapist-proctored simulation training. Can Respir J 2013; 20: $243-247$

129 Konge L, Annema J, Clementsen P et al. Using virtual-reality simulation to assess performance in endobronchial ultrasound. Respiration 2013; 86: 59-65

130 Konge L, Clementsen PF, Ringsted C et al. Simulator training for endobronchial ultrasound: a randomised controlled trial. Eur Respir J 2015; Epub ahead of print

131 Baron TH, DeSimio TM. New ex-vivo porcine model for endoscopic ultrasound-guided training in transmural puncture and drainage of pancreatic cysts and fluid collections (with videos). Endosc Ultrasound 2015; 4: $34-39$ 
132 Bhutani MS, Hoffman BJ, Hawes RH. A swine model for teaching endoscopic ultrasound (EUS) imaging and intervention under EUS guidance. Endoscopy 1998; 30: 605-609

133 Barthet M, Gasmi M, Boustiere C et al. EUS training in a live pig model: does it improve echo endoscope hands-on and trainee competence? Endoscopy 2007; 39: 535-539

134 Fritscher-Ravens A, Cuming T, Dhar S et al. Endoscopic ultrasoundguided fine needle aspiration training: evaluation of a new porcine lymphadenopathy model for in vivo hands-on teaching and training and review of the literature. Endoscopy 2013; 45: 114-120

$135 \mathrm{Xu}$ W, Liu Y, Pan P et al. Prior radial-scanning endoscopic ultrasonography training did not contribute to subsequent linear-array endoscopic ultrasonography study performance in the stomach of a porcine model. Gut Liver 2015; 9: 353 - 357

136 Cote GA, Hovis CE, Kohlmeier C et al. Training in EUS-Guided Fine Needle Aspiration: Safety and Diagnostic Yield of Attending Supervised, Trainee-Directed FNA from the Onset of Training. Diagn Ther Endosc 2011; 2011: 378540

137 Stather DR, Maceachern P, Rimmer K et al. Assessment and learning curve evaluation of endobronchial ultrasound skills following simulation and clinical training. Respirology 2011; 16: 698-704

138 Konge L, Vilmann P, Clementsen P et al. Reliable and valid assessment of competence in endoscopic ultrasonography and fine-needle aspiration for mediastinal staging of non-small cell lung cancer. Endoscopy 2012; 44: 928 - 933

139 Davoudi M, Colt HG, Osann KE et al. Endobronchial ultrasound skills and tasks assessment tool: assessing the validity evidence for a test of endobronchial ultrasound-guided transbronchial needle aspiration operator skill. Am J Respir Crit Care Med 2012; 186: 773 - 779

140 Konge L, Annema J, Vilmann P et al. Transesophageal ultrasonography for lung cancer staging: learning curves of pulmonologists. J Thorac Oncol 2013; 8: $1402-1408$

141 Wani S, Hall M, Keswani RN et al. Variation in Aptitude of Trainees in Endoscopic Ultrasonography, Based on Cumulative Sum Analysis. Clin Gastroenterol Hepatol 2015; 13: 1318-1325.e1312

142 Wani S, Cote GA, Keswani R et al. Learning curves for EUS by using cumulative sum analysis: implications for American Society for Gastrointestinal Endoscopy recommendations for training. Gastrointest Endosc 2013; 77: $558-565$

143 Mertz H, Gautam S. The learning curve for EUS-guided FNA of pancreatic cancer. Gastrointest Endosc 2004; 59: 33 - 37

144 Eloubeidi MA, Tamhane A. EUS-guided FNA of solid pancreatic masses: a learning curve with 300 consecutive procedures. Gastrointest Endosc 2005; 61: $700-708$

145 Eisen GM, Dominitz JA, Faigel DO et al. Guidelines for credentialing and granting privileges for endoscopic ultrasound. Gastrointest Endosc 2001; 54: $811-814$

146 Krishna SG, Li F, Bhattacharya A et al. Differentiation of pancreatic ductal adenocarcinoma from other neoplastic solid pancreatic lesions: a tertiary oncology center experience. Gastrointest Endosc 2015; 81: $370-379$

147 Krishna SG, Bhattacharya A, Ross WA et al. Pretest prediction and diagnosis of metastatic lesions to the pancreas by endoscopic ultrasound-guided fine needle aspiration. J Gastroenterol Hepatol 2015; 30: $1552-1560$

148 Haba S, Yamao K, Bhatia $V$ et al. Diagnostic ability and factors affecting accuracy of endoscopic ultrasound-guided fine needle aspiration for pancreatic solid lesions: Japanese large single center experience. J Gastroenterol 2013; 48: 973-981

149 Dumonceau JM, Koessler T, van Hooft JE et al. Endoscopic ultrasonography-guided fine needle aspiration: Relatively low sensitivity in the endosonographer population. World J Gastroenterol 2012; 18: $2357-2363$

150 Harewood GC, Wiersema LM, Halling AC et al. Influence of EUS training and pathology interpretation on accuracy of EUS-guided fine needle aspiration of pancreatic masses. Gastrointest Endosc 2002; 55 : $669-673$

151 Noh KW, Raimondo M, Woodward TA et al. Eliminating the "non-diagnostic" EUS-FNA specimen: effect of a quality improvement program on cytologic interpretation (abstract). Gastrointest Endosc 2005; 61: AB295

152 Eltoum IA, Chhieng DC, Jhala $D$ et al. Cumulative sum procedure in evaluation of EUS-guided FNA cytology: the learning curve and diagnostic performance beyond sensitivity and specificity. Cytopathology 2007; 18: $143-150$
153 Wahidi MM, Hulett C, Pastis N et al. Learning experience of linear endobronchial ultrasound among pulmonary trainees. Chest 2014; 145 : 574-578

154 Kemp SV, El Batrawy SH, Harrison RN et al. Learning curves for endobronchial ultrasound using cusum analysis. Thorax 2010; 65: 534 538

155 Medford AR. Learning curve for endobronchial ultrasound-guided transbronchial needle aspiration. Chest 2012; 141: 1643; author reply 1643-1644

156 Fernandez-Villar A, Leiro-Fernandez V, Botana-Rial M et al. The endobronchial ultrasound-guided transbronchial needle biopsy learning curve for mediastinal and hilar lymph node diagnosis. Chest 2012; 141: $278-279$

157 Folch E, Majid A. Point: are >50 supervised procedures required to develop competency in performing endobronchial ultrasound-guided transbronchial needle aspiration for mediastinal staging? Yes. Chest 2013; 143: 888 - 891; discussion 894-885

158 Kinsey CM, Channick CL. Counterpoint: are $>50$ supervised procedures required to develop competency in performing endobronchial ultrasound-guided transbronchial needle aspiration for lung cancer staging? No. Chest 2013; 143: 891 - 893; discussion 893-894

159 Bellinger $C R$, Chatterjee $A B$, Adair $N$ et al. Training in and experience with endobronchial ultrasound. Respiration 2014; 88: $478-483$

160 Stather DR, Chee A, MacEachern P et al. Endobronchial ultrasound learning curve in interventional pulmonary fellows. Respirology 2015; 20: 333 - 339

161 Skov BG, Baandrup U, Jakobsen GK et al. Cytopathologic diagnoses of fine-needle aspirations from endoscopic ultrasound of the mediastinum: reproducibility of the diagnoses and representativeness of aspirates from lymph nodes. Cancer 2007; 111: 234-241

162 Savides TJ, Donohue M, Hunt G et al. EUS-guided FNA diagnostic yield of malignancy in solid pancreatic masses: a benchmark for quality performance measurement. Gastrointest Endosc 2007; 66: 277 - 282

163 Rizk MK, Sawhney MS, Cohen J et al. Quality indicators common to all GI endoscopic procedures. Gastrointest Endosc 2015; 81: 3-16

164 Wiersema MJ, Vilmann P, Giovannini M et al. Endosonography-guided fine-needle aspiration biopsy: diagnostic accuracy and complication assessment. Gastroenterology 1997; 112: 1087-1095

165 Micames CG, McCrory DC, Pavey DA et al. Endoscopic ultrasoundguided fine-needle aspiration for non-small cell lung cancer staging: A systematic review and metaanalysis. Chest 2007; 131: $539-548$

166 Adams K, Shah PL, Edmonds L et al. Test performance of endobronchial ultrasound and transbronchial needle aspiration biopsy for mediastinal staging in patients with lung cancer: systematic review and meta-analysis. Thorax 2009; 64: 757 - 762

$167 \mathrm{Gu} P$, Zhao YZ, Jiang LY et al. Endobronchial ultrasound-guided transbronchial needle aspiration for staging of lung cancer: a systematic review and meta-analysis. Eur J Cancer 2009; 45: 1389-1396

168 Zhang $R$, Ying K, Shi L et al. Combined endobronchial and endoscopic ultrasound-guided fine needle aspiration for mediastinal lymph node staging of lung cancer: a meta-analysis. Eur J Cancer 2013; 49: $1860-1867$

169 Dong X, Qiu X, Liu Q et al. Endobronchial ultrasound-guided transbronchial needle aspiration in the mediastinal staging of non-small cell lung cancer: a meta-analysis. Ann Thorac Surg 2013; 96: 1502 - 1507

170 Dhooria S, Aggarwal AN, Gupta D et al. Utility and Safety of Endoscopic Ultrasound With Bronchoscope-Guided Fine-Needle Aspiration in Mediastinal Lymph Node Sampling: Systematic Review and Meta-Analysis. Respir Care 2015; 60: 1040-1050

171 Peric $R$, Schuurbiers OC, Veselic $M$ et al. Transesophageal endoscopic ultrasound-guided fine-needle aspiration for the mediastinal staging of extrathoracic tumours: a new perspective. Ann Oncol 2010; 21: 1468 - 1471

172 Yang B, Li F, Shi W et al. Endobronchial ultrasound-guided transbronchial needle biopsy for the diagnosis of intrathoracic lymph node metastases from extrathoracic malignancies: a meta-analysis and systematic review. Respirology 2014; 19: 834 -841

173 Mortensen MB, Pless T, Durup J et al. Clinical impact of endoscopic ultrasound-guided fine needle aspiration biopsy in patients with upper gastrointestinal tract malignancies. A prospective study. Endoscopy 2001; 33: 478 - 483

174 Hassan H, Vilmann P, Sharma V. Impact of EUS-guided FNA on management of gastric carcinoma. Gastrointest Endosc 2010; 71: 500-504 
175 Dewitt J, Ghorai S, Kahi C et al. EUS-FNA of recurrent postoperative extraluminal and metastatic malignancy. Gastrointest Endosc 2003; 58: $542-548$

176 Iwashita T, Yasuda I, Doi S et al. Endoscopic ultrasound-guided fineneedle aspiration in patients with lymphadenopathy suspected of recurrent malignancy after curative treatment. J Gastroenterol 2009; 44: $190-196$

177 DeWitt J, Sherman S, Al-Haddad $M$ et al. EUS-guided FNA of local recurrence of pancreatic cancer after surgical resection. Gastrointest Endosc 2010; 72: 1076-1080

178 Ulla-Rocha JL, Vilar-Cao Z, Alvarez-Martinez M et al. Extraparietal or lymphatic late relapse of neoplasms: confirmation by means of EUSFNA key for the treatment. J Gastrointest Cancer 2012; 43: 490 - 495

179 Ashida R, Nakata B, Shigekawa $M$ et al. Gemcitabine sensitivity-related mRNA expression in endoscopic ultrasound-guided fine-needle aspiration biopsy of unresectable pancreatic cancer.J Exp Clin Cancer Res 2009; 28: 83

180 Schuurbiers OC, Looijen-Salamon MG, Ligtenberg MJ et al. A brief retrospective report on the feasibility of epidermal growth factor receptor and KRAS mutation analysis in transesophageal ultrasound- and endobronchial ultrasound-guided fine needle cytological aspirates. J Thorac Oncol 2010; 5: 1664-1667

181 Wakatsuki T, Irisawa A, Terashima $M$ et al. ATP assay-guided chemosensitivity testing for gemcitabine with biopsy specimens obtained from unresectable pancreatic cancer using endoscopic ultrasonography-guided fine-needle aspiration. Int J Clin Oncol 2011; 16: 387-394

182 Ulivi P, Romagnoli M, Chiadini $E$ et al. Assessment of EGFR and K-ras mutations in fixed and fresh specimens from transesophageal ultrasound-guided fine needle aspiration in non-small cell lung cancer patients. Int J Oncol 2012; 41: 147-152

183 Eto K, Kawakami H, Kuwatani M et al. Human equilibrative nucleoside transporter 1 and Notch3 can predict gemcitabine effects in patients with unresectable pancreatic cancer. Br J Cancer 2013; 108: 14881494

184 Stigt JA, tHart NA, Knol AJ et al. Pyrosequencing analysis of EGFR and KRAS mutations in EUS and EBUS-derived cytologic samples of adenocarcinomas of the lung. J Thorac Oncol 2013; 8: $1012-1018$

185 Navina S, McGrath K, Chennat J et al. Adequacy assessment of endoscopic ultrasound-guided, fine-needle aspirations of pancreatic masses for theranostic studies: optimization of current practices is warranted. Arch Pathol Lab Med 2014; 138: 923 - 928

186 van der Heijden EH, Casal RF, Trisolini R et al. Guideline for the acquisition and preparation of conventional and endobronchial ultrasound-guided transbronchial needle aspiration specimens for the diagnosis and molecular testing of patients with known or suspected lung cancer. Respiration 2014; 88: 500-517

187 Gleeson FC, Kipp BR, Kerr SE et al. Kinase genotype analysis of gastric gastrointestinal stromal tumour cytology samples using targeted next-generation sequencing. Clin Gastroenterol Hepatol 2015; 13 : $202-206$

188 Mallery JS, Centeno BA, Hahn PF et al. Pancreatic tissue sampling guided by EUS, CT/US, and surgery: a comparison of sensitivity and specificity. Gastrointest Endosc 2002; 56: 218-224

189 Volmar KE, Vollmer RT, Jowell PS et al. Pancreatic FNA in 1000 cases: a comparison of imaging modalities. Gastrointest Endosc 2005; 61: $854-861$

190 Horwhat JD, Paulson EK, McGrath K et al. A randomized comparison of EUS-guided FNA versus CT or US-guided FNA for the evaluation of pancreatic mass lesions. Gastrointest Endosc 2006; 63: 966-975

191 Okasha HH, Naga MI, Esmat S et al. Endoscopic Ultrasound-Guided Fine Needle Aspiration versus Percutaneous Ultrasound-Guided Fine Needle Aspiration in Diagnosis of Focal Pancreatic Masses. Endosc Ultrasound 2013; 2: 190 - 193

192 Micames C, Jowell PS, White R et al. Lower frequency of peritoneal carcinomatosis in patients with pancreatic cancer diagnosed by EUSguided FNA vs. percutaneous FNA. Gastrointest Endosc 2003; 58: 690-695

193 Chen VK, Arguedas MR, Kilgore ML et al. A cost-minimization analysis of alternative strategies in diagnosing pancreatic cancer. Am J Gastroenterol 2004; 99: 2223-2234

194 Eltoum IA, Alston EA, Roberson J. Trends in pancreatic pathology practice before and after implementation of endoscopic ultrasound-guided fine-needle aspiration: an example of disruptive innovation effect? Arch Pathol Lab Med 2012; 136: 447-453
195 Roy A, Kim M, Hawes R et al. Changing trends in tissue acquisition in malignant pancreatic neoplasms. J Gastroenterol Hepatol 2015, Epub ahead of print

196 Hewitt MJ, McPhail MJ, Possamai L et al. EUS-guided FNA for diagnosis of solid pancreatic neoplasms: a meta-analysis. Gastrointest Endosc 2012; 75: 319-331

197 Chen G, Liu S, Zhao Y et al. Diagnostic accuracy of endoscopic ultrasound-guided fine-needle aspiration for pancreatic cancer: a meta-analysis. Pancreatology 2013; 13: 298 - 304

198 Chen J, Yang R, Lu Y et al. Diagnostic accuracy of endoscopic ultrasound-guided fine-needle aspiration for solid pancreatic lesion: a systematic review. J Cancer Res Clin Oncol 2012; 138: 1433 -1441

199 Puli SR, Bechtold ML, Buxbaum JL et al. How good is endoscopic ultrasound-guided fine-needle aspiration in diagnosing the correct etiology for a solid pancreatic mass?: A meta-analysis and systematic review. Pancreas 2013; 42: 20-26

200 Hebert-Magee S, Bae S, Varadarajulu S et al. The presence of a cytopathologist increases the diagnostic accuracy of endoscopic ultrasoundguided fine needle aspiration cytology for pancreatic adenocarcinoma: a meta-analysis. Cytopathology 2013; 24: 159-171

201 Figueiredo FA, Giovannini M, Monges $G$ et al. Pancreatic endocrine tumours: a large single-center experience. Pancreas 2009; 38: $936-$ 940

202 Pais SA, Al-Haddad M, Mohamadnejad M et al. EUS for pancreatic neuroendocrine tumours: a single-center, 11-year experience. Gastrointest Endosc 2010; 71: 1185-1193

203 Hasegawa T, Yamao K, Hijioka S et al. Evaluation of Ki-67 index in EUS-FNA specimens for the assessment of malignancy risk in pancreatic neuroendocrine tumours. Endoscopy 2014; 46: 32 - 38

204 Larghi A, Capurso G, Carnuccio A et al. Ki-67 grading of nonfunctioning pancreatic neuroendocrine tumours on histologic samples obtained by EUS-guided fine-needle tissue acquisition: a prospective study. Gastrointest Endosc 2012; 76: 570-577

205 Unno J, Kanno A, Masamune A et al. The usefulness of endoscopic ultrasound-guided fine-needle aspiration for the diagnosis of pancreatic neuroendocrine tumours based on the World Health Organization classification. Scand J Gastroenterol 2014; 49: 1367-1374

206 Fritscher-Ravens A, Sriram PV, Krause C et al. Detection of pancreatic metastases by EUS-guided fine-needle aspiration. Gastrointest Endosc 2001; 53: $65-70$

207 Jani N, Dewitt J, Eloubeidi M et al. Endoscopic ultrasound-guided fineneedle aspiration for diagnosis of solid pseudopapillary tumours of the pancreas: a multicenter experience. Endoscopy 2008; 40: $200-$ 203

208 Mortenson MM, Katz MH, Tamm EP et al. Current diagnosis and management of unusual pancreatic tumours. Am J Surg 2008; 196: $100-$ 113

209 Mizuno N, Bhatia V, Hosoda W et al. Histological diagnosis of autoimmune pancreatitis using EUS-guided trucut biopsy: a comparison study with EUS-FNA. J Gastroenterol 2009; 44: 742 - 750

210 Imaoka $\mathrm{H}$, Yamao K, Bhatia $V$ et al. Rare pancreatic neoplasms: the utility of endoscopic ultrasound-guided fine-needle aspiration-a large single center study. J Gastroenterol 2009; 44: 146-153

211 Khashab M, Mokadem M, DeWitt J et al. Endoscopic ultrasound-guided fine-needle aspiration with or without flow cytometry for the diagnosis of primary pancreatic lymphoma - a case series. Endoscopy 2010; 42: 228-231

212 Gilbert CM, Monaco SE, Cooper ST et al. Endoscopic ultrasound-guided fine-needle aspiration of metastases to the pancreas: A study of 25 cases. Cytojournal 2011; 8: 7

213 Hijioka S, Matsuo K, Mizuno N et al. Role of endoscopic ultrasound and endoscopic ultrasound-guided fine-needle aspiration in diagnosing metastasis to the pancreas: a tertiary center experience. Pancreatology 2011; 11: 390-398

214 Ardengh JC, Lopes CV, Kemp R et al. Accuracy of endoscopic ultrasound-guided fine-needle aspiration in the suspicion of pancreatic metastases. BMC Gastroenterol 2013; 13: 63

215 El Hajj II, LeBlanc JK, Sherman S et al. Endoscopic ultrasound-guided biopsy of pancreatic metastases: a large single-center experience. Pancreas 2013; 42: 524-530

216 Iwashita T, Yasuda I, Doi S et al. Use of samples from endoscopic ultrasound-guided 19-gauge fine-needle aspiration in diagnosis of autoimmune pancreatitis. Clin Gastroenterol Hepatol 2012; 10: 316-322

217 Kanno A, Ishida K, Hamada $S$ et al. Diagnosis of autoimmune pancreatitis by EUS-FNA by using a 22-gauge needle based on the Interna- 
tional Consensus Diagnostic Criteria. Gastrointest Endosc 2012; 76: $594-602$

218 Johnson EA, Benson ME, Guda N et al. Differentiating primary pancreatic lymphoma from adenocarcinoma using endoscopic ultrasound characteristics and flow cytometry: A case-control study. Endosc Ultrasound 2014; 3: $221-225$

219 Ramesh J, Hebert-Magee S, Kim H et al. Frequency of occurrence and characteristics of primary pancreatic lymphoma during endoscopic ultrasound guided fine needle aspiration: a retrospective study. Dig Liver Dis 2014; 46: 470-473

220 Law JK, Stoita A, Wever W et al. Endoscopic ultrasound-guided fine needle aspiration improves the pre-operative diagnostic yield of solid-pseudopapillary neoplasm of the pancreas: an international multicenter case series (with video). Surg Endosc 2014; 28: 2592 - 2598

221 Eloubeidi MA, Tamhane AR, Buxbaum JL. Unusual, metastatic, or neuroendocrine tumour of the pancreas: a diagnosis with endoscopic ultrasound-guided fine-needle aspiration and immunohistochemistry. Saudi J Gastroenterol 2012; 18: 99-105

222 Kosmahl M, Pauser U, Peters K et al. Cystic neoplasms of the pancreas and tumour-like lesions with cystic features: a review of 418 cases and a classification proposal. Virchows Arch 2004; 445: 168-178

223 Basturk O, Coban I, Adsay NV. Pancreatic cysts: pathologic classification, differential diagnosis, and clinical implications. Arch Pathol Lab Med 2009; 133: $423-438$

224 Nagata N, Kawazoe A, Mishima S et al. Development of Pancreatic Cancer, Disease-specific Mortality, and All-Cause Mortality in Patients with Nonresected IPMNs: A Long-term Cohort Study. Radiology 2015, Epub ahead of print

225 Tanaka M, Fernandez-del Castillo C, Adsay V et al. International consensus guidelines 2012 for the management of IPMN and MCN of the pancreas. Pancreatology 2012; 12: $183-197$

226 Buscarini E, Pezzilli R, Cannizzaro R. Italian Association of Hospital G, Endoscopists, Italian Association for the Study of the P. et al. Italian consensus guidelines for the diagnostic work-up and follow-up of cystic pancreatic neoplasms. Dig Liver Dis 2014; 46: 479-493

227 Del Chiaro M, Verbeke C, Salvia R et al. European experts consensus statement on cystic tumours of the pancreas. Dig Liver Dis 2013; 45: $703-711$

228 Jenssen C, Kahl S. Management of incidental pancreatic cystic lesions. Viszeralmedizin 2015; 31: 14-24

229 Wu RI, Yoon WJ, Brugge WR et al. Endoscopic ultrasound-guided fine needle aspiration (EUS-FNA) contributes to a triple-negative test in preoperative screening of pancreatic cysts. Cancer Cytopathol 2014; 122: $412-419$

230 Das A, Ngamruengphong S, Nagendra S et al. Asymptomatic pancreatic cystic neoplasm: a cost-effectiveness analysis of different strategies of management. Gastrointest Endosc 2009; 70: 690-699 e696

231 Brugge WR, Lewandrowski K, Lee-Lewandrowski $E$ et al. Diagnosis of pancreatic cystic neoplasms: a report of the cooperative pancreatic cyst study. Gastroenterology 2004; 126: 1330-1336

232 van der Waaij LA, van Dullemen HM, Porte RJ. Cyst fluid analysis in the differential diagnosis of pancreatic cystic lesions: a pooled analysis. Gastrointest Endosc 2005; 62: 383-389

233 de Jong $K$, Poley JW, van Hooft JE et al. Endoscopic ultrasound-guided fine-needle aspiration of pancreatic cystic lesions provides inadequate material for cytology and laboratory analysis: initial results from a prospective study. Endoscopy 2011; 43: 585-590

234 Thornton GD, McPhail MJ, Nayagam S et al. Endoscopic ultrasound guided fine needle aspiration for the diagnosis of pancreatic cystic neoplasms: a meta-analysis. Pancreatology 2013; 13: 48-57

235 Cizginer S, Turner BG, Bilge AR et al. Cyst fluid carcinoembryonic antigen is an accurate diagnostic marker of pancreatic mucinous cysts. Pancreas 2011; 40: 1024-1028

236 Oh HC, Kang H, Brugge WR. Cyst Fluid Amylase and CEA Levels in the Differential Diagnosis of Pancreatic Cysts: A Single-Center Experience with Histologically Proven Cysts. Dig Dis Sci 2014; 59: 3111 - 3116

237 Nagashio Y, Hijioka S, Mizuno $N$ et al. Combination of cyst fluid CEA and CA 125 is an accurate diagnostic tool for differentiating mucinous cystic neoplasms from intraductal papillary mucinous neoplasms. Pancreatology 2014; 14: 503-509

238 Gaddam S, Ge PS, Keach JW et al. Suboptimal accuracy of carcinoembryonic antigen in differentiation of mucinous and nonmucinous pancreatic cysts: results of a large multicenter study. Gastrointest Endosc 2015, Epub ahead of print
239 Thosani N, Thosani S, Qiao W et al. Role of EUS-FNA-based cytology in the diagnosis of mucinous pancreatic cystic lesions: a systematic review and meta-analysis. Dig Dis Sci 2010; 55: 2756-2766

240 Suzuki R, Thosani N, Annangi S et al. Diagnostic yield of EUS-FNAbased cytology distinguishing malignant and benign IPMNs: a systematic review and meta-analysis. Pancreatology 2014; 14: 380-384

241 Wang QX, Xiao J, Orange $M$ et al. EUS-Guided FNA for Diagnosis of Pancreatic Cystic Lesions: a Meta-Analysis. Cell Physiol Biochem 2015; 36: 1197-1209

242 Pitman MB, Michaels PJ, Deshpande V et al. Cytological and cyst fluid analysis of small $(<$ or $=3 \mathrm{~cm}$ ) branch duct intraductal papillary mucinous neoplasms adds value to patient management decisions. Pancreatology 2008; 8: 277-284

243 Pitman MB, Centeno BA, Daglilar ES et al. Cytological criteria of highgrade epithelial atypia in the cyst fluid of pancreatic intraductal papillary mucinous neoplasms. Cancer Cytopathol 2014; 122: 40-47

244 Pitman MB, Centeno BA, Genevay M et al. Grading epithelial atypia in endoscopic ultrasound-guided fine-needle aspiration of intraductal papillary mucinous neoplasms: an international interobserver concordance study. Cancer Cytopathol 2013; 121: 729-736

245 Sigel CS, Edelweiss M, Tong LC et al. Low interobserver agreement in cytology grading of mucinous pancreatic neoplasms. Cancer Cytopathol 2015; $123: 40-50$

246 Khalid A, Zahid M, Finkelstein SD et al. Pancreatic cyst fluid DNA analysis in evaluating pancreatic cysts: a report of the PANDA study. Gastrointest Endosc 2009; 69: 1095 - 1102

247 Rockacy MJ, Zahid M, McGrath KM et al. Association between KRAS mutation, detected in pancreatic cyst fluid, and long-term outcomes of patients. Clin Gastroenterol Hepatol 2013; 11: 425-429

248 Al-Haddad M, DeWitt J, Sherman S et al. Performance characteristics of molecular (DNA) analysis for the diagnosis of mucinous pancreatic cysts. Gastrointest Endosc 2014; 79: 79-87

249 Al-Haddad MA, Kowalski T, Siddiqui A et al. Integrated molecular pathology accurately determines the malignant potential of pancreatic cysts. Endoscopy 2015; 47: $136-142$

250 Singhi AD, Nikiforova MN, Fasanella KE et al. Preoperative GNAS and KRAS testing in the diagnosis of pancreatic mucinous cysts. Clin Cancer Res 2014; 20: 4381-4389

251 Konda VJ, Meining A, Jamil LH et al. A pilot study of in vivo identification of pancreatic cystic neoplasms with needle-based confocal laser endomicroscopy under endosonographic guidance. Endoscopy 2013; 45: $1006-1013$

252 Napoleon B, Lemaistre AI, Pujol B et al. A novel approach to the diagnosis of pancreatic serous cystadenoma: needle-based confocal laser endomicroscopy. Endoscopy 2015; 47: 26-32

253 Rockacy M, Khalid A. Update on pancreatic cyst fluid analysis. Ann Gastroenterol 2013; 26: $122-127$

254 Gillis A, Cipollone I, Cousins G et al. Does EUS-FNA molecular analysis carry additional value when compared to cytology in the diagnosis of pancreatic cystic neoplasm? A systematic review. HPB (Oxford) 2015; 17: $377-386$

255 Meara RS, Jhala D, Eloubeidi MA et al. Endoscopic ultrasound-guided FNA biopsy of bile duct and gallbladder: analysis of 53 cases. Cytopathology 2006; 17: $42-49$

256 Hijioka S, Mekky MA, Bhatia V et al. Can EUS-guided FNA distinguish between gallbladder cancer and xanthogranulomatous cholecystitis? Gastrointest Endosc 2010; 72: 622 -627

257 Hijioka S, Hara K, Mizuno $N$ et al. Diagnostic yield of endoscopic retrograde cholangiography and of EUS-guided fine needle aspiration sampling in gallbladder carcinomas. J Hepatobiliary Pancreat Sci 2012; 19: 650-655

$258 \mathrm{Kim}$ HJ, Lee SK, Jang JW et al. Diagnostic role of endoscopic ultrasonography-guided fine needle aspiration of gallbladder lesions. Hepatogastroenterology 2012; 59: 1691 - 1695

259 Ogura T, Kurisu Y, Masuda D et al. Can endoscopic ultrasound-guided fine needle aspiration offer clinical benefit for thick-walled gallbladders? Dig Dis Sci 2014; 59: 1917-1924

260 Fritscher-Ravens A, Broering DC, Sriram PV et al. EUS-guided fine-needle aspiration cytodiagnosis of hilar cholangiocarcinoma: a case series. Gastrointest Endosc 2000; 52: 534-540

261 Fritscher-Ravens A, Broering DC, Knoefel WT et al. EUS-guided fineneedle aspiration of suspected hilar cholangiocarcinoma in potentially operable patients with negative brush cytology. Am J Gastroenterol 2004; 99: $45-51$ 
262 Rosch T, Hofrichter K, Frimberger E et al. ERCP or EUS for tissue diagnosis of biliary strictures? A prospective comparative study. Gastrointest Endosc 2004; 60: 390-396

263 Byrne MF, Gerke H, Mitchell RM et al. Yield of endoscopic ultrasoundguided fine-needle aspiration of bile duct lesions. Endoscopy 2004; 36: $715-719$

264 Lee JH, Salem R, Aslanian H et al. Endoscopic ultrasound and fine-needle aspiration of unexplained bile duct strictures. Am J Gastroenterol 2004; 99: 1069-1073

265 Eloubeidi MA, Chen VK, Jhala NC et al. Endoscopic ultrasound-guided fine needle aspiration biopsy of suspected cholangiocarcinoma. Clin Gastroenterol Hepatol 2004; 2: 209-213

266 DeWitt J, Misra VL, Leblanc JK et al. EUS-guided FNA of proximal biliary strictures after negative ERCP brush cytology results. Gastrointest Endosc 2006; 64: 325-333

267 Ohshima Y, Yasuda I, Kawakami H et al. EUS-FNA for suspected malignant biliary strictures after negative endoscopic transpapillary brush cytology and forceps biopsy. J Gastroenterol 2011; 46: 921 -928

268 Nayar MK, Manas DM, Wadehra $V$ et al. Role of EUS/EUS-guided FNA in the management of proximal biliary strictures. Hepatogastroenterology 2011; 58: $1862-1865$

269 Mohamadnejad M, DeWitt JM, Sherman S et al. Role of EUS for preoperative evaluation of cholangiocarcinoma: a large single-center experience. Gastrointest Endosc 2011; 73: 71 - 78

270 Tummala P, Munigala S, Eloubeidi MA et al. Patients with obstructive jaundice and biliary stricture $+/$ - mass lesion on imaging: prevalence of malignancy and potential role of EUS-FNA. J Clin Gastroenterol 2013; 47: $532-537$

271 Weilert F, Bhat YM, Binmoeller KF et al. EUS-FNA is superior to ERCPbased tissue sampling in suspected malignant biliary obstruction: results of a prospective, single-blind, comparative study. Gastrointest Endosc 2014; 80: $97-104$

272 Ogura T, Hara K, Hijioka S et al. Can Endoscopic Ultrasound-Guided Fine Needle Aspiration Offer Clinical Benefit for Tumours of the Ampulla of Vater? - An Initial Study. Endoscopic Ultrasound 2012; 1: 84-89

273 Navaneethan $U$, Njei B, Venkatesh PG et al. Endoscopic ultrasound in the diagnosis of cholangiocarcinoma as the etiology of biliary strictures: a systematic review and meta-analysis. Gastroenterol Rep (Oxf) 2015; 3: 209-215

274 Wu LM, Jiang XX, Gu HY et al. Endoscopic ultrasound-guided fineneedle aspiration biopsy in the evaluation of bile duct strictures and gallbladder masses: a systematic review and meta-analysis. Eur J Gastroenterol Hepatol 2011; 23: 113-120

275 Gleeson FC, Rajan E, Levy MJ et al. EUS-guided FNA of regional lymph nodes in patients with unresectable hilar cholangiocarcinoma. Gastrointest Endosc 2008; 67: 438-443

276 Polkowski M. Endoscopic ultrasound and endoscopic ultrasoundguided fine-needle biopsy for the diagnosis of malignant submucosal tumours. Endoscopy 2005; 37: 635-645

277 Jenssen C, Dietrich CF. Endoscopic ultrasound of gastrointestinal subepithelial lesions. Ultraschall in Med 2008; 29: 236-256; quiz 257-264

278 Eckardt AJ, Jenssen C. Current EUS-guided Approach to the Incidental Subepithelial Lesion: Optimal or Optional? Ann Gastroenterol 2015; 28: $160-172$

279 Lee JH, Choi KD, Kim MY et al. Clinical impact of EUS-guided Trucut biopsy results on decision making for patients with gastric subepithelial tumours $>/=2 \mathrm{~cm}$ in diameter. Gastrointest Endosc 2011; 74: $1010-1018$

280 Larghi A, Fuccio L, Chiarello G et al. Fine-needle tissue acquisition from subepithelial lesions using a forward-viewing linear echoendoscope. Endoscopy 2014; 46: 39-45

281 Ando N, Goto H, Niwa $Y$ et al. The diagnosis of GI stromal tumours with EUS-guided fine needle aspiration with immunohistochemical analysis. Gastrointest Endosc 2002; 55: 37-43

282 Okubo K, Yamao K, Nakamura T et al. Endoscopic ultrasound-guided fine-needle aspiration biopsy for the diagnosis of gastrointestinal stromal tumours in the stomach. J Gastroenterol 2004; 39: 747-753

283 Akahoshi K, Sumida Y, Matsui $N$ et al. Preoperative diagnosis of gastrointestinal stromal tumour by endoscopic ultrasound-guided fine needle aspiration. World J Gastroenterol 2007; 13: 2077-2082

284 Sepe PS, Moparty B, Pitman MB et al. EUS-guided FNA for the diagnosis of GI stromal cell tumours: sensitivity and cytologic yield. Gastrointest Endosc 2009; 70: 254-261
285 Yoshida S, Yamashita K, Yokozawa M et al. Diagnostic findings of ultrasound-guided fine-needle aspiration cytology for gastrointestinal stromal tumours: proposal of a combined cytology with newly defined features and histology diagnosis. Pathol Int 2009; 59: 712 - 719

286 Philipper M, Hollerbach S, Gabbert HE et al. Prospective comparison of endoscopic ultrasound-guided fine-needle aspiration and surgical histology in upper gastrointestinal submucosal tumours. Endoscopy 2010; 42: 300-305

287 DeWitt J, Emerson RE, Sherman S et al. Endoscopic ultrasound-guided Trucut biopsy of gastrointestinal mesenchymal tumour. Surg Endosc 2011; 25: $2192-2202$

288 Fernandez-Esparrach $G$, Sendino O, Sole $M$ et al. Endoscopic ultrasound-guided fine-needle aspiration and trucut biopsy in the diagnosis of gastric stromal tumours: a randomized crossover study. Endoscopy 2010; 42: 292-299

289 Watson RR, Binmoeller KF, Hamerski CM et al. Yield and performance characteristics of endoscopic ultrasound-guided fine needle aspiration for diagnosing upper GI tract stromal tumours. Dig Dis Sci 2011; 56: $1757-1762$

290 Eckardt AJ, Adler A, Gomes EM et al. Endosonographic large-bore biopsy of gastric subepithelial tumours: a prospective multicenter study. Eur J Gastroenterol Hepatol 2012; 24: 1135 -1144

291 Rong L, Kida M, Yamauchi $\mathrm{H}$ et al. Factors affecting the diagnostic accuracy of endoscopic ultrasonography-guided fine-needle aspiration (EUS-FNA) for upper gastrointestinal submucosal or extraluminal solid mass lesions. Dig Endosc 2012; 24: 358 - 363

292 Caglar E, Hatemi I, Atasoy D et al. Concordance of endoscopic ultrasonography-guided fine needle aspiration diagnosis with the final diagnosis in subepithelial lesions. Clin Endosc 2013; 46: 379-383

293 Akahoshi K, Oya M, Koga T et al. Clinical usefulness of endoscopic ultrasound-guided fine needle aspiration for gastric subepithelial lesions smaller than $2 \mathrm{~cm}$. J Gastrointestin Liver Dis 2014; 23: 405-412

$294 \mathrm{Kim}$ GH, Cho YK, Kim EY et al. Comparison of 22-gauge aspiration needle with 22-gauge biopsy needle in endoscopic ultrasonographyguided subepithelial tumour sampling. Scand J Gastroenterol 2014; 49: $347-354$

295 Polkowski M, Gerke W, Jarosz D et al. Diagnostic yield and safety of endoscopic ultrasound-guided trucut [corrected] biopsy in patients with gastric submucosal tumours: a prospective study. Endoscopy 2009; 41: 329-334

296 Matsuzaki I, Miyahara R, Hirooka Y et al. Forward-viewing versus oblique-viewing echoendoscopes in the diagnosis of upper GI subepithelial lesions with EUS-guided FNA: a prospective, randomized, crossover study. Gastrointest Endosc 2015; 82: 287-295

297 Gomes AL, Bardales RH, Milanezi F et al. Molecular analysis of c-Kit and PDGFRA in GISTs diagnosed by EUS. Am J Clin Pathol 2007; 127: 89-96

298 Kobara H, Mori H, Rafiq K et al. Analysis of the amount of tissue sample necessary for mitotic count and Ki-67 index in gastrointestinal stromal tumour sampling. Oncol Rep 2015; 33: 215-222

299 Varadarajulu S, Hoffman BJ, Hawes RH et al. EUS-guided FNA of lung masses adjacent to or abutting the esophagus after unrevealing CTguided biopsy or bronchoscopy. Gastrointest Endosc 2004; 60: 293 297

300 Annema JT, Veselic M, Rabe KF. EUS-guided FNA of centrally located lung tumours following a non-diagnostic bronchoscopy. Lung Cancer 2005; 48: 357-361; discussion 363-354

301 Hernandez A, Kahaleh M, Olazagasti J et al. EUS-FNA as the initial diagnostic modality in centrally located primary lung cancers. J Clin Gastroenterol 2007; 41: 657-660

302 Tournoy KG, Rintoul RC, van Meerbeeck JP et al. EBUS-TBNA for the diagnosis of central parenchymal lung lesions not visible at routine bronchoscopy. Lung Cancer 2009; 63: 45-49

303 Lee JE, Kim HY, Lim KY et al. Endobronchial ultrasound-guided transbronchial needle aspiration in the diagnosis of lung cancer. Lung Cancer 2010; 70: 51-56

304 Bugalho A, Ferreira D, Eberhardt R et al. Diagnostic value of endobronchial and endoscopic ultrasound-guided fine needle aspiration for accessible lung cancer lesions after non-diagnostic conventional techniques: a prospective study. BMC Cancer 2013; 13: 130

305 Vazquez-Sequeiros E, Levy MJ, Van Domselaar M et al. Diagnostic yield and safety of endoscopic ultrasound guided fine needle aspiration of central mediastinal lung masses. Diagn Ther Endosc 2013; 2013: 150492 
306 Verma A, Jeon K, Koh WJ et al. Endobronchial ultrasound-guided transbronchial needle aspiration for the diagnosis of central lung parenchymal lesions. Yonsei Med J 2013; 54: 672 -678

307 Navani N, Brown JM, Nankivell M et al. Suitability of endobronchial ultrasound-guided transbronchial needle aspiration specimens for subtyping and genotyping of non-small cell lung cancer: a multicenter study of 774 patients. Am J Respir Crit Care Med 2012; 185: $1316-1322$

308 Esterbrook G, Anathhanam S, Plant PK. Adequacy of endobronchial ultrasound transbronchial needle aspiration samples in the subtyping of non-small cell lung cancer. Lung Cancer 2013; 80: 30-34

309 Yarmus L, Akulian J, Gilbert C et al. Optimizing endobronchial ultrasound for molecular analysis. How many passes are needed? Ann Am Thorac Soc 2013; 10: 636-643

310 Tournoy KG, Carprieaux M, Deschepper E et al. Are EUS-FNA and EBUSTBNA specimens reliable for subtyping non-small cell lung cancer? Lung Cancer 2012; 76: 46 - 50

311 Santis G, Angell R, Nickless G et al. Screening for EGFR and KRAS mutations in endobronchial ultrasound derived transbronchial needle aspirates in non-small cell lung cancer using COLD-PCR. PLoS One 2011; 6: e25191

312 Neat MJ, Foot NJ, Hicks A et al. ALK rearrangements in EBUS-derived transbronchial needle aspiration cytology in lung cancer. Cytopathology 2013; 24: $356-364$

313 Jurado J, Saqi A, Maxfield $R$ et al. The efficacy of EBUS-guided transbronchial needle aspiration for molecular testing in lung adenocarcinoma. Ann Thorac Surg 2013; 96: 1196-1202

314 Catalano MF, Sivak MV Jr, Rice T et al. Endosonographic features predictive of lymph node metastasis. Gastrointest Endosc 1994; 40: $442-446$

315 Bhutani MS, Hawes RH, Hoffman BJ. A comparison of the accuracy of echo features during endoscopic ultrasound (EUS) and EUS-guided fine-needle aspiration for diagnosis of malignant lymph node invasion. Gastrointest Endosc 1997; 45: 474-479

316 Faige DO. EUS in patients with benign and malignant lymphadenopathy. Gastrointest Endosc 2001; 53: 593-598

317 Chen VK, Eloubeidi MA. Endoscopic ultrasound-guided fine needle aspiration is superior to lymph node echofeatures: a prospective evaluation of mediastinal and peri-intestinal lymphadenopathy. Am J Gastroenterol 2004; 99: 628-633

318 Jamil LH, Kashani A, Scimeca D et al. Can endoscopic ultrasound distinguish between mediastinal benign lymph nodes and those involved by sarcoidosis, lymphoma, or metastasis? Dig Dis Sci 2014; 59: $2191-2198$

319 Puli SR, Batapati Krishna Reddy J, Bechtold ML et al. Endoscopic ultrasound: it's accuracy in evaluating mediastinal lymphadenopathy? A meta-analysis and systematic review. World J Gastroenterol 2008; 14: $3028-3037$

320 Schmulewitz N, Wildi SM, Varadarajulu S et al. Accuracy of EUS criteria and primary tumour site for identification of mediastinal lymph node metastasis from non-small-cell lung cancer. Gastrointest Endosc 2004; 59: 205-212

321 Gill KR, Ghabril MS, Jamil LH et al. Endosonographic features predictive of malignancy in mediastinal lymph nodes in patients with lung cancer. Gastrointest Endosc 2010; 72: 265-271

322 Fujiwara T, Yasufuku K, Nakajima T et al. The utility of sonographic features during endobronchial ultrasound-guided transbronchial needle aspiration for lymph node staging in patients with lung cancer: a standard endobronchial ultrasound image classification system. Chest 2010; 138: 641 -647

323 Luz LP, Moreira DM, Khan M et al. Predictors of malignancy in EUSguided FNA for mediastinal lymphadenopathy in patients without history of lung cancer. Ann Thorac Med 2011; 6: 126-130

324 Rana SS, Bhasin DK, Srinivasan $R$ et al. Endoscopic ultrasound (EUS) features of mediastinal tubercular lymphadenopathy. Hepatogastroenterology 2011; 58: 819-823

$325 \mathrm{Wu}$ M, Chen $\mathrm{H}$, Zheng $\mathrm{X}$ et al. Evaluation of a scoring system for predicting lymph node malignancy in ultrasound guided fine needle aspiration practice. Diagn Cytopathol 2013; 41: 1100-1106

326 Dhooria S, Agarwal R, Aggarwal AN et al. Differentiating tuberculosis from sarcoidosis by sonographic characteristics of lymph nodes on endobronchial ultrasonography: a study of 165 patients. J Thorac Cardiovasc Surg 2014; 148: $662-667$
327 Wang L, Wu W, Hu Y et al. Sonographic Features of Endobronchial Ultrasonography Predict Intrathoracic Lymph Node Metastasis in Lung Cancer Patients. Ann Thorac Surg 2015, Epub ahead of print

328 Fritscher-Ravens A, Sriram PV, Bobrowski C et al. Mediastinal lymphadenopathy in patients with or without previous malignancy: EUSFNA-based differential cytodiagnosis in 153 patients. Am J Gastroenterol 2000; 95: 2278 - 2284

329 Ribeiro A, Vazquez-Sequeiros E, Wiersema LM et al. EUS-guided fineneedle aspiration combined with flow cytometry and immunocytochemistry in the diagnosis of lymphoma. Gastrointest Endosc 2001; 53: $485-491$

330 Catalano MF, Nayar R, Gress F et al. EUS-guided fine needle aspiration in mediastinal lymphadenopathy of unknown etiology. Gastrointest Endosc 2002; 55: $863-869$

331 Stelow EB, Lai R, Bardales RH et al. Endoscopic ultrasound-guided fine-needle aspiration of lymph nodes: the Hennepin County Medical Center experience. Diagn Cytopathol 2004; 30: 301 - 306

332 Yasuda I, Tsurumi H, Omar S et al. Endoscopic ultrasound-guided fineneedle aspiration biopsy for lymphadenopathy of unknown origin Endoscopy 2006; 38: 919-924

333 Krishna NB, Gardner L, Collins BT et al. Periportal lymphadenopathy in patients without identifiable pancreatobiliary or hepatic malignancy. Clin Gastroenterol Hepatol 2006; 4: 1373-1377

334 Nakahara $O$, Yamao $K$, Bhatia $V$ et al. Usefulness of endoscopic ultrasound-guided fine needle aspiration (EUS-FNA) for undiagnosed intra-abdominal lymphadenopathy. J Gastroenterol 2009; 44: 562 567

335 Ardengh JC, Bammann RH, Giovani M et al. Endoscopic ultrasoundguided biopsies for mediastinal lesions and lymph node diagnosis and staging. Clinics (Sao Paulo) 2011; 66: 1579-1583

336 Dhir V, Mathew P, Bhandari S et al. Endosonography-guided fine needle aspiration cytology of intra-abdominal lymph nodes with unknown primary in a tuberculosis endemic region. J Gastroenterol Hepatol 2011; 26: $1721-1724$

337 Navani N, Nankivell M, Woolhouse I et al. Endobronchial ultrasoundguided transbronchial needle aspiration for the diagnosis of intrathoracic lymphadenopathy in patients with extrathoracic malignancy: a multicenter study. J Thorac Oncol 2011; 6: 1505-1509

338 Navani N, Lawrence DR, Kolvekar S et al. Endobronchial ultrasoundguided transbronchial needle aspiration prevents mediastinoscopies in the diagnosis of isolated mediastinal lymphadenopathy: a prospective trial. Am J Respir Crit Care Med 2012; 186: 255-260

339 Chandra S, Nehra M, Agarwal D et al. Diagnostic accuracy of endobronchial ultrasound-guided transbronchial needle biopsy in mediastinal lymphadenopathy: a systematic review and meta-analysis. Respir Care 2012; 57: 384-391

340 Eloubeidi MA, Khan AS, Luz LP et al. Combined use of EUS-guided FNA and immunocytochemical stains discloses metastatic and unusual diseases in the evaluation of mediastinal lymphadenopathy of unknown etiology. Ann Thorac Med 2012; 7: 84-91

341 Korenblit J, Anantharaman A, Loren DE et al. The role of endoscopic ultrasound-guided fine needle aspiration (eus-fna) for the diagnosis of intra-abdominal lymphadenopathy of unknown origin. J Interv Gastroenterol 2012; 2: $172-176$

342 Nunez AL, Jhala NC, Carroll AJ et al. Endoscopic ultrasound and endobronchial ultrasound-guided fine-needle aspiration of deep-seated lymphadenopathy: Analysis of 1338 cases. Cytojournal 2012; 9: 14

343 Coe A, Conway J, Evans J et al. The yield of EUS-FNA in undiagnosed upper abdominal adenopathy is very high. J Clin Ultrasound 2013; 41: $210-213$

344 Moonim MT, Breen R, Fields PA et al. Diagnosis and subtyping of de novo and relapsed mediastinal lymphomas by endobronchial ultrasound needle aspiration. Am J Respir Crit Care Med 2013; 188: $1216-1223$

$345 \mathrm{Kim}$ TH, Choi KH, Song HS et al. Histology combined with cytology by endoscopic ultrasound-guided fine needle aspiration for the diagnosis of solid pancreatic mass and intra-abdominal lymphadenopathy. Gut Liver 2013; 7: $605-610$

346 Mehmood S, Loya A, Yusuf MA. Clinical utility of endoscopic ultrasound-guided fine-needle aspiration in the diagnosis of mediastinal and intra-abdominal lymphadenopathy. Acta Cytol 2013; 57: 436 442

347 Mehmood S, Jahan A, Loya A et al. Onsite cytopathology evaluation and ancillary studies beneficial in EUS-FNA of pancreatic, mediastin- 
al, intra-abdominal, and submucosal lesions. Diagn Cytopathol 2015; 43: $278-286$

348 Zhu T, Zhang X, Xu J et al. Endobronchial ultrasound guided-transbronchial needle aspiration vs. conventional transbronchial needle aspiration in the diagnosis of mediastinal masses: A meta-analysis. Mol Clin Oncol 2014; 2: 151 - 155

349 Song HJ, Park YS, Seo DW et al. Diagnosis of mediastinal tuberculosis by using EUS-guided needle sampling in a geographic region with an intermediate tuberculosis burden. Gastrointest Endosc 2010; 71: $1307-1313$

350 Gauchotte G, Vignaud JM, Menard O et al. A combination of smears and cell block preparations provides high diagnostic accuracy for endobronchial ultrasound-guided transbronchial needle aspiration. Virchows Arch 2012; 461: 505-512

351 Ko HM, da Cunha Santos G, Darling G et al. Diagnosis and subclassification of lymphomas and non-neoplastic lesions involving mediastinal lymph nodes using endobronchial ultrasound-guided transbronchial needle aspiration. Diagn Cytopathol 2013; 41: 1023-1030

352 Sun J, Teng J, Yang $H$ et al. Endobronchial ultrasound-guided transbronchial needle aspiration in diagnosing intrathoracic tuberculosis. Ann Thorac Surg 2013; 96: 2021 - 2027

353 Toth JW, Zubelevitskiy K, Strow JA et al. Specimen processing techniques for endobronchial ultrasound-guided transbronchial needle aspiration. Ann Thorac Surg 2013; 95: 976-981

354 Loya A, Nadeem M, YusufMA. Use of ancillary techniques in improving the yield of samples obtained at endoscopic ultrasound-guided fine needle aspiration of thoracic and abdominal lymph nodes. Acta Cytol 2014; 58: $192-197$

355 Dhasmana DJ, Ross C, Bradley CJ et al. Performance of Xpert MTB/RIF in the diagnosis of tuberculous mediastinal lymphadenopathy by endobronchial ultrasound. Ann Am Thorac Soc 2014; 11: 392 - 396

356 Lourido-Cebreiro T, Leiro-Fernandez V, Tardio-Baiges A et al. The contribution of cell blocks in the diagnosis of mediastinal masses and hilar adenopathy samples from echobronchoscopy. Arch Bronconeumol 2014; 50: $267-271$

357 Nieuwoudt M, Lameris $R$, Corcoran C et al. Polymerase chain reaction amplifying mycobacterial DNA from aspirates obtained by endoscopic ultrasound allows accurate diagnosis of mycobacterial disease in HIV-positive patients with abdominal lymphadenopathy. Ultrasound Med Biol 2014; 40: 2031 -2038

358 VanderLaan PA, Wang HH, Majid A et al. Endobronchial ultrasoundguided transbronchial needle aspiration (EBUS-TBNA): an overview and update for the cytopathologist. Cancer Cytopathol 2014; 122 : $561-576$

359 Mehra M, Tamhane A, Eloubeidi MA. EUS-guided FNA combined with flow cytometry in the diagnoses of suspected or recurrent intrathoracic or retroperitoneal lymphoma. Gastrointest Endosc 2005; 62: 508-513

360 Pugh JL, Jhala NC, Eloubeidi MA et al. Diagnosis of deep-seated lymphoma and leukemia by endoscopic ultrasound-guided fine-needle aspiration biopsy. Am J Clin Pathol 2006; 125: 703-709

361 Yasuda I, Goto N, Tsurumi H et al. Endoscopic ultrasound-guided fine needle aspiration biopsy for diagnosis of lymphoproliferative disorders: feasibility of immunohistological, flow cytometric, and cytogenetic assessments. Am J Gastroenterol 2012; 107: 397-404

362 Ribeiro A, Pereira D, Escalon MP et al. EUS-guided biopsy for the diagnosis and classification of lymphoma. Gastrointest Endosc 2010; 71: $851-855$

363 Eloubeidi MA, Varadarajulu S, Eltoum I et al. Transgastric endoscopic ultrasound-guided fine-needle aspiration biopsy and flow cytometry of suspected lymphoma of the spleen. Endoscopy 2006; 38: 617-620

364 Al-Haddad M, Savabi MS, Sherman S et al. Role of endoscopic ultrasound-guided fine-needle aspiration with flow cytometry to diagnose lymphoma: a single center experience. J Gastroenterol Hepatol 2009; 24: 1826-1833

365 Talebian-Yazdi M, von Bartheld B, Waaijenborg $F$ et al. Endosonography for the diagnosis of malignant lymphoma presenting with mediastinal lymphadenopathy. J Bronchology Interv Pulmonol 2014; 21 : $298-305$

366 Fritscher-Ravens A, Sriram PV, Topalidis T et al. Diagnosing sarcoidosis using endosonography-guided fine-needle aspiration. Chest 2000; 118: 928 -935

367 Fritscher-Ravens A, Ghanbari A, Topalidis T et al. Granulomatous mediastinal adenopathy: can endoscopic ultrasound-guided fine-needle aspiration differentiate between tuberculosis and sarcoidosis? Endoscopy 2011; 43: 955-961

368 Annema JT, Veselic M, Rabe KF. Endoscopic ultrasound-guided fineneedle aspiration for the diagnosis of sarcoidosis. Eur Respir J 2005; 25: $405-409$

369 Iwashita T, Yasuda I, Doi S et al. The yield of endoscopic ultrasoundguided fine needle aspiration for histological diagnosis in patients suspected of stage I sarcoidosis. Endoscopy 2008; 40: 400-405

370 Michael $H$, Ho S, Pollack B et al. Diagnosis of intra-abdominal and mediastinal sarcoidosis with EUS-guided FNA. Gastrointest Endosc 2008; $67: 28-34$

371 Navani N, Booth HL, Kocjan G et al. Combination of endobronchial ultrasound-guided transbronchial needle aspiration with standard bronchoscopic techniques for the diagnosis of stage I and stage II pulmonary sarcoidosis. Respirology 2011; 16: 467-472

372 von Bartheld MB, Veselic-Charvat M, Rabe KF et al. Endoscopic ultrasound-guided fine-needle aspiration for the diagnosis of sarcoidosis. Endoscopy 2010; 42: 213-217

373 von Bartheld MB, Dekkers OM, Szlubowski A et al. Endosonography vs conventional bronchoscopy for the diagnosis of sarcoidosis: the GRANULOMA randomized clinical trial. JAMA 2013; 309: 2457-2464

374 Agarwal R, Srinivasan A, Aggarwal AN et al. Efficacy and safety of convex probe EBUS-TBNA in sarcoidosis: a systematic review and metaanalysis. Respir Med 2012; 106: 883-892

375 Oki M, Saka H, Kitagawa C et al. Prospective study of endobronchia ultrasound-guided transbronchial needle aspiration of lymph nodes versus transbronchial lung biopsy of lung tissue for diagnosis of sarcoidosis. J Thorac Cardiovasc Surg 2012; 143: 1324-1329

376 Gupta D, Dadhwal DS, Agarwal R et al. Endobronchial ultrasoundguided transbronchial needle aspiration vs conventional transbronchial needle aspiration in the diagnosis of sarcoidosis. Chest 2014; 146: $547-556$

377 Li K, Jiang S. A randomized controlled study of conventional TBNA versus EBUS-TBNA for diagnosis of suspected stage I and II sarcoidosis. Sarcoidosis Vasc Diffuse Lung Dis 2014; 31: 211 - 218

378 Gnass M, Szlubowski A, Soja J et al. Comaparison of conventional and ultrasoundguided needle biopsy techniques in the diagnosis of sarcoidosis: a randomized trial. Pol Arch Med Wewn 2015; 125: 321 328

379 Trisolini R, Lazzari Agli L, Tinelli $C$ et al. Endobronchial ultrasoundguided transbronchial needle aspiration for diagnosis of sarcoidosis in clinically unselected study populations. Respirology 2015; 20: $226-234$

380 Berzosa M, Tsukayama DT, Davies SF et al. Endoscopic ultrasoundguided fine-needle aspiration for the diagnosis of extra-pulmonary tuberculosis. Int J Tuberc Lung Dis 2010; 14: 578-584

381 Navani N, Molyneaux PL, Breen RA et al. Utility of endobronchial ultrasound-guided transbronchial needle aspiration in patients with tuberculous intrathoracic lymphadenopathy: a multicentre study. Thorax 2011; 66: 889-893

382 Puri R, Mangla R, Eloubeidi $M$ et al. Diagnostic yield of EUS-guided FNA and cytology in suspected tubercular intra-abdominal lymphadenopathy. Gastrointest Endosc 2012; 75: 1005-1010

383 Puri R, Thandassery RB, Eloubeidi MA et al. Diagnosis of isolated pancreatic tuberculosis: the role of EUS-guided FNA cytology. Gastrointest Endosc 2012; 75: 900-904

384 Ren S, Zhang Z, Jiang $H$ et al. Combination of endobronchial ultrasound-guided transbronchial needle aspiration with standard bronchoscopic techniques enhanced the diagnosis yields of pulmonary tuberculosis patients with lymphadenopathy. Panminerva Med 2013; 55: $363-370$

385 Gailey MP, Klutts JS, Jensen CS. Fine-needle aspiration of histoplasmosis in the era of endoscopic ultrasound and endobronchial ultrasound: cytomorphologic features and correlation with clinical laboratory testing. Cancer Cytopathol 2013; 121: 508-517

386 Gailey MP, Keeney ME, Jensen CS. A cytomorphometric analysis of pulmonary and mediastinal granulomas: differentiating histoplasmosis from sarcoidosis by fine-needle aspiration. Cancer Cytopathol 2015; 123: $51-58$

387 Oki M, Saka H, Ando $M$ et al. Transbronchial Versus Transesophageal Needle Aspiration Using an Ultrasound Bronchoscope for the Diagnosis of Mediastinal Lesions: A Randomized Study. Chest 2015; 147: $1259-1266$

388 Tournoy KG, Keller SM, Annema JT. Mediastinal staging of lung cancer: novel concepts. Lancet Oncol 2012; 13: e221 -e229 
389 Silvestri GA, Gonzalez AV, Jantz MA et al. Methods for staging nonsmall cell lung cancer: Diagnosis and management of lung cancer, 3rd ed: American College of Chest Physicians evidence-based clinical practice guidelines. Chest 2013; 143: e211S - e250S

390 Vilmann P, Clementsen PF, Colella $S$ et al. Combined endobronchial and esophageal endosonography for the diagnosis and staging of lung cancer: European Society of Gastrointestinal Endoscopy (ESGE) Guideline, in cooperation with the European Respiratory Society (ERS) and the European Society of Thoracic Surgeons (ESTS). Endoscopy 2015; 47: 545-559

391 Jenssen C, Siebert C, Gottschalk U. The Role of Endoscopic Ultrasound in M-Staging of Gastrointestinal and Pancreaticobiliary Cancer. Video Journal and Encyclopedia of GI Endoscopy 2013; 1: 105 -109

392 Gleeson FC, Kipp BR, Caudill JL et al. False positive endoscopic ultrasound fine needle aspiration cytology: incidence and risk factors. Gut 2010; 59: 586 - 593

393 Levy MJ, Gleeson FC, Campion MB et al. Prospective cytological assessment of gastrointestinal luminal fluid acquired during EUS: a potential source of false-positive FNA and needle tract seeding. Am J Gastroenterol 2010; 105: $1311-1318$

394 van Hemel BM, Lamprou AA, Weersma $R$ et al. Procedure-related, false-positive cytology results during EUS-guided FNA in patients with esophageal cancer. Gastrointest Endosc 2010; 71: 1130 - 1133

395 Kwong WT, Coyle WJ, Hasteh F et al. Malignant cell contamination may lead to false-positive findings at endosonographic fine needle aspiration for tumour staging. Endoscopy 2014; 46: 149-152

396 Gress FG, Savides TJ, Sandler A et al. Endoscopic ultrasonography, fineneedle aspiration biopsy guided by endoscopic ultrasonography, and computed tomography in the preoperative staging of non-small-cell lung cancer: a comparison study. Ann Intern Med 1997; 127: $604-$ 612

397 Fritscher-Ravens A, Bohuslavizki KH, Brandt L et al. Mediastinal lymph node involvement in potentially resectable lung cancer: comparison of CT, positron emission tomography, and endoscopic ultrasonography with and without fine-needle aspiration. Chest 2003; 123 : $442-451$

398 Wallace MB, Ravenel J, Block MI et al. Endoscopic ultrasound in lung cancer patients with a normal mediastinum on computed tomography. Ann Thorac Surg 2004; 77: 1763-1768

399 Eloubeidi MA, Cerfolio RJ, Chen VK et al. Endoscopic ultrasound-guided fine needle aspiration of mediastinal lymph node in patients with suspected lung cancer after positron emission tomography and computed tomography scans. Ann Thorac Surg 2005; 79: 263-268

400 Larsen SS, Vilmann P, Krasnik $M$ et al. Endoscopic ultrasound guided biopsy performed routinely in lung cancer staging spares futile thoracotomies: preliminary results from a randomised clinical trial. Lung Cancer 2005; 49: 377-385

401 Eloubeidi MA, Desmond R, Desai S et al. Impact of staging transesophageal EUS on treatment and survival in patients with non-small-cell lung cancer. Gastrointest Endosc 2008; 67: 193-198

402 Annema JT, Versteegh MI, Veselic M et al. Endoscopic ultrasound-guided fine-needle aspiration in the diagnosis and staging of lung cancer and its impact on surgical staging. J Clin Oncol 2005; 23: 8357-8361

403 Tournoy KG, De Ryck F, Vanwalleghem LR et al. Endoscopic ultrasound reduces surgical mediastinal staging in lung cancer: a randomized trial. Am J Respir Crit Care Med 2008; 177: 531 - 535

404 Liberman M, Sampalis J, Duranceau A et al. Endosonographic mediastinal lymph node staging of lung cancer. Chest 2014; 146: 389-397

405 Annema JT, Versteegh MI, Veselic M et al. Endoscopic ultrasound added to mediastinoscopy for preoperative staging of patients with lung cancer. JAMA 2005; 294: 931-936

406 Rintoul RC, Skwarski KM, Murchison JT et al. Endoscopic and endobronchial ultrasound real-time fine-needle aspiration for staging of the mediastinum in lung cancer. Chest 2004; 126: 2020-2022

407 Herth FJ, Lunn W, Eberhardt $R$ et al. Transbronchial versus transesophageal ultrasound-guided aspiration of enlarged mediastinal lymph nodes. Am J Respir Crit Care Med 2005; 171: 1164-1167

408 Rintoul RC, Skwarski KM, Murchison JT et al. Endobronchial and endoscopic ultrasound-guided real-time fine-needle aspiration for mediastinal staging. Eur Respir J 2005; 25: 416-421

409 Vilmann P, Krasnik M, Larsen SS et al. Transesophageal endoscopic ultrasound-guided fine-needle aspiration (EUS-FNA) and endobronchial ultrasound-guided transbronchial needle aspiration (EBUSTBNA) biopsy: a combined approach in the evaluation of mediastinal lesions. Endoscopy 2005; 37: 833-839
410 Wallace MB, Pascual JM, Raimondo M et al. Minimally invasive endoscopic staging of suspected lung cancer. JAMA 2008; 299: 540-546

411 Annema JT, van Meerbeeck JP, Rintoul RC et al. Mediastinoscopy vs endosonography for mediastinal nodal staging of lung cancer: a randomized trial. JAMA 2010; 304: 2245-2252

412 Herth FJ, Krasnik M, Kahn N et al. Combined endoscopic-endobronchial ultrasound-guided fine-needle aspiration of mediastinal lymph nodes through a single bronchoscope in 150 patients with suspected lung cancer. Chest 2010; 138: 790 - 794

413 Hwangbo B, Lee GK, Lee HS et al. Transbronchial and transesophageal fine-needle aspiration using an ultrasound bronchoscope in mediastinal staging of potentially operable lung cancer. Chest 2010; 138: $795-802$

414 Szlubowski A, Zielinski M, Soja J et al. A combined approach of endobronchial and endoscopic ultrasound-guided needle aspiration in the radiologically normal mediastinum in non-small-cell lung cancer staging-a prospective trial. Eur J Cardiothorac Surg 2010; 37: 11751179

415 Ohnishi R, Yasuda I, Kato T et al. Combined endobronchial and endoscopic ultrasound-guided fine needle aspiration for mediastinal nodal staging of lung cancer. Endoscopy 2011; 43: 1082 - 1089

416 Kang HJ, Hwangbo B, Lee GK et al. EBUS-centred versus EUS-centred mediastinal staging in lung cancer: a randomised controlled trial. Thorax 2014; 69: 261 - 268

417 Lee KJ, Suh GY, Chung MP et al. Combined endobronchial and transesophageal approach of an ultrasound bronchoscope for mediastinal staging of lung cancer. PLoS One 2014; 9: e91893

418 Oki M, Saka H, Ando M et al. Endoscopic ultrasound-guided fine needle aspiration and endobronchial ultrasound-guided transbronchial needle aspiration: Are two better than one in mediastinal staging of non-small cell lung cancer? J Thorac Cardiovasc Surg 2014; 148: $1169-1177$

419 Vilmann P, Clementsen PF, Colella S et al. Combined endobronchial and esophageal endosonography for the diagnosis and staging of lung cancer: European Society of Gastrointestinal Endoscopy (ESGE) Guideline, in cooperation with the European Respiratory Society (ERS) and the European Society of Thoracic Surgeons (ESTS). Endoscopy $2015 ; 47$ : 11

420 Vilmann $P$, Clementsen PF, Colella $S$ et al. Combined endobronchial and oesophageal endosonography for the diagnosis and staging of lung cancer. Eur Respir J 2015; 46: 40 -60

421 Vilmann $P$, Frost Clementsen P, Colella $S$ et al. Combined endobronchial and esophageal endosonography for the diagnosis and staging of lung cancer: European Society of Gastrointestinal Endoscopy (ESGE) Guideline, in cooperation with the European Respiratory Society (ERS) and the European Society of Thoracic Surgeons (ESTS). Eur J Cardiothorac Surg 2015; 48: 1 - 15

422 Tournoy KG, Govaerts E, Malfait T et al. Endobronchial ultrasoundguided transbronchial needle biopsy for M1 staging of extrathoracic malignancies. Ann Oncol 2011; 22: 127-131

423 Parmaksiz ET, Caglayan B, Salepci B et al. The utility of endobronchial ultrasound-guided transbronchial needle aspiration in mediastinal or hilar lymph node evaluation in extrathoracic malignancy: Benign or malignant? Ann Thorac Med 2012; 7: 210-214

424 Sanz-Santos J, Cirauqui B, Sanchez E et al. Endobronchial ultrasoundguided transbronchial needle aspiration in the diagnosis of intrathoracic lymph node metastases from extrathoracic malignancies. Clin Exp Metastasis 2013; 30: $521-528$

425 Ozgul MA, Cetinkaya E, Tutar $N$ et al. Endobronchial ultrasound-guided transbronchial needle aspiration for the diagnosis of intrathoracic lymphadenopathy in patients with extrathoracic malignancy: A study in a tuberculosis-endemic country. J Cancer Res Ther 2013; 9: $416-421$

426 Senturk A, Kilic $H$, Hezer $H$ et al. Endobronchial ultrasound-guided transbronchial needle biopsy for the diagnosis of mediastinal lymphadenopathy in patients with extrathoracic malignancies. Turk J Med Sci 2014; 44: 989-995

427 Giovannini M, Bernardini D, Seitz JF et al. Value of endoscopic ultrasonography for assessment of patients presenting elevated tumour marker levels after surgery for colorectal cancers. Endoscopy 1998; 30: $469-476$

428 Hahn M, Faigel DO. Frequency of mediastinal lymph node metastases in patients undergoing EUS evaluation of pancreaticobiliary masses. Gastrointest Endosc 2001; 54: 331 - 335 
429 Wildi SM, Fickling WE, Day TA et al. Endoscopic ultrasonography in the diagnosis and staging of neoplasms of the head and neck. Endoscopy 2004; 36: 624-630

430 Agarwal B, Gogia S, Eloubeidi MA et al. Malignant mediastinal lymphadenopathy detected by staging EUS in patients with pancreaticobiliary cancer. Gastrointest Endosc 2005; 61: 849-853

431 Sobel JM, Lai R, Mallery $S$ et al. The utility of EUS-guided FNA in the diagnosis of metastatic breast cancer to the esophagus and the mediastinum. Gastrointest Endosc 2005; 61: 416-420

432 Giovannini M, Monges G, Seitz JF et al. Distant lymph node metastases in esophageal cancer: impact of endoscopic ultrasound-guided biopsy. Endoscopy 1999; 31: 536-540

433 Marsman WA, Brink MA, Bergman JJ et al. Potential impact of EUS-FNA staging of proximal lymph nodes in patients with distal esophageal carcinoma. Endoscopy 2006; 38: 825 - 829

434 Vazquez-Sequeiros E, Norton ID, Clain JE et al. Impact of EUS-guided fine-needle aspiration on lymph node staging in patients with esophageal carcinoma. Gastrointest Endosc 2001; 53: 751 - 757

435 Vazquez-Sequeiros E, Wiersema MJ, Clain JE et al. Impact of lymph node staging on therapy of esophageal carcinoma. Gastroenterology 2003; 125: $1626-1635$

436 Vazquez-Sequeiros E, Levy MJ, Clain JE et al. Routine vs. selective EUSguided FNA approach for preoperative nodal staging of esophageal carcinoma. Gastrointest Endosc 2006; 63: 204-211

437 Eloubeidi MA, Cerfolio RJ, Bryant AS et al. Efficacy of endoscopic ultrasound in patients with esophageal cancer predicted to have NO disease. Eur J Cardiothorac Surg 2011; 40: 636-641

438 Cerfolio RJ, Bryant AS, Ohja B et al. The accuracy of endoscopic ultrasonography with fine-needle aspiration, integrated positron emission tomography with computed tomography, and computed tomography in restaging patients with esophageal cancer after neoadjuvant chemoradiotherapy. J Thorac Cardiovasc Surg 2005; 129: 1232 - 1241

439 Eloubeidi MA, Wallace MB, Reed CE et al. The utility of EUS and EUSguided fine needle aspiration in detecting celiac lymph node metastasis in patients with esophageal cancer: a single-center experience. Gastrointest Endosc 2001; 54: 714-719

440 Parmar KS, Zwischenberger JB, Reeves AL et al. Clinical impact of endoscopic ultrasound-guided fine needle aspiration of celiac axis lymph nodes (M1a disease) in esophageal cancer. Ann Thorac Surg 2002; 73: 916-920; discussion 920-911

441 Romagnuolo J, Scott J, Hawes RH et al. Helical CT versus EUS with fine needle aspiration for celiac nodal assessment in patients with esophageal cancer. Gastrointest Endosc 2002; 55: 648-654

442 Sobin LH, Gospodarowicz MK, Wittekind C. UICC: TNM classification of malignant tumours. 7th edition. Oxford: Eiley-Blackwell; 2009

443 Harewood GC, Wiersema MJ, Nelson H et al. A prospective, blinded assessment of the impact of preoperative staging on the management of rectal cancer. Gastroenterology 2002; 123: 24-32

444 Harewood GC. Assessment of clinical impact of endoscopic ultrasound on rectal cancer. Am J Gastroenterol 2004; 99: 623-627

445 Jenssen C, Dietrich CF. Ultrasound and endoscopic ultrasound of the adrenal glands. Ultraschall in Med 2010; 31: 228 - 247; quiz 248-250

446 Chang KJ, Erickson RA, Nguyen P. Endoscopic ultrasound (EUS) and EUS-guided fine-needle aspiration of the left adrenal gland. Gastrointest Endosc 1996; 44: 568-572

447 Jhala NC, Jhala D, Eloubeidi MA et al. Endoscopic ultrasound-guided fine-needle aspiration biopsy of the adrenal glands: analysis of 24 patients. Cancer 2004; 102: 308 - 314

448 Ang TL, Chua TS, Fock KM et al. EUS-FNA of the left adrenal gland is safe and useful. Ann Acad Med Singapore 2007; 36: 954-957

449 DeWitt J, Alsatie M, LeBlanc J et al. Endoscopic ultrasound-guided fine-needle aspiration of left adrenal gland masses. Endoscopy 2007; 39: $65-71$

450 DeWitt JM. Endoscopic ultrasound-guided fine-needle aspiration of right adrenal masses: report of 2 cases. J Ultrasound Med 2008; 27: $261-267$

451 Eloubeidi MA. Endoscopic ultrasound in the evaluation of adrenal masses. Gastroenterol Hepatol (N Y) 2008; 4: 535 - 537

452 Eloubeidi MA, Morgan DE, Cerfolio RJ et al. Transduodenal EUS-guided FNA of the right adrenal gland. Gastrointest Endosc 2008; 67: 522 527

453 Eloubeidi MA, Black KR, Tamhane A et al. A large single-center experience of EUS-guided FNA of the left and right adrenal glands: diagnostic utility and impact on patient management. Gastrointest Endosc 2010; 71: $745-753$
454 Eloubeidi MA, Beydoun M, Jurdi N et al. Transduodenal EUS-guided FNA of the right adrenal gland to diagnose lung cancer where percutaneous approach was not possible. J Med Liban 2011; 59: 173-175

455 Bodtger U, Vilmann P, Clementsen Pet al. Clinical impact of endoscopic ultrasound-fine needle aspiration of left adrenal masses in established or suspected lung cancer. J Thorac Oncol 2009; 4: 1485-1489

456 Schuurbiers OC, Tournoy KG, Schoppers HJ et al. EUS-FNA for the detection of left adrenal metastasis in patients with lung cancer. Lung Cancer 2011; 73: $310-315$

457 Uemura S, Yasuda I, Kato T et al. Preoperative routine evaluation of bilateral adrenal glands by endoscopic ultrasound and fine-needle aspiration in patients with potentially resectable lung cancer. Endoscopy 2013; 45: 195-201

458 Martinez M, LeBlanc J, Al-Haddad M et al. Role of endoscopic ultrasound fine-needle aspiration evaluating adrenal gland enlargement or mass. World J Nephrol 2014; 3: 92 - 100

459 Singh P, Mukhopadhyay P, Bhatt B et al. Endoscopic ultrasound versus CT scan for detection of the metastases to the liver: results of a prospective comparative study. J Clin Gastroenterol 2009; 43: 367 - 373

460 Fujii-Lau LL, Abu Dayyeh BK, Bruno MJ et al. EUS-derived criteria for distinguishing benign from malignant metastatic solid hepatic masses. Gastrointest Endosc 2015; 81: 1188-1196 e1181-1187

461 Nguyen P, Feng JC, Chang KJ. Endoscopic ultrasound (EUS) and EUSguided fine-needle aspiration (FNA) of liver lesions. Gastrointest Endosc 1999; 50: 357 - 361

462 tenBerge J, Hoffman BJ, Hawes RH et al. EUS-guided fine needle aspiration of the liver: indications, yield, and safety based on an international survey of 167 cases. Gastrointest Endosc 2002; 55: 859-862

463 Hollerbach S, Willert J, Topalidis T et al. Endoscopic ultrasound-guided fine-needle aspiration biopsy of liver lesions: histological and cytological assessment. Endoscopy 2003; 35: 743 - 749

464 DeWitt J, LeBlanc J, McHenry L et al. Endoscopic ultrasound-guided fine needle aspiration cytology of solid liver lesions: a large singlecenter experience. Am J Gastroenterol 2003; 98: 1976-1981

465 McGrath K, Brody D, Luketich J et al. Detection of unsuspected left hepatic lobe metastases during EUS staging of cancer of the esophagus and cardia. Am J Gastroenterol 2006; 101: 1742 - 1746

466 DeWitt J, Yu M, Al-Haddad MA et al. Survival in patients with pancreatic cancer after the diagnosis of malignant ascites or liver metastases by EUS-FNA. Gastrointest Endosc 2010; 71: 260-265

467 Lee YN, Moon JH, Kim HK et al. Usefulness of endoscopic ultrasoundguided sampling using core biopsy needle as a percutaneous biopsy rescue for diagnosis of solid liver mass: Combined histological-cytological analysis. J Gastroenterol Hepatol 2015; 30: 1161 -1166

468 Shami VM, Parmar KS, Waxman I. Clinical impact of endoscopic ultrasound and endoscopic ultrasound-guided fine-needle aspiration in the management of rectal carcinoma. Dis Colon Rectum 2004; 47: $59-65$

469 Fritscher-Ravens A, Mylonaki M, Pantes A et al. Endoscopic ultrasound-guided biopsy for the diagnosis of focal lesions of the spleen. Am J Gastroenterol 2003; 98: 1022 -1027

470 Iwashita T, Yasuda I, Tsurumi H et al. Endoscopic ultrasound-guided fine needle aspiration biopsy for splenic tumour: a case series. Endoscopy 2009; 41: 179-182

471 Rzouq F, Brown J, Fan F et al. The utility of lower endoscopic ultrasound-guided fine needle aspiration for the diagnosis of benign and malignant pelvic diseases. J Clin Gastroenterol 2014; 48: 127 - 130

472 Chang KJ, Albers CG, Nguyen P. Endoscopic ultrasound-guided fine needle aspiration of pleural and ascitic fluid. Am J Gastroenterol 1995; 90: $148-150$

473 Nguyen PT, Chang KJ. EUS in the detection of ascites and EUS-guided paracentesis. Gastrointest Endosc 2001; 54: 336 - 339

474 Kaushik N, Khalid A, Brody D et al. EUS-guided paracentesis for the diagnosis of malignant ascites. Gastrointest Endosc 2006; 64: 908-913

475 DeWitt J, LeBlanc J, McHenry L et al. Endoscopic ultrasound-guided fine-needle aspiration of ascites. Clin Gastroenterol Hepatol 2007; 5: 609-615

476 Peter S, Eltoum I, Eloubeidi MA. EUS-guided FNA of peritoneal carcinomatosis in patients with unknown primary malignancy. Gastrointest Endosc 2009; 70: 1266-1270

477 Rana SS, Bhasin DK, Srinivasan R et al. Endoscopic ultrasound-guided fine needle aspiration of peritoneal nodules in patients with ascites of unknown cause. Endoscopy 2011; 43: 1010-1013

478 Rana SS, Bhasin DK, Gupta $R$ et al. EUS-guided FNA of peritoneal carcinomatosis. Gastrointest Endosc 2011; 73: 188-189 
479 Rana SS, Bhasin DK, Rao C et al. Endoscopic ultrasound-guided fineneedle aspiration of omental deposits in undiagnosed ascites. Dig Endosc 2013; 25: 212-213

480 Wardeh R, Lee JG, Gu M. Endoscopic ultrasound-guided paracentesis of ascitic fluid: a morphologic study with ultrasonographic correlation. Cancer Cytopathol 2011; 119: 27-36

481 Montgomery MM, Leitman IM. Endoscopic ultrasound and paracentesis in the evaluation of small volume ascites in patients with intraabdominal malignancies. World J Gastroenterol 2014; 20: 10219 10222

482 Suzuki R, Irisawa A, Bhutani MS et al. An automated spring-loaded needle for endoscopic ultrasound-guided abdominal paracentesis in cancer patients. World J Gastrointest Endosc 2014; 6: 55 - 59

483 Levy MJ, Abu Dayyeh BK, Fujii LL et al. Detection of peritoneal carcinomatosis by EUS fine-needle aspiration: impact on staging and resectability (with videos). Gastrointest Endosc 2015; 81: 1215-1224

484 Fuccio L, Larghi A. Endoscopic ultrasound-guided fine needle aspiration: How to obtain a core biopsy? Endosc Ultrasound 2014; 3 : 71 81

485 Panic N, Larghi A. Techniques for endoscopic ultrasound-guided fineneedle biopsy. Gastrointest Endosc Clin N Am 2014; 24: 83-107

486 Jenssen C, Moller K, Wagner S et al. Endoscopic ultrasound-guided biopsy: diagnostic yield, pitfalls, quality management. Part 2: Opportunities of differential diagnosis, pitfalls, and problem solutions. Z Gastroenterol 2008; 46: 897-908

487 Eisendrath $P$, Ibrahim $M$. How good is fine needle aspiration? What results should you expect? Endosc Ultrasound 2014; 3: 3 -11

488 Jenssen C, Burmester E, Will U et al. Erfahrungen mit der endosonografischen Feinnadelpunktion (EUS-FNP) in Deutschland: Deutlich geringere diagnostische Ausbeute als in Studien. Endo heute 2013; 26: FV9

489 DiMaio CJ, Buscaglia JM, Gross SA et al. Practice patterns in FNA technique: A survey analysis. World J Gastrointest Endosc 2014; 6: 499505

490 Affolter KE, Schmidt RL, Matynia AP et al. Needle size has only a limited effect on outcomes in EUS-guided fine needle aspiration: a systematic review and meta-analysis. Dig Dis Sci 2013; 58: 1026-1034

491 Madhoun MF, Wani SB, Rastogi A et al. The diagnostic accuracy of 22 gauge and 25-gauge needles in endoscopic ultrasound-guided fine needle aspiration of solid pancreatic lesions: a meta-analysis. Endoscopy 2013; 45: $86-92$

492 Imazu H, Uchiyama Y, Kakutani $H$ et al. A prospective comparison of EUS-guided FNA using 25-gauge and 22-gauge needles. Gastroenterol Res Pract 2009; 2009: 546390

493 Sakamoto H, Kitano M, Komaki T et al. Prospective comparative study of the EUS guided 25-gauge FNA needle with the 19-gauge Trucut needle and 22-gauge FNA needle in patients with solid pancreatic masses. J Gastroenterol Hepatol 2009; 24: $384-390$

494 Camellini L, Carlinfante $G$, Azzolini $F$ et al. A randomized clinical trial comparing 22G and 25G needles in endoscopic ultrasound-guided fine-needle aspiration of solid lesions. Endoscopy 2011; 43: 709 - 715

495 Bang JY, Ramesh J, Trevino J et al. Objective assessment of an algorithmic approach to EUS-guided FNA and interventions. Gastrointest Endosc 2013; 77: $739-744$

496 Fabbri C, Polifemo AM, Luigiano C et al. Endoscopic ultrasound-guided fine needle aspiration with 22- and 25-gauge needles in solid pancreatic masses: a prospective comparative study with randomisation of needle sequence. Dig Liver Dis 2011; 43: 647-652

497 Lee JK, Lee KT, Choi ER et al. A prospective, randomized trial comparing 25-gauge and 22-gauge needles for endoscopic ultrasound-guided fine needle aspiration of pancreatic masses. Scand J Gastroenterol 2013; 48: $752-757$

498 Vilmann P, Saftoiu A, Hollerbach S et al. Multicenter randomized controlled trial comparing the performance of 22 gauge versus 25 gauge EUS-FNA needles in solid masses. Scand J Gastroenterol 2013; 48: $877-883$

499 Wee E, Lakhtakia S, Gupta R et al. Endoscopic ultrasound guided fineneedle aspiration of lymph nodes and solid masses: factors influencing the cellularity and adequacy of the aspirate. J Clin Gastroenterol 2012; 46: $487-493$

500 Song TJ, Kim JH, Lee SS et al. The prospective randomized, controlled trial of endoscopic ultrasound-guided fine-needle aspiration using 22G and 19G aspiration needles for solid pancreatic or peripancreatic masses. Am J Gastroenterol 2010; 105: 1739-1745

501 Itoi T, Itokawa F, Sofuni A et al. Puncture of solid pancreatic tumours guided by endoscopic ultrasonography: a pilot study series compar- ing Trucut and 19-gauge and 22-gauge aspiration needles. Endoscopy 2005; 37: $362-366$

502 Itoi T, Itokawa F, Kurihara T et al. Experimental endoscopy: objective evaluation of EUS needles. Gastrointest Endosc 2009; 69: 509-516

503 Varadarajulu S, Bang JY, Hebert-Magee S. Assessment of the technical performance of the flexible 19-gauge EUS-FNA needle. Gastrointest Endosc 2012; 76: 336 - 343

504 Ramesh J, Bang JY, Hebert-Magee S et al. Randomized Trial Comparing the Flexible 19G and 25G Needles for Endoscopic Ultrasound-Guided Fine Needle Aspiration of Solid Pancreatic Mass Lesions. Pancreas 2015; 44: 128 - 133

505 Giri S, Pathak R, Yarlagadda V et al. Meta-analysis of 21- versus 22-G aspiration needle during endobronchial ultrasound-guided transbronchial needle aspiration. J Bronchology Interv Pulmonol 2015; 22: $107-113$

506 de la Fuente SG, Arnoletti JP. Beyond cytology: why and when does the oncologist require core tissue? Gastrointest Endosc Clin N Am 2014; 24: $9-17$

507 Varadarajulu S, Hawes $R H$. The changing paradigm in EUS-guided tissue acquisition. Gastrointest Endosc Clin N Am 2014; $24: 1$ - 7

508 Larghi A, Verna EC, Stavropoulos SN et al. EUS-guided trucut needle biopsies in patients with solid pancreatic masses: a prospective study. Gastrointest Endosc 2004; 59: 185-190

509 Varadarajulu S, Fraig M, Schmulewitz $N$ et al. Comparison of EUSguided 19-gauge Trucut needle biopsy with EUS-guided fine-needle aspiration. Endoscopy 2004; 36: $397-401$

510 Bang JY, Hebert-Magee S, Trevino J et al. Randomized trial comparing the 22-gauge aspiration and 22-gauge biopsy needles for EUS-guided sampling of solid pancreatic mass lesions. Gastrointest Endosc 2012; 76: $321-327$

511 Iwashita T, Nakai Y, Samarasena JB et al. High single-pass diagnostic yield of a new 25-gauge core biopsy needle for EUS-guided FNA biopsy in solid pancreatic lesions. Gastrointest Endosc 2013; 77: 909-915

512 Dietrich CF, Jenssen C. Endoscopic ultrasound-guided sampling in gastroenterology: European society of gastrointestinal endoscopy technical guidelines. Endosc Ultrasound 2013; 2: 117-122

513 Diehl DL, Johal AS, Khara HS et al. Endoscopic ultrasound-guided live biopsy: a multicenter experience. Endosc Int Open 2015; 3: E210E215

514 Varadarajulu S, Bang JY, Holt BA et al. The 25-gauge EUS-FNA needle: Good for on-site but poor for off-site evaluation? Results of a randomized trial. Gastrointest Endosc 2014; 80: 1056-1063

515 Kudo T, Kawakami H, Hayashi T et al. High and low negative pressure suction techniques in EUS-guided fine-needle tissue acquisition by using 25-gauge needles: a multicenter, prospective, randomized controlled trial. Gastrointest Endosc 2014; 80: 1030 - 1037 e1031

516 Gerke H, Rizk MK, Vanderheyden AD et al. Randomized study comparing endoscopic ultrasound-guided Trucut biopsy and fine needle aspiration with high suction. Cytopathology 2010; 21: 44-51

517 Brais RJ, Davies SE, O'Donovan M et al. Direct histological processing of EUS biopsies enables rapid molecular biomarker analysis for interventional pancreatic cancer trials. Pancreatology 2012; 12: 8-15

518 Voss M, Hammel P, Molas G et al. Value of endoscopic ultrasound guided fine needle aspiration biopsy in the diagnosis of solid pancreatic masses. Gut 2000; 46: 244-249

519 Sudhoff T, Hollerbach S, Wilhelms I et al. Clinical utility of EUS-FNA in upper gastrointestinal and mediastinal disease. Dtsch Med Wochenschr 2004; 129: 2227 -2232

520 Iglesias-Garcia J, Dominguez-Munoz E, Lozano-Leon A et al. Impact of endoscopic ultrasound-guided fine needle biopsy for diagnosis of pancreatic masses. World J Gastroenterol 2007; 13: 289-293

521 Moller K, Papanikolaou IS, Toermer T et al. EUS-guided FNA of solid pancreatic masses: high yield of 2 passes with combined histologiccytologic analysis. Gastrointest Endosc 2009; 70: 60-69

522 Takahashi K, Yamao K, Okubo K et al. Differential diagnosis of pancreatic cancer and focal pancreatitis by using EUS-guided FNA. Gastrointest Endosc 2005; 61: $76-79$

523 Larghi A, Noffsinger A, Dye CE et al. EUS-guided fine needle tissue acquisition by using high negative pressure suction for the evaluation of solid masses: a pilot study. Gastrointest Endosc 2005; 62: 768 774

524 Iwashita T, Yasuda I, Mukai T et al. Macroscopic on-site quality evaluation of biopsy specimens to improve the diagnostic accuracy during EUS-guided FNA using a 19-gauge needle for solid lesions: a single- 
center prospective pilot study (MOSE study). Gastrointest Endosc 2015; 81: $177-185$

525 Larghi A, Verna EC, Ricci R et al. EUS-guided fine-needle tissue acquisition by using a 19-gauge needle in a selected patient population: a prospective study. Gastrointest Endosc 2011; 74: 504-510

526 Stavropoulos SN, Im GY, Jlayer Z et al. High yield of same-session EUSguided liver biopsy by 19-gauge FNA needle in patients undergoing EUS to exclude biliary obstruction. Gastrointest Endosc 2012; 75: $310-318$

527 Gor N, Salem SB, Jakate $S$ et al. Histological adequacy of EUS-guided liver biopsy when using a 19-gauge non-Tru-Cut FNA needle. Gastrointest Endosc 2014; 79: 170-172

528 Paik WH, Park Y, Park do $\mathrm{H}$ et al. Prospective evaluation of new 22 gauge endoscopic ultrasound core needle using capillary sampling with stylet slow-pull technique for intra-abdominal solid masses. J Clin Gastroenterol 2015; 49: 199-205

529 Fabbri C, Luigiano C, Maimone A et al. Endoscopic ultrasound-guided fine-needle biopsy of small solid pancreatic lesions using a 22-gauge needle with side fenestration. Surg Endosc 2015; 29: 1586-1590

530 Barresi L, Tarantino I, Traina $M$ et al. Endoscopic ultrasound-guided fine needle aspiration and biopsy using a 22-gauge needle with side fenestration in pancreatic cystic lesions. Dig Liver Dis 2014; 46: 45-50

531 Attili F, Petrone G, Abdulkader I et al. Accuracy and inter-observer agreement of the Procore 25 gauge needle for endoscopic ultrasound-guided tissue core biopsy. Dig Liver Dis 2015, Epub ahead of print

$532 \mathrm{Hucl}$ T, Wee E, Anuradha S et al. Feasibility and efficiency of a new 22G core needle: a prospective comparison study. Endoscopy 2013; 45: $792-798$

533 Lee YN, Moon JH, Kim HK et al. Core biopsy needle versus standard aspiration needle for endoscopic ultrasound-guided sampling of solid pancreatic masses: a randomized parallel-group study. Endoscopy 2014; 46: 1056 - 1062

534 Vanbiervliet G, Napoleon B, Saint Paul MC et al. Core needle versus standard needle for endoscopic ultrasound-guided biopsy of solid pancreatic masses: a randomized crossover study. Endoscopy 2014; 46: $1063-1070$

535 Strand DS, Jeffus SK, Sauer BG et al. EUS-guided 22-gauge fine-needle aspiration versus core biopsy needle in the evaluation of solid pancreatic neoplasms. Diagn Cytopathol 2014; 42: 751 - 758

536 Witt BL, Adler DG, Hilden $K$ et al. A comparative needle study: EUSFNA procedures using the HD ProCore() and $\operatorname{EchoTip((R))~22-gauge~}$ needle types. Diagn Cytopathol 2013; 41: 1069-1074

537 Bang JY, Hasan M, Hawes RH et al. EUS-Guided Tissue Acquisition: Meta-Analysis Comparing the Procore and Standard FNA Needles. Gastrointest Endosc 2014; 79: AB427

538 Jeyabalan A, Shelley-Fraser G, Medford AR. Impact of needle gauge on characterization of endobronchial ultrasound-guided transbronchial needle aspiration (EBUS-TBNA) histology samples. Respirology 2014; 19: $735-739$

539 Rocca R, De Angelis C, Daperno $M$ et al. Endoscopic ultrasound-fine needle aspiration (EUS-FNA) for pancreatic lesions: effectiveness in clinical practice. Dig Liver Dis 2007; 39: 768 - 774

540 Hwang CY, Lee SS, Song TJ et al. Endoscopic ultrasound guided fine needle aspiration biopsy in diagnosis of pancreatic and peripancreatic lesions: a single center experience in Korea. Gut Liver 2009; 3 : $116-121$

541 Siddiqui AA, Brown LJ, Hong SK et al. Relationship of pancreatic mass size and diagnostic yield of endoscopic ultrasound-guided fine needle aspiration. Dig Dis Sci 2011; 56: 3370-3375

542 Nakai $Y$, Isayama $\mathrm{H}$, Chang $\mathrm{KJ}$ et al. Slow pull versus suction in endoscopic ultrasound-guided fine-needle aspiration of pancreatic solid masses. Dig Dis Sci 2014; 59: 1578-1585

543 Jhala NC, Jhala D, Eltoum I et al. Endoscopic ultrasound-guided fineneedle aspiration biopsy: a powerful tool to obtain samples from small lesions. Cancer 2004; 102: 239-246

544 Uehara H, Ikezawa K, Kawada $N$ et al. Diagnostic accuracy of endoscopic ultrasound-guided fine needle aspiration for suspected pancreatic malignancy in relation to the size of lesions. J Gastroenterol Hepatol 2011; 26: 1256 - 1261

545 Ranney N, Phadnis $M$, Trevino J et al. Impact of biliary stents on EUSguided FNA of pancreatic mass lesions. Gastrointest Endosc 2012; 76 : $76-83$

546 Fritscher-Ravens A, Brand L, Knofel WT et al. Comparison of endoscopic ultrasound-guided fine needle aspiration for focal pancreatic lesions in patients with normal parenchyma and chronic pancreatitis. Am J Gastroenterol 2002; 97: 2768 - 2775

547 Varadarajulu S, Tamhane A, Eloubeidi MA. Yield of EUS-guided FNA of pancreatic masses in the presence or the absence of chronic pancreatitis. Gastrointest Endosc 2005; 62: 728 - 736; quiz 751, 753

548 Ardengh JC, Lopes CV, Campos AD et al. Endoscopic ultrasound and fine needle aspiration in chronic pancreatitis: differential diagnosis between pseudotumoural masses and pancreatic cancer. JOP 2007; 8: $413-421$

549 Krishna NB, Mehra M, Reddy AV et al. EUS/EUS-FNA for suspected pancreatic cancer: influence of chronic pancreatitis and clinical presentation with or without obstructive jaundice on performance characteristics. Gastrointest Endosc 2009; 70: 70 - 79

550 Will $U$, Mueller A, Topalidis T et al. Value of endoscopic ultrasonography-guided fine needle aspiration (FNA) in the diagnosis of neoplastic tumour(-like) pancreatic lesions in daily clinical practice. Ultraschall in Med 2010; 31: 169-174

551 Siddiqui AA, Fein M, Kowalski TE et al. Comparison of the influence of plastic and fully covered metal biliary stents on the accuracy of EUSFNA for the diagnosis of pancreatic cancer. Dig Dis Sci 2012; 57: $2438-2445$

552 Fisher JM, Gordon SR, Gardner TB. The impact of prior biliary stenting on the accuracy and complication rate of endoscopic ultrasound fineneedle aspiration for diagnosing pancreatic adenocarcinoma. Pancreas 2011; 40: $21-24$

$553 \mathrm{Kim}$ JJ, Walia S, Lee SH et al. Lower yield of endoscopic ultrasoundguided fine-needle aspiration in patients with pancreatic head mass with a biliary stent. Dig Dis Sci 2015; 60: 543-549

554 Wallace MB, Kennedy T, Durkalski V et al. Randomized controlled tria of EUS-guided fine needle aspiration techniques for the detection of malignant lymphadenopathy. Gastrointest Endosc 2001; 54: 441 447

555 Bang JY, Magee SH, Ramesh J et al. Randomized trial comparing fanning with standard technique for endoscopic ultrasound-guided fine-needle aspiration of solid pancreatic mass lesions. Endoscopy 2013; 45: $445-450$

556 Storch IM, Sussman DA, Jorda $M$ et al. Evaluation of fine needle aspiration vs. fine needle capillary sampling on specimen quality and diagnostic accuracy in endoscopic ultrasound-guided biopsy. Acta Cytol 2007; 51: 837-842

557 Ardengh JC, Lopes CV, de Lima LF et al. Diagnosis of pancreatic tumours by endoscopic ultrasound-guided fine-needle aspiration. World J Gastroenterol 2007; 13: $3112-3116$

558 Shiroyama T, Okamoto $N$, Suzuki $H$ et al. Usefulness of high suction pressure for sufficient tissue collection during endobronchial ultrasound guided transbronchial needle aspiration. PLoS One 2013; 8: e82787

559 Bhutani MS, Suryaprasad S, Moezzi J et al. Improved technique for performing endoscopic ultrasound guided fine needle aspiration of lymph nodes. Endoscopy 1999; 31: 550-553

560 Katanuma A, Itoi T, Baron TH et al. Bench-top testing of suction forces generated through endoscopic ultrasound-guided aspiration needles. J Hepatobiliary Pancreat Sci 2015; 22: 379-385

561 Puri R, Vilmann P, Saftoiu A et al. Randomized controlled trial of endoscopic ultrasound-guided fine-needle sampling with or without suction for better cytological diagnosis. Scand J Gastroenterol 2009; 44: 499-504

562 Casal RF, Staerkel GA, Ost D et al. Randomized clinical trial of endobronchial ultrasound needle biopsy with and without aspiration. Chest 2012; 142: 568-573

563 Lee JK, Choi JH, Lee KH et al. A prospective, comparative trial to optimize sampling techniques in EUS-guided FNA of solid pancreatic masses. Gastrointest Endosc 2013; 77: 745 - 751

564 Tarantino I, Di Mitri R, Fabbri $C$ et al. Is diagnostic accuracy of fine needle aspiration on solid pancreatic lesions aspiration-related? A multicentre randomised trial. Dig Liver Dis 2014; 46: 523-526

565 Sahai AV, Paquin SC, Gariepy G. A prospective comparison of endoscopic ultrasound-guided fine needle aspiration results obtained in the same lesion, with and without the needle stylet. Endoscopy 2010; 42: 900-903

566 Rastogi A, Wani S, Gupta N et al. A prospective, single-blind, randomized, controlled trial of EUS-guided FNA with and without a stylet. Gastrointest Endosc 2011; 74: 58-64 
567 Wani S, Gupta N, Gaddam S et al. A comparative study of endoscopic ultrasound guided fine needle aspiration with and without a stylet. Dig Dis Sci 2011; 56: 2409-2414

568 Wani S, Early D, Kunkel J et al. Diagnostic yield of malignancy during EUS-guided FNA of solid lesions with and without a stylet: a prospective, single blind, randomized, controlled trial. Gastrointest Endosc 2012; 76: 328 - 335

569 Gimeno-Garcia AZ, Paquin SC, Gariepy G et al. Comparison of endoscopic ultrasonography-guided fine-needle aspiration cytology results with and without the stylet in 3364 cases. Dig Endosc 2013; 25: $303-307$

570 Abe Y, Kawakami H, Oba Ket al. Effect of a stylet on a histological specimen in EUS-guided fine-needle tissue acquisition by using 22gauge needles: a multicenter, prospective, randomized, controlled trial. Gastrointest Endosc 2015, Epub ahead of print

571 Schmidt RL, Walker BS, Howard K et al. Rapid on-site evaluation reduces needle passes in endoscopic ultrasound-guided fine-needle aspiration for solid pancreatic lesions: a risk-benefit analysis. Dig Dis Sci 2013; 58: 3280 - 3286

572 Schmidt RL, Kordy MA, Howard K et al. Risk-benefit analysis of sampling methods for fine-needle aspiration cytology: a mathematical modeling approach. Am J Clin Pathol 2013; 139: 336 - 344

573 Erickson RA, Sayage-Rabie L, Beissner RS. Factors predicting the number of EUS-guided fine-needle passes for diagnosis of pancreatic malignancies. Gastrointest Endosc 2000; 51: 184-190

574 LeBlanc JK, Ciaccia D, Al-Assi MT et al. Optimal number of EUS-guided fine needle passes needed to obtain a correct diagnosis. Gastrointest Endosc 2004; 59: 475-481

575 Pellise Urquiza M, Fernandez-Esparrach G, Sole M et al. Endoscopic ultrasound-guided fine needle aspiration: predictive factors of accurate diagnosis and cost-minimization analysis of on-site pathologist. Gastroenterol Hepatol 2007; 30: 319-324

576 Suzuki R, Irisawa A, Bhutani MS et al. Prospective evaluation of the optimal number of 25-gauge needle passes for endoscopic ultrasound-guided fine-needle aspiration biopsy of solid pancreatic lesions in the absence of an onsite cytopathologist. Dig Endosc 2012; 24: $452-456$

577 Cheng TY, Wang HP, Jan IS et al. Presence of intratumoural anechoic foci predicts an increased number of endoscopic ultrasound-guided fine-needle aspiration passes required for the diagnosis of pancreatic adenocarcinoma. J Gastroenterol Hepatol 2007; 22: 315-319

578 Uehara H, Sueyoshi H, Takada R et al. Optimal number of needle passes in endoscopic ultrasound-guided fine needle aspiration for pancreatic lesions. Pancreatology 2015; 15: $392-396$

579 Lim LG, Lakhtakia S, Ang TL et al. Factors determining diagnostic yield of endoscopic ultrasound guided fine-needle aspiration for pancreatic cystic lesions: a multicentre Asian study. Dig Dis Sci 2013; 58: $1751-1757$

580 Lee HS, Lee GK, Lee HS et al. Real-time endobronchial ultrasoundguided transbronchial needle aspiration in mediastinal staging of non-small cell lung cancer: how many aspirations per target lymph node station? Chest 2008; 134: 368 - 374

581 Piscaglia F, Nolsoe C, Dietrich CF et al. The EFSUMB Guidelines and Recommendations on the Clinical Practice of Contrast Enhanced Ultrasound (CEUS): update 2011 on non-hepatic applications. Ultraschall in Med 2012; 33: 33 -59

582 Cosgrove D, Piscaglia F, Bamber J et al. EFSUMB guidelines and recommendations on the clinical use of ultrasound elastography. Part 2: Clinical applications. Ultraschall in Med 2013; 34: 238-253

583 Cui XW, Jenssen C, Saftoiu A et al. New ultrasound techniques for lymph node evaluation. World J Gastroenterol 2013; 19: 4850 - 4860

584 Cui XW, Hocke M, Jenssen C et al. Conventional ultrasound for lymph node evaluation, update 2013. Z Gastroenterol 2014; 52: 212-221

585 Hocke $M$, Menges $M$, Topalidis $T$ et al. Contrast-enhanced endoscopic ultrasound in discrimination between benign and malignant mediastinal and abdominal lymph nodes. J Cancer Res Clin Oncol 2008; 134: $473-480$

586 Kanamori A, Hirooka $Y$, Itoh $A$ et al. Usefulness of contrast-enhanced endoscopic ultrasonography in the differentiation between malignant and benign lymphadenopathy. Am J Gastroenterol 2006; 101 : $45-51$

$587 \mathrm{Xu}$ W, Shi J, Zeng X et al. EUS elastography for the differentiation of benign and malignant lymph nodes: a meta-analysis. Gastrointest Endosc 2011; 74: 1001 -1009; quiz 1115 e1001-e1004
588 Saftoiu A, Vilmann P, Hassan H et al. Analysis of endoscopic ultrasound elastography used for characterisation and differentiation of benign and malignant lymph nodes. Ultraschall in Med 2006; 27: $535-542$

589 Bergeron JP, Perry KD, Houser PM et al. Endoscopic ultrasound-guided pancreatic fine-needle aspiration: potential pitfalls in one institution's experience of 1212 procedures. Cancer Cytopathol 2015; 123: $98-107$

590 Abdelgawwad MS, Alston E, Eltoum IA. The frequency and cancer risk associated with the atypical cytologic diagnostic category in endoscopic ultrasound-guided fine-needle aspiration specimens of solid pancreatic lesions: a meta-analysis and argument for a Bethesda System for Reporting Cytopathology of the Pancreas. Cancer Cytopathol 2013; $121: 620-628$

591 Layfield LJ, Dodd L, Factor R et al. Malignancy risk associated with diagnostic categories defined by the Papanicolaou Society of Cytopathology pancreaticobiliary guidelines. Cancer Cytopathol 2014; 122: $420-427$

592 Layfield LJ, Schmidt RL, Hirschowitz SL et al. Significance of the diagnostic categories "atypical" and "suspicious for malignancy" in the cytologic diagnosis of solid pancreatic masses. Diagn Cytopathol 2014; 42: 292-296

593 Alston E, Bae S, Eltoum IA. Atypical cytologic diagnostic category in EUS-FNA of the pancreas: follow-up, outcomes, and predictive models. Cancer Cytopathol 2014; 122: $428-434$

594 Adler G, Seufferlein T, Bischoff SC et al. S3-Guidelines "Exocrine pancreatic cancer" 2007. Z Gastroenterol 2007; 45: 487-523

595 Asbun HJ, Conlon K, Fernandez-Cruz L et al. When to perform a pancreatoduodenectomy in the absence of positive histology? A consensus statement by the International Study Group of Pancreatic Surgery. Surgery 2014; 155: 887-892

596 Gagovic V, Spier BJ, DeLee RJ et al. Endoscopic ultrasound fine-needle aspiration characteristics of primary adenocarcinoma versus other malignant neoplasms of the pancreas. Can J Gastroenterol 2012; 26 691-696

597 D'Onofrio M, Biagioli E, Gerardi C et al. Diagnostic Performance of Contrast-Enhanced Ultrasound (CEUS) and Contrast-Enhanced Endoscopic Ultrasound (ECEUS) for the Differentiation of Pancreatic Lesions: A Systematic Review and Meta-Analysis. Ultraschall in Med 2014; 35: 515-521

598 Fusaroli P, Kypraios D, Mancino MG et al. Interobserver agreement in contrast harmonic endoscopic ultrasound. J Gastroenterol Hepatol 2012; 27: $1063-1069$

599 Kitano M, Kudo M, Yamao K et al. Characterization of small solid tumours in the pancreas: the value of contrast-enhanced harmonic endoscopic ultrasonography. Am J Gastroenterol 2012; 107: 303 - 310

600 Gincul R, Palazzo M, Pujol B et al. Contrast-harmonic endoscopic ultrasound for the diagnosis of pancreatic adenocarcinoma: a prospective multicenter trial. Endoscopy 2014; 46: 373-379

601 Gong TT, Hu DM, Zhu Q. Contrast-enhanced EUS for differential diagnosis of pancreatic mass lesions: a meta-analysis. Gastrointest Endosc 2012; 76: $301-309$

602 Fusaroli P, Eloubeidi MA. Diagnosis of pancreatic cancer by contrastharmonic endoscopic ultrasound (EUS): complementary and not competitive with EUS-guided fine-needle aspiration. Endoscopy 2014; 46: 380 - 381

603 Sugimoto M, Takagi T, Hikichi T et al. Conventional versus contrast-enhanced harmonic endoscopic ultrasonography-guided fine-needle aspiration for diagnosis of solid pancreatic lesions: A prospective randomized trial. Pancreatology 2015, Epub ahead of print

604 Pei Q Zou X, Zhang X et al. Diagnostic value of EUS elastography in differentiation of benign and malignant solid pancreatic masses: meta-analysis. Pancreatology 2012; 12: 402-408

605 Ying L, Lin X, Xie ZL et al. Clinical utility of endoscopic ultrasound elastography for identification of malignant pancreatic masses: a meta-analysis. J Gastroenterol Hepatol 2013; 28: 1434-1443

$606 \mathrm{Hu}$ DM, Gong TT, Zhu Q. Endoscopic ultrasound elastography for differential diagnosis of pancreatic masses: a meta-analysis. Dig Dis Sci 2013; 58: 1125 - 1131

$607 \mathrm{Mei}$ M, Ni J, Liu D et al. EUS elastography for diagnosis of solid pancreatic masses: a meta-analysis. Gastrointest Endosc 2013; 77: 578-589

$608 \mathrm{Xu} \mathrm{W}$, Shi J, Li X et al. Endoscopic ultrasound elastography for differentiation of benign and malignant pancreatic masses: a systemic review and meta-analysis. Eur J Gastroenterol Hepatol 2013; 25: 218 224 
$609 \mathrm{Li} X, \mathrm{Xu}$ W, Shi J et al. Endoscopic ultrasound elastography for differentiating between pancreatic adenocarcinoma and inflammatory masses: a meta-analysis. World J Gastroenterol 2013; 19: 62846291

610 Saftoiu A, Iordache SA, Gheonea DI et al. Combined contrast-enhanced power Doppler and real-time sonoelastography performed during EUS, used in the differential diagnosis of focal pancreatic masses (with videos). Gastrointest Endosc 2010; 72: 739-747

611 Eloubeidi MA, Varadarajulu S, Desai S et al. Value of repeat endoscopic ultrasound-guided fine needle aspiration for suspected pancreatic cancer. J Gastroenterol Hepatol 2008; 23: 567 - 570

612 Suzuki R, Lee JH, Krishna SG et al. Repeat endoscopic ultrasound-guided fine needle aspiration for solid pancreatic lesions at a tertiary referral center will alter the initial inconclusive result. J Gastrointestin Liver Dis 2013; 22: 183-187

613 Anand $N$, Sampath $K, W u$ BU. Cyst features and risk of malignancy in intraductal papillary mucinous neoplasms of the pancreas: a meta-analysis. Clin Gastroenterol Hepatol 2013; 11: 913-921; quiz e959e960

614 Kim KW, Park SH, Pyo J et al. Imaging features to distinguish malignant and benign branch-duct type intraductal papillary mucinous neoplasms of the pancreas: a meta-analysis. Ann Surg 2014; 259 : $72-81$

615 Hong SK, Loren DE, Rogart JN et al. Targeted cyst wall puncture and aspiration during EUS-FNA increases the diagnostic yield of premalignant and malignant pancreatic cysts. Gastrointest Endosc 2012; 75: $775-782$

616 Rogart JN, Loren DE, Singu BS et al. Cyst wall puncture and aspiration during EUS-guided fine needle aspiration may increase the diagnostic yield of mucinous cysts of the pancreas. J Clin Gastroenterol 2011; 45: $164-169$

617 Ohno E, Hirooka Y, Itoh A et al. Intraductal papillary mucinous neoplasms of the pancreas: differentiation of malignant and benign tumours by endoscopic ultrasound findings of mural nodules. Ann Surg 2009; 249: 628-634

618 Ohno E, Itoh A, Kawashima H et al. Malignant transformation of branch duct-type intraductal papillary mucinous neoplasms of the pancreas based on contrast-enhanced endoscopic ultrasonography morphological changes: focus on malignant transformation of intraductal papillary mucinous neoplasm itself. Pancreas 2012; 41: 855-862

619 Yamashita $Y$, Ueda $K$, Itonaga $M$ et al. Usefulness of contrast-enhanced endoscopic sonography for discriminating mural nodules from mucous clots in intraductal papillary mucinous neoplasms: a single-center prospective study. J Ultrasound Med 2013; 32: 61 - 68

620 Harima H, Kaino S, Shinoda S et al. Differential diagnosis of benign and malignant branch duct intraductal papillary mucinous neoplasm using contrast-enhanced endoscopic ultrasonography. World J Gastroenterol 2015; $21: 6252-6260$

621 Dietrich CF, Jenssen C, Hocke $M$ et al. Imaging of gastrointestinal stromal tumours with modern ultrasound techniques - a pictorial essay. Z Gastroenterol 2012; 50: 457 - 467

622 Kannengiesser K, Mahlke R, Petersen F et al. Contrast-enhanced harmonic endoscopic ultrasound is able to discriminate benign submucosal lesions from gastrointestinal stromal tumours. Scand J Gastroenterol 2012; 47: 1515-1520

623 Sakamoto H, Kitano M, Matsui S et al. Estimation of malignant potential of GI stromal tumours by contrast-enhanced harmonic EUS (with videos). Gastrointest Endosc 2011; 73: 227-237

624 Yamashita Y, Kato J, Ueda K et al. Contrast-enhanced endoscopic ultrasonography can predict a higher malignant potential of gastrointestinal stromal tumours by visualizing large newly formed vessels. J Clin Ultrasound 2015; 43: 89-97

625 Vilmann $P$, Hancke S. A new biopsy handle instrument for endoscopic ultrasound-guided fine-needle aspiration biopsy. Gastrointest Endosc 1996; 43: $238-242$

626 Hollerbach S, Juergensen C, Hocke $M$ et al. EUS-FNA: how to improve biopsy results? An evidence based review. Z Gastroenterol 2014; 52 : $1081-1092$

627 Niehaus J, Burmester E, Rode M et al. EUS-FNA: a prospective study for the evaluation of the histological and cytological material (abstract). Gastrointest Endosc 2006; 63: AB275

628 Hebert-Magee S. How can an endosonographer assess for diagnostic sufficiency and options for handling the endoscopic ultrasound-guided fine-needle aspiration specimen and ancillary studies. Gastrointest Endosc Clin N Am 2014; 24: 29-56
629 Jenssen C, Beyer T. Fine Needle Aspiration Cytology. In: Dietrich CF Nuernberg D eds. Interventional Ultrasound. A Practical Guide and Atlas. Stuttgart, New York, Delhi, Rio: Thieme; 2015: 49-67

630 Weynand B, Borbath I, Galant C et al. Optimizing specimen collection and laboratory procedures reduces the non-diagnostic rate for endoscopic ultrasound-guided fine-needle aspiration of solid lesions of the pancreas. Cytopathology 2013; 24: 177-184

631 Jhala $N$, Jhala $D$. Definitions in tissue acquisition: core biopsy, cell block, and beyond. Gastrointest Endosc Clin N Am 2014; 24: 19-27

632 Hebert-Magee S. Basic technique for solid lesions: Cytology, core, or both? Endosc Ultrasound 2014; 3: 28 - 34

633 LeBlanc JK, Emerson RE, Dewitt J et al. A prospective study comparing rapid assessment of smears and ThinPrep for endoscopic ultrasoundguided fine-needle aspirates. Endoscopy 2010; 42: 389-394

634 Lee JK, Choi ER, Jang TH et al. A prospective comparison of liquidbased cytology and traditional smear cytology in pancreatic endoscopic ultrasound-guided fine needle aspiration. Acta Cytol 2011; 55: $401-407$

635 Stelow EB, Murad FM, Debol SM et al. A limited immunocytochemical panel for the distinction of subepithelial gastrointestinal mesenchymal neoplasms sampled by endoscopic ultrasound-guided fine-needle aspiration. Am J Clin Pathol 2008; 129: 219-225

636 Layfield LJ, Ehya H, Filie AC et al. Utilization of ancillary studies in the cytologic diagnosis of biliary and pancreatic lesions: The Papanicolaou Society of Cytopathology Guidelines. Cytojournal 2014; 11: 4

637 Layfield LJ, Ehya H, Filie AC et al. Utilization of ancillary studies in the cytologic diagnosis of biliary and pancreatic lesions: the Papanicolaou Society of Cytopathology guidelines for pancreatobiliary cytology. Diagn Cytopathol 2014; 42: 351 - 362

638 Jain D, Mathur SR, Iyer VK. Cell blocks in cytopathology: a review of preparative methods, utility in diagnosis and role in ancillary studies. Cytopathology 2014; 25: 356-371

639 Thomas T, Kaye PV, Ragunath K et al. Efficacy, safety, and predictive factors for a positive yield of EUS-guided Trucut biopsy: a large tertiary referral center experience. Am J Gastroenterol 2009; 104: 584-591

640 Itoi $T$, Tsuchiya T, Itokawa F et al. Histological diagnosis by EUS-guided fine-needle aspiration biopsy in pancreatic solid masses without onsite cytopathologist: a single-center experience. Dig Endosc 2011; 23 (Suppl 1): 34-38

641 Papanikolaou IS, Adler A, Wegener K et al. Prospective pilot evaluation of a new needle prototype for endoscopic ultrasonography-guided fine-needle aspiration: comparison of cytology and histology yield. Eur J Gastroenterol Hepatol 2008; 20: 342-348

642 Ardengh JC, Paulo GA, Nakao FS et al. Endoscopic ultrasound guided fine-needle aspiration core biopsy: comparison between an automatic biopsy device and two conventional needle systems. Acta Gastroenterol Latinoam 2008; 38: 105-115

643 Sakairi Y, Nakajima T, Yasufuku K et al. EML4-ALK fusion gene assessment using metastatic lymph node samples obtained by endobronchial ultrasound-guided transbronchial needle aspiration. Clin Cancer Res 2010; 16: 4938 - 4945

644 Araya T, Demura Y, Kasahara $\mathrm{K}$ et al. Usefulness of transesophageal bronchoscopic ultrasound-guided fine-needle aspiration in the pathologic and molecular diagnosis of lung cancer lesions adjacent to the esophagus. J Bronchology Interv Pulmonol 2013; 20: 121 - 126

645 Noda Y, Fujita N, Kobayashi G et al. Diagnostic efficacy of the cell block method in comparison with smear cytology of tissue samples obtained by endoscopic ultrasound-guided fine-needle aspiration. J Gastroenterol 2010; 45: 868-875

646 Kopelman Y, Marmor S, Ashkenazi I et al. Value of EUS-FNA cytological preparations compared with cell block sections in the diagnosis of pancreatic solid tumours. Cytopathology 2011; 22: 174-178

647 Ardengh JC, Lopes CV, de Lima LF et al. Cell block technique and cytological smears for the differential diagnosis of pancreatic neoplasms after endosonography-guided fine-needle aspiration. Acta Gastroenterol Latinoam 2008; 38: 246-251

648 Qin SY, Zhou Y, Li P et al. Diagnostic efficacy of cell block immunohistochemistry, smear cytology, and liquid-based cytology in endoscopic ultrasound-guided fine-needle aspiration of pancreatic lesions: a single-institution experience. PLoS One 2014; 9: e108762

649 Ieni A, Todaro P, Crino SF et al. Endoscopic ultrasound-guided fineneedle aspiration cytology in pancreaticobiliary carcinomas: diagnostic efficacy of cell-block immunocytochemistry. Hepatobiliary Pancreat Dis Int 2015; 14: 305 - 312 
650 Khan S, Omar T, Michelow P. Effectiveness of the cell block technique in diagnostic cytopathology. J Cytol 2012; 29: 177-182

651 Puri R, Vilmann P, Sud $R$ et al. Endoscopic ultrasound-guided fineneedle aspiration cytology in the evaluation of suspected tuberculosis in patients with isolated mediastinal lymphadenopathy. Endoscopy 2010; 42: $462-467$

652 Manucha V, Kaur G, Verma K. Endoscopic ultrasound-guided fine needle aspiration (EUS-FNA) of mediastinal lymph nodes: experience from region with high prevalence of tuberculosis. Diagn Cytopathol 2013; 41: 1019-1022

653 Song TJ, Lee SS, Park do H et al. Yield of EUS-guided FNA on the diagnosis of pancreatic/peripancreatic tuberculosis. Gastrointest Endosc 2009; 69: 484-491

654 Li W, Zhang T, Chen Y et al. Diagnostic Value of Convex Probe Endobronchial Ultrasound-Guided Transbronchial Needle Aspiration in Mediastinal Tuberculous Lymphadenitis: A Systematic Review and Meta-Analysis. Med Sci Monit 2015; 21: 2064-2072

655 Klapman JB, Logrono R, Dye CE et al. Clinical impact of on-site cytopathology interpretation on endoscopic ultrasound-guided fine needle aspiration. Am J Gastroenterol 2003; 98: 1289-1294

656 Jhala NC, Eltoum IA, Eloubeidi MA et al. Providing on-site diagnosis of malignancy on endoscopic-ultrasound-guided fine-needle aspirates: should it be done? Ann Diagn Pathol 2007; 11: 176 - 181

657 Alsohaibani F, Girgis S, Sandha GS. Does onsite cytotechnology evaluation improve the accuracy of endoscopic ultrasound-guided fineneedle aspiration biopsy? Can J Gastroenterol 2009; 23: 26-30

658 Cleveland P, Gill KR, Coe SG et al. An evaluation of risk factors for inadequate cytology in EUS-guided FNA of pancreatic tumours and lymph nodes. Gastrointest Endosc 2010; 71: 1194 - 1199

659 Turner BG, Cizginer S, Agarwal D et al. Diagnosis of pancreatic neoplasia with EUS and FNA: a report of accuracy. Gastrointest Endosc 2010; 71: $91-98$

660 Iglesias-Garcia J, Dominguez-Munoz JE, Abdulkader I et al. Influence of on-site cytopathology evaluation on the diagnostic accuracy of endoscopic ultrasound-guided fine needle aspiration (EUS-FNA) of solid pancreatic masses. Am J Gastroenterol 2011; 106: 1705 - 1710

661 Eapen GA, Shah AM, Lei $X$ et al. Complications, consequences, and practice patterns of endobronchial ultrasound-guided transbronchial needle aspiration: Results of the AQuIRE registry. Chest 2013; 143: $1044-1053$

662 Nakajima T, Yasufuku K, Saegusa F et al. Rapid on-site cytologic evaluation during endobronchial ultrasound-guided transbronchial needle aspiration for nodal staging in patients with lung cancer. Ann Thorac Surg 2013; 95: 1695-1699

663 Oki M, Saka H, Kitagawa C et al. Rapid on-site cytologic evaluation during endobronchial ultrasound-guided transbronchial needle aspiration for diagnosing lung cancer: a randomized study. Respiration 2013; 85: 486-492

663a Wani S, Mullady D, Early DS et al. The Clinical Impact of Immediate On-Site Cytopathology Evaluation During Endoscopic UltrasoundGuided Fine Needle Aspiration of Pancreatic Masses: A Prospective Multicenter Randomized Controlled Trial. Am J Gastroenterol 2015, Epub ahead of print

664 Lee YN, Moon JH, Kim HK et al. A triple approach for diagnostic assessment of endoscopic ultrasound-guided fine needle aspiration in pancreatic solid masses and lymph nodes. Dig Dis Sci 2014; 59: $2286-$ 2293

665 Collins BT, Murad FM, Wang JF et al. Rapid on-site evaluation for endoscopic ultrasound-guided fine-needle biopsy of the pancreas decreases the incidence of repeat biopsy procedures. Cancer Cytopathol 2013; $121: 518-524$

666 Eloubeidi MA, Tamhane A, Jhala $N$ et al. Agreement between rapid onsite and final cytologic interpretations of EUS-guided FNA specimens: implications for the endosonographer and patient management. Am J Gastroenterol 2006; 101: 2841 - 2847

667 Woon C, Bardales RH, Stanley MW et al. Rapid assessment of fine needle aspiration and the final diagnosis-how often and why the diagnoses are changed. Cytojournal 2006; 3: 25

668 Cherian PT, Mohan P, Douiri A et al. Role of endoscopic ultrasoundguided fine-needle aspiration in the diagnosis of solid pancreatic and peripancreatic lesions: is onsite cytopathology necessary? HPB (Oxford) 2010; 12: 389-395

669 Griffin AC, Schwartz LE, Baloch ZW. Utility of on-site evaluation of endobronchial ultrasound-guided transbronchial needle aspiration specimens. Cytojournal 2011; 8: 20
670 Joseph M, Jones T, Lutterbie Y et al. Rapid on-site pathologic evaluation does not increase the efficacy of endobronchial ultrasonographic biopsy for mediastinal staging. Ann Thorac Surg 2013; 96: 403-410

671 Cermak TS, Wang B, DeBrito P et al. Does on-site adequacy evaluation reduce the nondiagnostic rate in endoscopic ultrasound-guided fineneedle aspiration of pancreatic lesions? Cancer Cytopathol 2012; 120: $319-325$

672 Schmidt RL, Witt BL, Matynia AP et al. Rapid on-site evaluation increases endoscopic ultrasound-guided fine-needle aspiration adequacy for pancreatic lesions. Dig Dis Sci 2013; 58: 872-882

673 Matynia AP, Schmidt RL, Barraza G et al. Impact of rapid on-site evaluation on the adequacy of endoscopic-ultrasound guided fine-needle aspiration of solid pancreatic lesions: a systematic review and metaanalysis. J Gastroenterol Hepatol 2014; 29: 697-705

674 Krishnan K, Dalal S, Nayar R et al. Rapid on-site evaluation of endoscopic ultrasound core biopsy specimens has excellent specificity and positive predictive value for gastrointestinal lesions. Dig Dis Sci 2013; 58: 2007-2012

675 Keswani RN, Krishnan K, Wani S et al. Addition of Endoscopic Ultrasound (EUS)-Guided Fine Needle Aspiration and On-Site Cytology to EUS-Guided Fine Needle Biopsy Increases Procedure Time but Not Diagnostic Accuracy. Clin Endosc 2014; 47: 242 - 247

676 Layfield LJ, Bentz JS, Gopez EV. Immediate on-site interpretation of fine-needle aspiration smears: a cost and compensation analysis. Cancer 2001; 93: 319-322

677 Nasuti JF, Gupta PK, Baloch ZW. Diagnostic value and cost-effectiveness of on-site evaluation of fine-needle aspiration specimens: review of 5688 cases. Diagn Cytopathol 2002; 27: 1-4

678 Ecka RS, Sharma M. Rapid on-site evaluation of EUS-FNA by cytopathologist: an experience of a tertiary hospital. Diagn Cytopathol 2013; 41: 1075 - 1080

679 Kim B, Chhieng DC, Crowe DR et al. Dynamic telecytopathology of on site rapid cytology diagnoses for pancreatic carcinoma. Cytojournal 2006; $3: 27$

680 Buxbaum JL, Eloubeidi MA, Lane CJ et al. Dynamic telecytology compares favorably to rapid onsite evaluation of endoscopic ultrasound fine needle aspirates. Dig Dis Sci 2012; 57: 3092 - 3097

681 Khurana KK, Rong R, Wang D et al. Dynamic telecytopathology for onsite preliminary diagnosis of endoscopic ultrasound-guided fine needle aspiration of pancreatic masses. J Telemed Telecare 2012; 18 $253-259$

682 Marotti JD, Johncox $V, N g$ et al. Implementation of telecytology for immediate assessment of endoscopic ultrasound-guided fine-needle aspirations compared to conventional on-site evaluation: analysis of 240 consecutive cases. Acta Cytol 2012; 56: 548-553

683 Khurana KK, Graber B, Wang D et al. Telecytopathology for on-site adequacy evaluation decreases the nondiagnostic rate in endoscopic ultrasound-guided fine-needle aspiration of pancreatic lesions. Telemed J E Health 2014; 20: $822-827$

684 Bott MJ, James B, Collins BT et al. A Prospective Clinical Trial of Telecytopathology for Rapid Interpretation of Specimens Obtained During Endobronchial Ultrasound-Fine Needle Aspiration. Ann Thorac Surg 2015; 100: 201-206

685 Mayall F, Cormack A, Slater $S$ et al. The utility of assessing the gross appearances of FNA specimens. Cytopathology 2010; 21: 395-397

686 Nguyen YP, Maple JT, Zhang Q et al. Reliability of gross visual assessment of specimen adequacy during EUS-guided FNA of pancreatic masses. Gastrointest Endosc 2009; 69: 1264-1270

687 Savoy AD, Raimondo M, Woodward TA et al. Can endosonographers evaluate on-site cytologic adequacy? A comparison with cytotechnologists. Gastrointest Endosc 2007; 65: $953-957$

688 Hikichi T, Irisawa A, Bhutani MS et al. Endoscopic ultrasound-guided fine-needle aspiration of solid pancreatic masses with rapid on-site cytological evaluation by endosonographers without attendance of cytopathologists. J Gastroenterol 2009; 44: 322 - 328

689 Hayashi T, Ishiwatari $H$, Yoshida $M$ et al. Rapid on-site evaluation by endosonographer during endoscopic ultrasound-guided fine needle aspiration for pancreatic solid masses. J Gastroenterol Hepatol 2013; 28: $656-663$

690 Varadarajulu S, Holt BA, Bang JY et al. Training endosonographers in cytopathology: improving the results of EUS-guided FNA. Gastrointest Endosc 2015; 81: 104-110

691 Harada R, Kato H, Fushimi S et al. An expanded training program for endosonographers improved self-diagnosed accuracy of endoscopic 
ultrasound-guided fine-needle aspiration cytology of the pancreas. Scand J Gastroenterol 2014; 49: 1119-1123

692 Hocke M, Ignee A, Topalidis T et al. Back to the roots - should gastroenterologists perform their own cytology? Z Gastroenterol 2013; 51: $191-195$

693 Crothers BA, Tench WD, Schwartz MR et al. Guidelines for the reporting of nongynecologic cytopathology specimens. Arch Pathol Lab Med 2009; 133: $1743-1756$

694 Guidelines of the Papanicolaou Society of Cytopathology for fineneedle aspiration procedure and reporting. The Papanicolaou Society of Cytopathology Task Force on Standards of Practice. Diagn Cytopathol 1997; 17: 239-247

695 Pitman MB, Centeno BA, Ali SZ et al. Standardized terminology and nomenclature for pancreatobiliary cytology: the Papanicolaou Society of Cytopathology guidelines. Diagn Cytopathol 2014; 42: 338 - 350

696 Chee A, Khalil M, Stather DR et al. Cytologic assessment of endobronchial ultrasound-guided transbronchial needle aspirates in sarcoidosis. J Bronchology Interv Pulmonol 2012; 19: 24-28

697 Weynand B, Borbath I, Bernard V et al. Pancreatic neuroendocrine tumour grading on endoscopic ultrasound-guided fine needle aspiration: high reproducibility and inter-observer agreement of the Ki-67 labelling index. Cytopathology 2014; 25: 389-395

698 Larghi A, Correale L, Ricci R et al. Interobserver agreement and accuracy of preoperative endoscopic ultrasound-guided biopsy for histological grading of pancreatic cancer. Endoscopy 2015; 47: 308 - 314

699 Steinfort DP, Russell PA, Tsui A et al. Interobserver agreement in determining non-small cell lung cancer subtype in specimens acquired by EBUS-TBNA. Eur Respir J 2012; 40: 699-705

700 Jhala NC, Jhala DN, Chhieng DC et al. Endoscopic ultrasound-guided fine-needle aspiration. A cytopathologist's perspective. Am J Clin Pathol 2003; 120: 351 - 367

701 Kulesza P, Eltoum IA. Endoscopic ultrasound-guided fine-needle aspiration: sampling, pitfalls, and quality management. Clin Gastroenterol Hepatol 2007; 5: 1248-1254

702 Jenssen C, Moller K, Wagner S et al. Endoscopic ultrasound-guided biopsy: diagnostic yield, pitfalls, quality management part 1: optimizing specimen collection and diagnostic efficiency.Z Gastroenterol 2008; 46: 590-600

703 Cerfolio RJ, Bryant AS, Eloubeidi MA et al. The true false negative rates of esophageal and endobronchial ultrasound in the staging of mediastinal lymph nodes in patients with non-small cell lung cancer. Ann Thorac Surg 2010; 90: 427-434

704 Woolf KM, Liang H, Sletten ZJ et al. False-negative rate of endoscopic ultrasound-guided fine-needle aspiration for pancreatic solid and cystic lesions with matched surgical resections as the gold standard: one institution's experience. Cancer Cytopathol 2013; 121: 449-458

705 Kurtycz DF, Field A, Tabatabai L et al. Post-brushing and fine-needle aspiration biopsy follow-up and treatment options for patients with pancreatobiliary lesions: The Papanicolaou Society of Cytopathology Guidelines. Cytojournal 2014; 11: 5

706 Schwartz DA, Unni KK, Levy MJ et al. The rate of false-positive results with EUS-guided fine-needle aspiration. Gastrointest Endosc 2002; 56: $868-872$

707 Siddiqui AA, Kowalski TE, Shahid $H$ et al. False-positive EUS-guided FNA cytology for solid pancreatic lesions. Gastrointest Endosc 2011; 74: $535-540$

708 Alsharif M, Andrade RS, Groth SS et al. Endobronchial ultrasoundguided transbronchial fine-needle aspiration: the University of Minnesota experience, with emphasis on usefulness, adequacy assessment, and diagnostic difficulties. Am J Clin Pathol 2008; 130: 434443

709 Chen S, Lin J, Wang X et al. EUS-guided FNA cytology of pancreatic neuroendocrine tumour (PanNET): a retrospective study of 132 cases over an 18-year period in a single institution. Cytopathology 2014; 25: $396-403$

710 Eltoum IA, Chen VK, Chhieng DC et al. Probabilistic reporting of EUSFNA cytology: Toward improved communication and better clinical decisions. Cancer 2006; 108: 93-101

711 Fuccio L, Hassan C, Laterza L et al. The role of K-ras gene mutation analysis in EUS-guided FNA cytology specimens for the differential diagnosis of pancreatic solid masses: a meta-analysis of prospective studies. Gastrointest Endosc 2013; 78: 596-608

712 Yang D, MoezArdalan K, Collins DP et al. Predictors of malignancy in patients with suspicious or indeterminate cytology on pancreatic en- doscopic ultrasound-guided fine-needle aspiration: a multivariate model. Pancreas 2014; 43: 922 - 926

713 Shi J, Lew M, Zalupski MM et al. Implication of Suspicious Cytology in Endoscopic Ultrasound-Guided Fine-Needle Aspiration for Pancreatic Cancer. J Gastrointest Cancer 2015; 46: 54 - 59

714 Sun B, Yang X, Ping B et al. Impact of inconclusive endoscopic ultrasound-guided fine-needle aspiration results in the management and outcome of patients with solid pancreatic masses. Dig Endosc 2015; 27: $130-136$

715 Prachayakul V, Sriprayoon T, Asawakul P et al. Repeated endoscopic ultrasound guided fine needle aspiration (EUS-FNA) improved diagnostic yield of inconclusive initial cytology for suspected pancreatic cancer and unknown intra-abdominal lymphadenopathy. J Med Assoc Thai 2012; 95 (Suppl 2): S68-S74

716 Early DS, Acosta RD, Chandrasekhara V. ASGE Standards of Practice Committee. et al. Adverse events associated with EUS and EUS with FNA. Gastrointest Endosc 2013; 77: 839-843

717 Wang KX, Ben QW, Jin ZD et al. Assessment of morbidity and mortality associated with EUS-guided FNA: a systematic review. Gastrointest Endosc 2011; 73: 283-290

718 von Bartheld MB, van Breda A, Annema JT. Complication rate of endosonography (endobronchial and endoscopic ultrasound): a systematic review. Respiration 2014; 87: 343-351

719 von Bartheld MB, Annema JT. Endosonography-related mortality and morbidity for pulmonary indications: a nationwide survey in the Netherlands. Gastrointest Endosc 2015, Epub ahead of print

720 Asano F, Aoe M, Ohsaki Y et al. Complications associated with endobronchial ultrasound-guided transbronchial needle aspiration: a nationwide survey by the Japan Society for Respiratory Endoscopy. Respir Res 2013; 14: 50

721 Buscarini E, De Angelis C, Arcidiacono PG et al. Multicentre retrospective study on endoscopic ultrasound complications. Dig Liver Dis 2006; 38: $762-767$

722 Jenssen C, Faiss S, Nurnberg D. Complications of endoscopic ultrasound and endoscopic ultrasound-guided interventions - results of a survey among German centers. Z Gastroenterol 2008; 46: 1177-1184

723 Rosch T, Dittler H, Fockens P et al. Major complications of endoscopic ultrasonography: results of a survey of 42105 cases (abstract). Gastrointest Endosc 1993; 39: 341, AB370

724 Das A, Sivak MV Jr, Chak A. Cervical esophageal perforation during EUS: a national survey. Gastrointest Endosc 2001; 53: 599-602

725 Mortensen MB, Fristrup C, Holm FS et al. Prospective evaluation of patient tolerability, satisfaction with patient information, and complications in endoscopic ultrasonography. Endoscopy 2005; 37: 146-153

726 Eloubeidi MA, Tamhane A, Lopes TL et al. Cervical esophageal perforations at the time of endoscopic ultrasound: a prospective evaluation of frequency, outcomes, and patient management. Am J Gastroenterol 2009; 104: $53-56$

727 Affi A, Vazquez-Sequeiros E, Norton ID et al. Acute extraluminal hemorrhage associated with EUS-guided fine needle aspiration: frequency and clinical significance. Gastrointest Endosc 2001; 53: $221-225$

728 Hamada T, Yasunaga H, Nakai Y et al. Severe bleeding and perforation are rare complications of endoscopic ultrasound-guided fine needle aspiration for pancreatic masses: an analysis of 3090 patients from 212 hospitals. Gut Liver 2014; 8: 215-218

729 Varadarajulu S, Eloubeidi MA. Frequency and significance of acute intracystic hemorrhage during EUS-FNA of cystic lesions of the pancreas. Gastrointest Endosc 2004; 60: 631 -635

730 Carrara S, Arcidiacono PG, Mezzi G et al. Pancreatic endoscopic ultrasound-guided fine needle aspiration: complication rate and clinical course in a single centre. Dig Liver Dis 2010; 42: 520-523

731 Tarantino I, Fabbri C, Di Mitri R et al. Complications of endoscopic ultrasound fine needle aspiration on pancreatic cystic lesions: final results from a large prospective multicenter study. Dig Liver Dis 2014; 46: $41-44$

732 Kien-Fong $V u$ C, Chang F, Doig $L$ et al. A prospective control study of the safety and cellular yield of EUS-guided FNA or Trucut biopsy in patients taking aspirin, nonsteroidal anti-inflammatory drugs, or prophylactic low molecular weight heparin. Gastrointest Endosc 2006; 63: 808-813

733 Ernst $A$, Eberhardt $R$, Wahidi $M$ et al. Effect of routine clopidogrel use on bleeding complications after transbronchial biopsy in humans. Chest 2006; 129: 734-737 
734 Stather DR, MacEachern P, Chee A et al. Safety of endobronchial ultrasound-guided transbronchial needle aspiration for patients taking clopidogrel: a report of 12 consecutive cases. Respiration 2012; 83: $330-334$

735 Adler DG, Jacobson BC, Davila RE et al. ASGE guideline: complications of EUS. Gastrointest Endosc 2005; 61: 8-12

736 Veitch AM, Baglin TP, Gershlick AH et al. Guidelines for the management of anticoagulant and antiplatelet therapy in patients undergoing endoscopic procedures. Gut 2008; 57: 1322-1329

737 Boustiere C, Veitch A, Vanbiervliet G et al. Endoscopy and antiplatelet agents. European Society of Gastrointestinal Endoscopy (ESGE) Guideline. Endoscopy 2011; 43: 445 - 461

738 Barawi M, Gottlieb K, Cunha B et al. A prospective evaluation of the incidence of bacteremia associated with EUS-guided fine-needle aspiration. Gastrointest Endosc 2001; 53: 189 - 192

739 Levy MJ, Norton ID, Wiersema MJ et al. Prospective risk assessment of bacteremia and other infectious complications in patients undergoing EUS-guided FNA. Gastrointest Endosc 2003; 57: 672 - 678

740 Janssen J, Konig K, Knop-Hammad V et al. Frequency of bacteremia after linear EUS of the upper GI tract with and without FNA. Gastrointest Endosc 2004; 59: 339-344

741 Levy MJ, Norton ID, Clain JE et al. Prospective study of bacteremia and complications With EUS FNA of rectal and perirectal lesions. Clin Gastroenterol Hepatol 2007; 5: 684-689

742 Chang KJ, Nguyen P, Erickson RA et al. The clinical utility of endoscopic ultrasound-guided fine-needle aspiration in the diagnosis and staging of pancreatic carcinoma. Gastrointest Endosc 1997; 45: 387 - 393

743 Eloubeidi MA, Tamhane A, Varadarajulu $S$ et al. Frequency of major complications after EUS-guided FNA of solid pancreatic masses: a prospective evaluation. Gastrointest Endosc 2006; 63: 622 - 629

744 Sing J Jr, Erickson R, Fader R. An in vitro analysis of microbial transmission during EUS-guided FNA and the utility of sterilization agents. Gastrointest Endosc 2006; 64: 774-779

745 Williams DB, Sahai AV, Aabakken L et al. Endoscopic ultrasound guided fine needle aspiration biopsy: a large single centre experience. Gut 1999; 44: $720-726$

746 Bournet B, Migueres I, Delacroix M et al. Early morbidity of endoscopic ultrasound: 13 years' experience at a referral center. Endoscopy 2006; 38: 349 - 354

747 Al-Haddad M, Wallace MB, Woodward TA et al. The safety of fine-needle aspiration guided by endoscopic ultrasound: a prospective study. Endoscopy 2008; 40: 204-208

748 Marinos E, Lee S, Jones B et al. Outcomes of single-dose peri-procedural antibiotic prophylaxis for endoscopic ultrasound-guided fine-needle aspiration of pancreatic cystic lesions. United European Gastroenterol J 2014; 2: 391 - 396

749 Guarner-Argente C, Shah P, Buchner A et al. Use of antimicrobials for EUS-guided FNA of pancreatic cysts: a retrospective, comparative analysis. Gastrointest Endosc 2011; 74: 81 - 86

750 Maturu VN, Dhooria S, Agarwal R. Efficacy and Safety of Transbronchial Needle Aspiration in Diagnosis and Treatment of Mediastinal Bronchogenic Cysts: Systematic Review of Case Reports. J Bronchology Interv Pulmonol 2015; 22: 195 - 203

751 von Bartheld MB, van Kralingen KW, Veenendaal RA et al. Mediastinalesophageal fistulae after EUS-FNA of tuberculosis of the mediastinum. Gastrointest Endosc 2010; 71: 210-212

752 von Bartheld $M$, van der Heijden E, Annema J. Mediastinal abscess formation after EUS-guided FNA: are patients with sarcoidosis at increased risk? Gastrointest Endosc 2012; 75: 1104-1107

753 Kumagai S, Muta Y, Yazumi S. Tuberculous abscess formation with liver invasion after endoscopic ultrasound-guided fine-needle aspiration for abdominal lymphadenopathy. Endoscopy 2014; 46 (Suppl 1): UCTN:E188-189

754 Sailer M, Bussen D, Fein M et al. Endoscopic ultrasound-guided transrectal biopsies of pelvic tumours. J Gastrointest Surg 2002; 6: 342 346

755 Sasaki Y, Niwa Y, Hirooka Y et al. The use of endoscopic ultrasoundguided fine-needle aspiration for investigation of submucosal and extrinsic masses of the colon and rectum. Endoscopy 2005; 37 : $154-160$

756 Beane JD, House MG, Cote GA et al. Outcomes after preoperative endoscopic ultrasonography and biopsy in patients undergoing distal pancreatectomy. Surgery 2011; 150: $844-853$

757 El Chafic AH, Dewitt J, Leblanc JK et al. Impact of preoperative endoscopic ultrasound-guided fine needle aspiration on postoperative re- currence and survival in cholangiocarcinoma patients. Endoscopy 2013; 45: $883-889$

758 Kudo T, Kawakami H, Kuwatani M et al. Influence of the safety and diagnostic accuracy of preoperative endoscopic ultrasound-guided fine-needle aspiration for resectable pancreatic cancer on clinical performance. World J Gastroenterol 2014; 20: 3620 - 3627

759 Yoon WJ, Daglilar ES, Fernandez-del Castillo C et al. Peritoneal seeding in intraductal papillary mucinous neoplasm of the pancreas patients who underwent endoscopic ultrasound-guided fine-needle aspiration: the PIPE Study. Endoscopy 2014; 46: 382 - 387

760 Ikezawa K, Uehara H, Sakai A et al. Risk of peritoneal carcinomatosis by endoscopic ultrasound-guided fine needle aspiration for pancreatic cancer. J Gastroenterol 2013; 48: 966 - 972

761 Ngamruengphong $S, X u C$, Woodward TA et al. Risk of gastric or peritoneal recurrence, and long-term outcomes, following pancreatic cancer resection with preoperative endosonographically guided fine needle aspiration. Endoscopy 2013; 45: 619-626

762 Ngamruengphong S, Swanson KM, Shah ND et al. Preoperative endoscopic ultrasound-guided fine needle aspiration does not impair survival of patients with resected pancreatic cancer. Gut 2015; 64: $1105-1110$

763 Hirooka $Y$, Goto $H$, Itoh A et al. Case of intraductal papillary mucinous tumour in which endosonography-guided fine-needle aspiration biopsy caused dissemination. J Gastroenterol Hepatol 2003; 18: $1323-1324$

764 Paquin SC, Gariepy G, Lepanto L et al. A first report of tumour seeding because of EUS-guided FNA of a pancreatic adenocarcinoma. Gastrointest Endosc 2005; 61: 610-611

765 Chong A, Venugopal K, Segarajasingam $D$ et al. Tumour seeding after EUS-guided FNA of pancreatic tail neoplasia. Gastrointest Endosc 2011; 74: $933-935$

766 Ahmed K, Sussman JJ, Wang J et al. A case of EUS-guided FNA-related pancreatic cancer metastasis to the stomach. Gastrointest Endosc 2011; 74: $231-233$

767 Katanuma A, Maguchi H, Hashigo S et al. Tumour seeding after endoscopic ultrasound-guided fine-needle aspiration of cancer in the body of the pancreas. Endoscopy 2012; 44 (Suppl 2): UCTN: E160161

768 Virgilio E, Mercantini P, Ferri $M$ et al. Is EUS-FNA of solid-pseudopapillary neoplasms of the pancreas as a preoperative procedure really necessary and free of acceptable risks? Pancreatology 2014; 14 : $536-538$

769 Minaga K, Kitano M, Yamashita Y. Surgically resected needle tract seeding following endoscopic ultrasound-guided fine-needle aspiration in pancreatic cancer. J Hepatobiliary Pancreat Sci 2015, Epub ahead of print

770 Tomonari A, Katanuma A, Matsumori T et al. Resected tumour seeding in stomach wall due to endoscopic ultrasonography-guided fine needle aspiration of pancreatic adenocarcinoma. World J Gastroenterol $2015 ; 21: 8458-8461$

771 Shah JN, Fraker D, Guerry D et al. Melanoma seeding of an EUS-guided fine needle track. Gastrointest Endosc 2004; 59: 923-924

772 Doi S, Yasuda I, Iwashita T et al. Needle tract implantation on the esophageal wall after EUS-guided FNA of metastatic mediastinal lymphadenopathy. Gastrointest Endosc 2008; 67: 988-990

773 Anderson B, Singh J, Jafri SF. Tumour seeding following endoscopic ultrasonography-guided fine-needle aspiration of a celiac lymph node. Dig Endosc 2013; 25: 344-345

774 Chen $\mathrm{HY}$, Lee $\mathrm{CH}$, Hsieh $\mathrm{CH}$. Bile peritonitis after EUS-guided fine-needle aspiration. Gastrointest Endosc 2002; 56: 594-596

775 Jacobson BC, Waxman I, Parmar K et al. Endoscopic ultrasound-guided gallbladder bile aspiration in idiopathic pancreatitis carries a significant risk of bile peritonitis. Pancreatology 2002; 2: 26-29

776 Andrews $A H$, Horwhat JD. Massive pneumoperitoneum after EUS-FNA aspiration of the pancreas. Gastrointest Endosc 2006; 63: 876-877

777 Babich JP, Bonasera RJ, Klein J et al. Pancreatic ascites: complication after endoscopic ultrasound-guided fine needle aspiration of a pancreatic cyst. Endoscopy 2009; 41 (Suppl 2): E211 - E212

778 Reddymasu S, Oropeza-Vail MM, Williamson S et al. Pancreatic leak after endoscopic ultrasound guided fine needle aspiration managed by transpapillary pancreatic duct stenting. JOP 2011; 12: 489 - 490

779 Itonaga $M$, Ueda $K$, Ichinose $M$. Phlegmonous gastritis caused by endoscopic ultrasound-guided fine-needle aspiration (EUS-FNA). Dig Endosc 2012; 24: 488 
780 Akdamar MK, Eltoum I, Eloubeidi MA. Retroperitoneal paraganglioma: EUS appearance and risk associated with EUS-guided FNA. Gastrointest Endosc 2004; 60: 1018 - 1021

781 de Vries AC, Poley JW. Hypertensive crisis after endoscopic ultrasound-guided fine-needle aspiration of the right adrenal gland. Endoscopy 2014; 46 (Suppl 1): UCTN:E447-448

782 Katanuma A, Maguchi $H$, Yane $K$ et al. Factors predictive of adverse events associated with endoscopic ultrasound-guided fine needle aspiration of pancreatic solid lesions. Dig Dis Sci 2013; 58: 2093 - 2099

783 Tarantino I, Barresi L, Di Pisa M et al. Simultaneous endoscopic ultrasound fine needle aspiration and endoscopic retrograde cholangiopancreatography: Evaluation of safety. World J Gastroenterol 2007; 13: $3861-3863$

784 Ross WA, Wasan SM, Evans DB et al. Combined EUS with FNA and ERCP for the evaluation of patients with obstructive jaundice from presumed pancreatic malignancy. Gastrointest Endosc 2008; 68: $461-466$

785 Ascunce G, Ribeiro A, Rocha-Lima C et al. Single-session endoscopic ultrasonography and endoscopic retrograde cholangiopancreatography for evaluation of pancreaticobiliary disorders. Surg Endosc 2010; 24: $1447-1450$

786 Oppong $K$, Raine $D$, Nayar $M$ et al. EUS-FNA versus biliary brushings and assessment of simultaneous performance in jaundiced patients with suspected malignant obstruction. JOP 2010; 11: 560 - 567
787 Aslanian HR, Estrada JD, Rossi F et al. Endoscopic ultrasound and endoscopic retrograde cholangiopancreatography for obstructing pancreas head masses: combined or separate procedures? J Clin Gastroenterol 2011; 45: 711-713

788 Camus M, Trouilloud I, Villacis AL et al. Effectiveness of combined endoscopic ultrasound-guided fine-needle aspiration biopsy and stenting in patients with suspected pancreatic cancer. Eur J Gastroenterol Hepatol 2012; 24: $1281-1287$

789 Gornals JB, Moreno R, Castellote J et al. Single-session endosonography and endoscopic retrograde cholangiopancreatography for biliopancreatic diseases is feasible, effective and cost beneficial. Dig Liver Dis 2013; 45: $578-583$

790 Noma Y, Kawamoto $\mathrm{H}$, Kato $\mathrm{H}$ et al. The efficacy and safety of singlesession endoscopic ultrasound-guided fine needle aspiration and endoscopic retrograde cholangiopancreatography for evaluation of pancreatic masses. Hepatogastroenterology 2014; 61: 1775-1779

791 Bhalala M, Rude K, Wang A et al. Analysis of complications after EUSFNA in patients with obstructive jaundice and drained with plastic biliary stents or self-expandable metal stent (SEMS): do complications differ between the type of stent? J Interv Gastroenterol 2013; 3: $128-132$ 